\title{
CALPHAD XXXIV 2005 conference summary
}

\author{
Harry A.J. Oonk \\ Chemical Thermodynamics Group, Faculty of Chemistry, Petrology Group, Faculty of Geosciences, Utrecht University, Padualaan 8, NL-3584 CH Utrecht, \\ The Netherlands
}

Received 10 January 2006; accepted 10 January 2006

Available online 21 February 2006

\begin{abstract} 10 sessions:

1. First Principles and Other Matters

2. High Pressure

3. Modeling and Experiments

4. CALPHAD Thermodynamics

5. Kinetic Matters

6. Miscellaneous (a collection of diverse subjects)

7. Experimental Thermodynamics

8. Nuclear Materials and Other Matters

9. Cluster Variation Subjects

10. CALPHAD Thermodynamics and Related Subjects.
\end{abstract}

The thirty-fourth annual CALPHAD meeting was held at Kasteel Vaeshartelt, Maastricht, The Netherlands, on May 22-27, 2005. The local organizing committee consisted of Harry A.J. Oonk (chairman), Aad C.G. van Genderen, Michel H.G. Jacobs, Paul J. van Ekeren, and Marjan Hogenbirk (secretary); all employed at Utrecht University, Faculties of Chemistry and Geosciences.

There were 134 delegates and 6 accompanying guests from 23 different countries. Oral communications (72) were presented in the following

Posters (60) were exposed in a continuous manner from Monday morning to Thursday evening. The posters were largely divided into two groups with one group closely related to Calphad Thermodynamics: first principles; thermodynamic phase diagram analysis; algorithms for Gibbs energy minimization; and kinetics, and another group covering a variety of subjects: teaching; statistical thermo-dynamics; experimental determination of phase equilibrium relationships; (micro)-calorimetry; molar volume; viscosity; waste heat; and subjects from the realm of molecular alloys.

After Monday's last lecture, a lively plenary discussion took place-some kind of a game between (traditional) CALPHAD thermodynamics and first principles. The discussion was continued on Tuesday evening. The present summary is organized into three sections

I. Summaries of oral communications

II. Titles of the exposed posters

III. Summary of the discussions on Monday and Tuesday evening.

(c) 2006 Elsevier Ltd. All rights reserved.

\section{Summaries of oral communications}

\section{First principles and other matters}

\section{Stability, metastability, and instability: On integrating first- principles and CALPHAD modeling}

Zi-Kui Liu

E-mail address: oonk@chem.uu.nl.
Results from first-principles calculations are becoming more and more important in CALPHAD modeling. This is particularly true for phases with homogeneity ranges of compositions, which are typically represented by sublattice models. In these sublattice models, the enthalpy of formation of the end-members are calculated by means of the firstprinciples techniques in the same manner as for stable, ordered compounds. One issue largely overlooked in this practice is whether those calculations suffer the same problem as the 
lattice stability of pure elements, which are still an unresolved issue between the data from the CALPHAD modeling and firstprinciples calculations. In this presentation, structure stability, metastability, and instability are discussed in terms of the vibrational entropy calculations of end-members in sublattice models.

\section{Embedded atom study of the interaction between point defects in iron aluminides}

\section{Renata Nascimento Nogueira and Cláudio Geraldo Schön}

The embedded atom method (EAM) has been used to perform atomistic simulations in the molecular statics framework, aiming to investigate the interaction between point defects (both vacancies and antisite atoms) in $\mathrm{Fe}-\mathrm{Al}$ alloys. This method is particularly useful in obtaining the self-energies of crystal defects characterized by strong core relaxation strains, which generate long-range elastic fields. The following cases have been considered:

- Double defects (divacancies, antisite-vacancy and antisiteantisite pairs) in $\mathrm{Fe}(\mathrm{A} 2), \mathrm{FeAl}$ (B2) and $\mathrm{Fe}_{3} \mathrm{Al}\left(\mathrm{DO}_{3}\right)$ otherwise stoichiometric crystals as a function of the separation distance (up to the seventh neighbourhood) and

- Selected triple defects configurations in Fe (A2) and FeAl (B2).

It has been observed that the double defects are usually characterized by strong (with magnitudes of the order of $0.1 \mathrm{eV}$ ) long-range interactions (either attractive, as in the general case of the divacancies, or repulsive, as in the case of antisite-antisite pairs in $\mathrm{A} 2 \mathrm{Fe}$ ) while triple defects present weaker interactions.

The results of the present work allow us, at least qualitatively, to explain several "anomalous" properties of point defects in iron aluminides, as, for example, the large equilibrium concentration of vacancies in concentrated alloys near the solidus temperature, the resistance that nonequilibrium vacancies produced after quenching from high temperatures present to annealing and the formation of "predominance fields" for given defect complexes in certain regions of the $\mathrm{Fe}-\mathrm{Al}$ phase diagram [1].

\section{References}

[1] Wolff J. et al., Point defects and their properties in FeAl and FeSi alloys, Intermetallics 7 (1999) 289-300.

\section{Ab initio studies of displacive phase transformations in metallic systems}

\section{M. Šob, M. Friák, D. Legut, M. Čák, T. Káňa and M. Zelený}

We give an account of applications of quantum-mechanical (first-principles) electronic structure calculations to the problem of mechanical stability of metals and intermetallics and of change or loss of magnetic ordering during volume and shape deformation. First, we review previous as well as ongoing research on this subject. We then describe briefly the electronic structure calculational methods. Our approach is illustrated by the analysis of stability and magnetic behaviour of selected ferromagnetic metals and intermetallics ( $\mathrm{Fe}, \mathrm{Ni}$, $\mathrm{Fe}_{3} \mathrm{Al}, \mathrm{Ni}_{3} \mathrm{Al}$, FeNi, FeCo etc.). We calculate total energies along the tetragonal and trigonal displacive transformation paths at various atomic volumes by the spin-polarized full potential linearized augmented plane waves (FLAPW) method employing the generalized gradient approximation (GGA) for exchange-correlation energy. The results are displayed in contour plots as functions of tetragonal or trigonal deformation and volume. Borderlines between various magnetic phases are shown and application of the calculated results for determination of atomic configuration and magnetic moments in thin films are discussed.

\section{Ab initio lattice stability in Laves phases: All-electron (WIEN) vs. pseudopotential (VASP) calculations}

Jana Houserová and Mojmír Šob

$\mathrm{Ab}$ initio electronic structure calculations may provide valuable information concerning the structure and thermodynamics of various phases. These characteristics were investigated for about 10 intermetallic compounds with the C14 Laves phase structure.

Our survey was accomplished using two codes. The fullpotential linear augmented plane wave (FLAPW) method incorporated in the WIEN97 code [1] provided reliable results based on the all-electron approach whereas the pseudopotential VASP code [2] allows full structure relaxation. In all our calculations the general gradient approximation (GGA) [3] for the exchange-correlation energy term was employed.

It turned out that the equilibrium lattice parameters of the standard element reference (SER) states (e.g. bcc ferromagnetic Fe, bcc Mo, etc.) calculated using both codes do not differ more than one percent from the experimental values, which provides a reasonable starting point for our study. After that we used the VASP code for the full relaxation of the Laves phases with $\mathrm{C} 14$ structure. The deviation of the equilibrium lattice parameters of existing Laves phases $\left(\mathrm{Cr}_{2} \mathrm{Ta}, \mathrm{Fe}_{2} \mathrm{Mo}, \mathrm{Fe}_{2} \mathrm{Ta}\right.$ and $\mathrm{Fe}_{2} \mathrm{~W}$ ) from the experimental values does not exceed $2.9 \%$. In the case of hypothetical Laves phases we do not have any hint from experiment so that the effect of relaxation on the lattice parameters was much more pronounced.

Our study shows that ab initio calculations performed at experimental lattice parameters essentially reproduce the stability of existing Laves phases but in some cases the total energies of formation found by the above-mentioned codes (i.e. WIEN97 and VASP) are considerably different (up to $13 \mathrm{~kJ} / \mathrm{mol}$ for $\mathrm{Fe}_{2} \mathrm{Ta}$ and $\mathrm{Fe}_{2} \mathrm{~W}$ ). Additional structural relaxation performed by the VASP code does not influence these total energy differences very much (up to $2 \mathrm{~kJ} / \mathrm{mol}$ ).

For all Laves phases studied, we have also calculated energies of formation of other (hypothetical) configurations with different occupations of sublattices. These structures are significantly influenced by relaxation, which becomes evident from both the lattice parameters and energies of formation. Again as we do not know a priori what are the lattice parameters 
of these hypothetical structures even a qualified guess provides total energies which are considerably higher than the energies at relaxed minimum. These effects are most obvious in the case of the Laves phases of pure constituents. Therefore if intended to study such hypothetical structures the relaxation of structural parameters is absolutely necessary.

\section{Acknowledgements}

This research was supported by the Grant Agency of the Czech Republic (Projects Nos. 106/03/P002 and 202/03/1351) and Research Projects AV0Z20410507 and MSM0021622410. The use of computer facilities of the MetaCenter of Masaryk University, Brno, is acknowledged.

\section{References}

[1] P. Blaha, K. Schwarz, J. Luitz, WIEN97, Vienna University of Technology, 1997 (improved and updated Unix version of the original copyrighted WIEN code, which was published by P. Blaha, K. Schwarz, P. Sorantin and S.B. Trickey in Comput. Phys. Commun. 59 (1990) 399).

[2] G. Kresse, J. Furthmüller, Comput. Mater. Sci. 6 (1996) 15.

[3] J.P. Perdew, J.A. Chevary, S.H. Vosko, K.A. Jackson, M.R. Pederson, D.J. Singh, C. Fiolhais, Phys. Rev. B 46 (1992) 6671.

\section{Semi-empirical interatomic potentials for carbon and $\mathrm{Fe}-\mathrm{C}$ system}

\section{Byeong-Joo Lee}

A semi-empirical interatomic potential for carbon has been developed based on the Modified Embedded Atom Method formalism. The potential describes the structural properties of various poly-types of carbon, elastic, defect and surface properties of diamonds as satisfactorily as the wellknown Tersoff potential. Combined with the Lennard-Jones potential, it can also reproduce the physical properties of graphite and amorphous carbon reasonably well. The applicability of the present potential to atomistic approaches on carbon nanotubes and fullerenes is also presented. The potential has the same formalism as previously developed MEAM potentials for bcc, fcc and hcp elements, and can be easily extended to describe various metal-carbon alloy systems. As an example, the MEAM potential for carbon was applied to develop an interatomic potential for a $\mathrm{Fe}-\mathrm{C}$ binary system. The potential parameters were determined by fitting to experimental information on dilute heat of solution of carbon, vacancy-carbon binding energy and its configuration, location of interstitial carbon atoms and migration energy of carbon atoms in bcc-Fe, and to a first principles calculation result on the cohesive energy of hypothetic $\mathrm{NaCl}$ type $\mathrm{FeC}$ carbide. The potential reproduces known physical properties of carbon as an interstitial solute element in bcc- and fcc-Fe very well. The applicability of the present potential to atomistic approaches to investigate the interactions between carbon interstitial solute atoms and other defects such as vacancies, dislocations and grain boundaries, etc., and also to investigate the effects of carbon on various deformation and mechanical behaviors of iron, is demonstrated. The extensibility of the potential into ternary Fe-metal-C systems, its applicability to simulate the energetic and structural behaviors of relatively simple MC and $\mathrm{M}_{2} \mathrm{C}$ type carbides as well as the solution effects of the solute "metal" elements, and the limitations of the present potential are also presented.

\section{References}

[1] Byeong-Joo Lee, Jin Wook Lee, A modified embedded atom method interatomic potential for carbon, CALPHAD (in press).

[2] Byeong-Joo Lee, A Modified Embedded Atom Method Interatomic Potential for Fe-C System (submitted for publication).

The use of first principles calculations for the thermodynamic modelling of $\mathbf{B} 2$ in the Al-Ni-Ru system

Sara Prins, Raymundo Arroyave and Zi-Kui Liu

The ordered B2 NiAl and RuAl compounds are of interest as high-temperature stable bond coat materials on Ni-based superalloys (NBSAs) used in aerospace applications. NiAl is a stable high-strength high-temperature phase and has been used as protective coating on NBSAs for many years. RuAl has even more robust high temperature physical properties than $\mathrm{NiAl}$ and shows good room temperature ductility. Furthermore, $\mathrm{Ru}$ is an alloying element in 4th generation NBSAs and can thus be present in the $\mathrm{NiAl}$ bond coat, and more recently RuAl has been investigated as a bond coat material itself.

Despite many recent experimental investigations [1-6] there is still disagreement on the existence (or not) of a miscibility gap in the $\mathrm{Al}-\mathrm{Ni}-\mathrm{Ru}$ system, and if it exists, at which temperature the miscibility gap will close. Experimental work is complicated by the fact that, depending on the cooling/quenching method, a Ru-rich B2 phase can solidify first followed by a Ni-rich B2, and this can give the appearance of a miscibility gap. Furthermore, as Ru has a very slow diffusion coefficient [7], much longer homogenisation times may then be required to reach true equilibrium. The lattice parameters of $\mathrm{NiAl}$ and $\mathrm{RuAl}$ are also very close to each other, with third element solubility on these phases increasing the $\mathrm{NiAl}$ and decreasing the RuAl lattice parameters. Discerning the phases by lattice parameter measurements using XRD analysis can thus be complicated [8].

To overcome the experimental challenges and facilitate a better understanding of the ternary effects of $\mathrm{Ru}$ on $\mathrm{NiAl}$ and $\mathrm{Ni}$ on RuAl and the associated defect structures, as well as to glean information on the existence or absence of a miscibility gap between $\mathrm{NiAl}$ and $\mathrm{RuAl}$ in the $\mathrm{Al}-\mathrm{Ni}-\mathrm{Ru}$ system, the $\mathrm{B} 2$ phases were studied from first principles. A 32-atom two-sublattice B2 supercell $(A)_{16}(B)_{(16)}$ was constructed. Following the Special Quasirandom Structure approach for B2 phases [9], one type of defects was allowed on only one sublattice per calculation. Vacancies, anti-site atoms and ternary element additions were considered. Vibrational entropy calculations using the quasiharmonic approach were used to determine the temperature dependence.

Enthalpies of formation and lattice parameters were calculated and compared to experimental results. The enthalpies of formation for the different defects over the composition ranges of the $\mathrm{B} 2$ phases have been used to 
determine which excess mixing parameters should be assessed in the CALPHAD extrapolation of the Al-Ni-Ru system.

It will be shown how incorporating first principles calculations of the defects in B2 can be used as a guideline in the modelling and evaluation of excess interaction parameters.

\section{References}

[1] K.W. Liu, F. Mucklich, W. Pitschke, R. Birringer, K. Wetzig, Mater. Sci. Eng. A-Struct. Mater. Prop. Microstruct. Process. 313 (1-2) (2001) 187-197.

[2] H. Su, Ph.D., Illinois Institute of Technology, 2004.

[3] B. Tryon, Ph.D., University of Michigan, 2005.

[4] I. Vjunitsky, E. Schonfeld, T. Kaiser, W. Steurer, V. Shklover, Intermetallics 13 (1) (2005) 35-45.

[5] I.J. Horner, N. Hall, L.A. Cornish, M.J. Witcomb, M.B. Cortie, T.D. Boniface, J. Alloys Compounds 264 (1-2) (1998) 173-179.

[6] G.H. Bozzolo, R.D. Noebe, C. Amador, Intermetallics 10 (2) (2002) 149-159.

[7] B. Tryon, Q. Feng, T. Pollock, Intermetallics 12 (7-9) (2004) 957-962.

[8] H.A. Gobran, K.W. Liu, D. Heger and F. Mucklich, Scr. Mater. 49 (11) (2003) 1097-1102.

[9] C. Jiang, Z.-K. Liu, L.-Q. Chen, Acta Met. (in press).

\section{Thermodynamic analysis of the $\mathrm{Zr}$-Be system using thermochemical properties based on ab initio calculations}

Tokunaga Tatsuya, Ohtani Hiroshi and Hasebe Mitsuhiro

The experimental investigation has shown that the $\mathrm{Zr}$ rich alloys produced by rapid-quenching exhibit a fully glass state in the composition range $30-45 \mathrm{~mol} \%$ Be [1]. In addition, the experimental work showed that the metastable $\mathrm{ZrBe}$ phase with a CrB-type structure appeared in the asquenched alloys with Be content of 15, 55, and $60 \mathrm{~mol} \%$. Concerning this binary system, thermodynamic assessment was performed based on mainly experimental data on phase boundaries [2,3], and the glass-forming ability was also evaluated theoretically by combining phase diagram calculations and the Davies-Uhlmann kinetic approach [4]. Although both calculated phase diagram and compositional range of glass formation agree with the experimental results, more precise evaluation of thermochemical properties for both stable and metastable phases seems necessary for the quantitative evaluation of the glass-forming ability of this binary alloy. Therefore, the energy of formation of some bccbased ordered phases and stoichiometric compound phases was obtained from ab initio energetic calculations, based on the Full Potential Linearized Augmented Plane Wave (FLAPW) method. According to the results, the $\mathrm{ZrBe}$ phase with a CrB-type structure is stable at the ground state, while the $\mathrm{ZrBe}$ phase with a CsCl-type B2 structure is metastable. To describe the $\mathrm{B} 2$ ordering state, the bcc phase was described using the two-sublattice model with the formula $(\mathrm{Zr}, \mathrm{Be})_{0.5}(\mathrm{Zr}, \mathrm{Be})_{0.5}$. Thermodynamic analysis was carried out using the results from ab initio calculations as well as the experimental phase diagram data. Furthermore, the evaluation of the glass-forming ability of this binary alloy was attempted by combining the Davies-Uhlmann kinetic formulations and the thermochemical properties obtained from the present phase diagram calculations.

\section{References}

[1] L.E. Tanner, R. Ray, Acta Metall. 27 (1979) 1727-1747.

[2] L. Kaufman, L.E. Tanner, CALPHAD 3 (1979) 91-107.

[3] N. Saunders, CALPHAD 9 (1985) 297-309.

[4] N. Saunders, A.P. Miodownik, Mater. Sci. Technol. 4 (1988) 768-777.

The Impurity Method and its applications to oxide solid solutions with coupled substitutions

\section{Victor L. Vinograd, Marcel H.F. Sluiter and Björn Winkler}

$\mathrm{Ab}$ initio calculation of phase diagrams is still hindered by limited computer resources. This necessitates designing very economical schemes of sampling of atomic configurations. Recent studies [1,2] have shown that the mixing enthalpy of a two-component substitution-type solid solution, e.g. $\mathrm{CaAl}_{2 / 3} \mathrm{Si}_{4}-\mathrm{MgAl}_{2 / 3} \mathrm{SiO}_{4}$ garnet, can be well predicted from $\mathrm{ab}$ initio calculated static energies of only four structures (configurations). The first two structures represent the endmembers, while the others are derived from the end-members by substituting one exchangeable atom in their supercells with an atom of the different sort. The changes in the relaxed energies of the end-members due to the incorporation of the impurity atoms give the Margules parameters. Similar calculations can be performed with empirical force-field methods [3]. Here we extend the application of the Impurity Method to solid solutions with coupled substitutions such as $\mathrm{CaMgSi}_{2} \mathrm{O}_{6}-\mathrm{NaAlSi}_{2} \mathrm{O}_{6}-\mathrm{KAlSi}_{2} \mathrm{O}_{6}$ pyroxenes. The concept of impurity atom is then replaced with the concept of impurity pair. However, due to different possible locations of the impurity pairs in the end-member hosts, one arrives at two sets of different configuration energies corresponding to the two doped compositions. The Margules parameters can be easily extracted from these sets by applying Boltzmann weighting to the different configurations. Thus, it becomes possible to estimate the enthalpy of mixing in the high-temperature limit. LRO effect in the low-temperature limit can be predicted with the impurity calculations applied to the end-members and stable ordered compounds. Here the results of the impurity calculations are compared to the results of full-scale Monte Carlo simulations. This permits us to estimate the effectiveness of the impurity sampling scheme.

\section{References}

[1] M.H.F. Sluiter, Y. Kawazoe, Prediction of mixing enthalpy of alloys, Europhys. Lett. 57 (2002) 526-532.

[2] M.H.F. Sluiter, V.L. Vinograd, Y. Kawazoe, Intermixing tendencies in garnets: Pyrope and grossular, Phys. Rev. B 70 (2004) 184120-1-4.

[3] V.L. Vinograd, M.H.F. Sluiter, B. Winkler, A. Putnis, U. Hålenius, J.D. Gale, U. Becker, Thermodynamics of mixing and ordering in pyrope-grossular solid solution, Min. Mag. 68 (2004) 101-121.

\section{Calculating defect chemistry using the CALPHAD Ap- proach}

A. Nicholas Grundy, Bengt Hallstedt, and Ludwig J. Gauckler

The ( $\mathrm{La}, \mathrm{Sr}) \mathrm{MnO}_{3}$ perovskites show quite a complex defect chemistry. This is due to the fact, that Mn can have the valency states $\mathrm{Mn}^{2+}, \mathrm{Mn}^{3+}$ and $\mathrm{Mn}^{4+}$ leading to the perovskites exhibiting both oxygen deficiency and cation deficiency, as 
well as cation nonstoichiometry. Further there is evidence that suggests that under certain circumstances Mn can form antisite defects on the A-sites. The defect chemistry of this phase is extremely important, as all the interesting and useful properties of this phase, such as electrical and ionic conductivity and giant magnetoresistivity originate from its defect chemistry.

The Gibbs energy of the perovskite phase with and without $\mathrm{Mn}$ on A-sites and also all other phases stable in the $\mathrm{La}-\mathrm{Sr}-\mathrm{Mn}-\mathrm{O}$ system are described using the compound energy formalism as a function of temperature and composition. The sublattice model used for the perovskite phase is $\left(\mathrm{La}^{3+}\right.$, $\left.\mathrm{Sr}^{2+}, \mathrm{Mn}^{2+/ 3+}, \mathrm{Va}\right)\left(\mathrm{Mn}^{2+}, \mathrm{Mn}^{3+}, \mathrm{Mn}^{4+}, \mathrm{Va}\right)\left(\mathrm{O}^{2-}, \mathrm{Va}\right)_{3}$. The model parameters are obtained by applying the CALPHAD methodology. This method requires that all experimental data of a phase-in the case of the perovskite phase thermodynamic data, phase diagram data and also defect chemistry data-be simultaneously reproduced by the model description.

The defect chemistry community has expended considerable effort on modeling the defect chemistry of this phase using conventional defect chemistry. However this work shows certain serious shortcomings. We present these problems and show how they can be amended using the CALPHAD approach to calculate the defect chemistry. This is done by a step by step comparison of the defect chemistry modeling using the CALPHAD approach [1] and the conventional defect chemistry modeling of Poulsen [2].

Further a comparison is made between the perovskite described using the compound energy formalism and a model using associates. Here it is shown that modeling the perovskite phase with associates is dangerous, as a wrong choice of associates leads to a wrong description of the defect chemistry.

\section{References}

[1] A.N. Grundy, B. Hallstedt, L.J. Gauckler, $\mathrm{La}_{1-x} \mathrm{Mn}_{1-y} \mathrm{O}_{3-z}$ perovskites modelled with and without antisite defects using the CALPHAD approach, Solid State Ionics 173 (1-4) (2004) 17-21.

[2] F.W. Poulsen, Defect chemistry modelling of oxygen-stoichiometry, vacancy concentrations, and conductivity of $\left(\mathrm{La}_{1-x} \mathrm{Sr}_{x}\right)_{y} \mathrm{MnO}_{3+/-\delta}$, Solid State Ionics 129 (1-4) (2000) 145-162.

\section{High pressure}

\section{Thermodynamic database for the $\mathrm{ZrO}_{2}-\mathrm{Gd}_{2} \mathrm{O}_{3}-\mathrm{Y}_{2} \mathrm{O}_{3}-$ $\mathrm{Al}_{2} \mathrm{O}_{3}$ system}

\section{O. Fabrichnaya, S. Lakiza, M. Zinkevich, F. Aldinger}

The thermodynamic description of the $\mathrm{ZrO}_{2}-\mathrm{Y}_{2} \mathrm{O}_{3}-\mathrm{Al}_{2} \mathrm{O}_{3}$ system was published by [3]. Since the models for fluorite, tetragonal and monoclinic phases have been changed in [5], the system $\mathrm{ZrO}_{2}-\mathrm{Y}_{2} \mathrm{O}_{3}-\mathrm{Al}_{2} \mathrm{O}_{3}$ needs to be re-assessed. The re-assessment of binary systems $\mathrm{ZrO}_{2}-\mathrm{Al}_{2} \mathrm{O}_{3}$ and $\mathrm{ZrO}_{2}-\mathrm{Y}_{2} \mathrm{O}_{3}$ is presented in [5,6]. It is shown in the present study that changing thermodynamic parameters of fluorite and tetragonal phases aimed to reduce $\mathrm{Al}_{2} \mathrm{O}_{3}$ content in fluorite and tetragonal phases leads to a decrease of consistency with the phase diagram of $\mathrm{ZrO}_{2}-\mathrm{Al}_{2} \mathrm{O}_{3}$ system. Also the calculations show that the description obtained in the present study for the
$\mathrm{ZrO}_{2}-\mathrm{Y}_{2} \mathrm{O}_{3}-\mathrm{Al}_{2} \mathrm{O}_{3}$ system reproduces experimental data of Stough [2] for equilibrium of fluorite with corundum.

Calculations of [3] for the $\mathrm{ZrO}_{2}-\mathrm{Y}_{2} \mathrm{O}_{3}-\mathrm{Al}_{2} \mathrm{O}_{3}$ system indicated that tie-lines between $\delta$, fluorite, YAM and YAG phases differ from the experimental data of [1] at $1250{ }^{\circ} \mathrm{C}$. The experimental investigation of a mixture with composition of 50 mol\% $\mathrm{ZrO}_{2}$ and $42 \mathrm{~mol} \% \mathrm{Y}_{2} \mathrm{O}_{3}$ at 1250,1300 and $1340^{\circ} \mathrm{C}$ showed that at 1250 and $1300{ }^{\circ} \mathrm{C}$ the tie-lines are consistent with results of [3] and calculations made in the present study. The invariant reaction $\delta+\mathrm{YAP}=\mathrm{YAM}+$ Fluorite occurs at temperatures between 1300 and $1340{ }^{\circ} \mathrm{C}$.

The thermodynamic description obtained in this study is combined with the descriptions of the $\mathrm{ZrO}_{2}-\mathrm{Gd}_{2} \mathrm{O}_{3}-\mathrm{Al}_{2} \mathrm{O}_{3}$, $\mathrm{ZrO}_{2}-\mathrm{Gd}_{2} \mathrm{O}_{3}-\mathrm{Y}_{2} \mathrm{O}_{3}$ and $\mathrm{Gd}_{2} \mathrm{O}_{3}-\mathrm{Y}_{2} \mathrm{O}_{3}-\mathrm{Al}_{2} \mathrm{O}_{3}$ from [5,6,4], respectively, assuming that there are no quaternary interactions in the system.

The $\mathrm{T}^{\circ}$ lines for diffusionless transitions have been calculated in the systems $\mathrm{ZrO}_{2}-\mathrm{Al}_{2} \mathrm{O}_{3}, \mathrm{ZrO}_{2}-\mathrm{Gd}_{2} \mathrm{O}_{3}, \mathrm{ZrO}_{2}-\mathrm{GdAlO}_{3}$, $\mathrm{ZrO}_{2}-\mathrm{Y}_{2} \mathrm{O}_{3}, \mathrm{ZrO}_{2}-\mathrm{YAlO}_{3}$ and other vertical sections of the $\mathrm{ZrO}_{2}-\mathrm{Gd}_{2} \mathrm{O}_{3}-\mathrm{Al}_{2} \mathrm{O}_{3}$ and $\mathrm{ZrO}_{2}-\mathrm{Y}_{2} \mathrm{O}_{3}-\mathrm{Al}_{2} \mathrm{O}_{3}$ systems at fixed $\mathrm{Gd} / \mathrm{Al}$ and $\mathrm{Y} / \mathrm{Al}$ ratio. The calculated $\mathrm{T}^{\circ}$ lines for the fluorite $\Leftrightarrow$ tetragonal transition in the $\mathrm{ZrO}_{2}-\mathrm{Gd}_{2} \mathrm{O}_{3}-\mathrm{Al}_{2} \mathrm{O}_{3}$ and $\mathrm{ZrO}_{2}-\mathrm{Y}_{2} \mathrm{O}_{3}-\mathrm{Al}_{2} \mathrm{O}_{3}$ systems constrain the composition range at each temperature, where the metastable tetragonal phase can be obtained. Isoplethal sections of the $\mathrm{ZrO}_{2}-\mathrm{Gd}_{2} \mathrm{O}_{3}-\mathrm{Y}_{2} \mathrm{O}_{3}-\mathrm{Al}_{2} \mathrm{O}_{3}$ system for two industrially important compositions $(3.8 \mathrm{~mol} \%$ $\mathrm{Y}+3.8 \mathrm{~mol} \% \mathrm{Gd}$ and $7.6 \mathrm{~mol} \% \mathrm{Y}+7.6 \mathrm{~mol} \% \mathrm{Gd}$ ) have been calculated. They are presented in the figure.
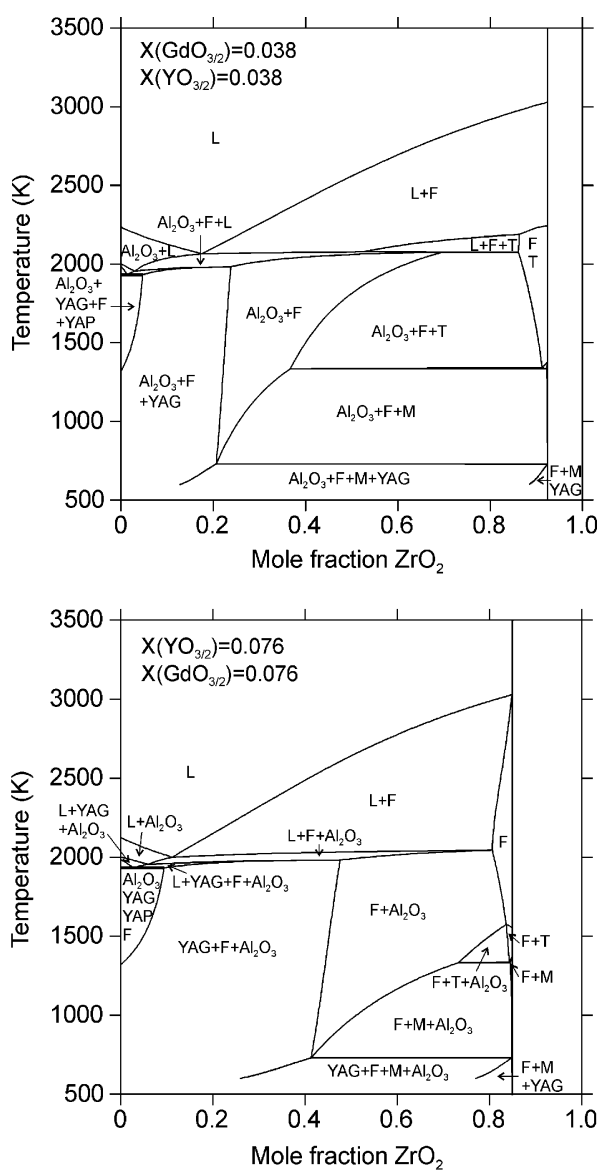


\section{References}

[1] L.M. Lopato, L.V. Nazarenko, G.V. Gerasimjuk, A.V. Shevchenko, Neorg. Mater. 28 (1992) 835.

[2] M.A. Stough, J.R. Hellmann, J. Am. Ceram. Soc. 85 (2002) 2895.

[3] O. Fabrichnaya, F. Aldinger, Z. Metallkd. 95 (2004) 27.

[4] O. Fabrichnaya, Ch. Wang, S. Lakiza, M. Zinkevich, F. Aldinger, Program and Abstracts of Calphad XXXIII, May 30 - June 4, 2004, Krakow, Poland, p. 96.

[5] S. Lakiza, O. Fabrichnaya, Ch. Wang, M. Zinkevich, F. Aldinger, J. Eur. Ceram. Soc. (2005) (in press).

[6] O. Fabrichnaya, Ch. Wang, C. Levi, M. Zinkevich, F.J. Aldinger, Phase Equilibria (2005) (submitted for publication).

\section{Theoretical calculation of phase diagram: Introduction of the pressure dependence}

A.E. Gheribi, J. Rogez, J.C. Mathieu, F. Marinelli and M.C. Record

Currently, the deformed systems under hydrostatic compression are described either by the Helmholtz energy through the Birch-Murnaghan equation of state [1,2] or by the Gibbs energy through the Murnaghan equation of state [3]. The Birch-Murnaghan equation based on physical considerations of finite strain theory describes the thermodynamic properties of materials in a pressure range broader than the empirical Murnaghan equation. In the present study the Gibbs energy is deduced from the Helmholtz energy formulated with the Birch-Murnaghan equation, through a new formulation in the inversion of the $\mathrm{P}(\mathrm{V})$ equation.

A new formulation of the interaction parameters of the solutions versus the variable pressure is also proposed and consequently the excess Gibbs energy for binary and ternary systems. All the used thermodynamic functions are built from experimental data obtained versus the temperature around the normal pressure. The extrapolations of the quantities away from the range of measurement is based on the anharmonic and quasiharmonic theory for the solids [4], and on the "hard sphere model" [5,6,7 and 10] or on the "modified hard-sphere model" for the liquid [8]. Finally, taking into account the Gibbs energy of the pure elements and the excess Gibbs energies, the phase diagram under pressure are calculated by means of the THERMO-CALC software. As an illustration we present the results on the $\mathrm{Ag}-\mathrm{Cu}$ phase diagram at high pressure which is compared with the experimental one [9].

\section{References}

[1] K. Saxena, N. Chatterjee, Y. Fei, G. Shen, Thermodynamic Data on Oxides and Silicates, Springer Verlag, 1993.

[2] H. Mao, B. Sundman, Z. Wang, S.K. Saxena, J. Alloys Compounds 327 253.

[3] A.F. Guillermet, P. Gustafson, M. Hillert, J. Phys. Chem. Solids 46 (1985) 1427.

[4] G. Leibfried, W. Ludwig, Solid State Phys. 12 (1961) 275.

[5] P. Ascarelli, Phys. Rev. 173 (1) (1968) 271.

[6] M. Hasegawa, Solid State Commun. 11 (1972) 531.

[7] R.D. Present, J. Chem. Phys. 61 (10) (1974) 4267.

[8] M. Shimoji, Liquid Metals: An Introduction to the Physics and Chemistry of Metals in the Liquid State, Academic Press, 1977.

[9] G. Leloup, Cuivre, Laitons, Alliages 96 (1967) 21.

[10] Y. Rosenfeld, J. Phys.: Condens. Matter, 11 (1999) 71.
Thermo-physical properties and phase equilibria of mantle materials derived from lattice vibrations

M.H.G. Jacobs, B.H.W.S. de Jong, A.P. van den Berg and H.A.J. Oonk

Accurate material properties are essential for geodynamic model calculations and for the interpretation of seismological observations. We present ongoing work [1-6] of constructing a thermodynamic database for materials of geophysical relevance with the aim to predict thermo-physical and thermo-chemical properties and phase equilibria at conditions prevailing in planetary mantles.

We developed a computational technique based on an extended form of Kieffer's [7] approach to model the vibrational density of states of a substance, a key property to derive the Helmholtz energy. The developed thermodynamic framework, which uses input parameters related to Raman and infrared spectroscopic data, puts tighter constraints on thermodynamic properties compared to methods based on polynomial parameterizations of thermal expansivity, heat capacity and isothermal bulk modulus.

The ramifications of our approach are that (1) a highly accurate representation of experimental data is achieved, (2) the description is free from non-physical anomalies in the pressure and temperature range prevailing in planetary mantles, which are quite common in more conventional thermodynamic descriptions, (3) it allows a fast computation of thermodynamic and mechanical properties, which makes it suitable for geodynamic modelling, (4) it allows the calculation of longitudinal and transverse sound wave velocities.

We present results on the application of our approach to the $\mathrm{Mg}_{2} \mathrm{SiO}_{4}$ olivine $(\alpha)$, wadsleyite $(\beta)$ and ringwoodite $(\gamma)$ polymorphs, which are key materials in the upper mantle of the Earth $(P<24 \mathrm{GPa})$. At pressures larger than $24 \mathrm{GPa}$, the $\mathrm{MgO}$ (periclase) $+\mathrm{MgSiO}_{3}$ (perovskite) phase assemblage is more stable than $\gamma-\mathrm{Mg}_{2} \mathrm{SiO}_{4}$, but experimental data are scant for $\mathrm{MgSiO}_{3}$. We have included in our work the Gibbs energy formulation of the recently discovered post-perovskite phase $(P \approx 125 \mathrm{GPa})$ for which no thermodynamic data are available except for the volume in one $P-T$ point. In the case of perovskite and post-perovskite results of ab initio calculations were incorporated in our assessment. We show how our approach is used in a thermodynamic assessment of experimental data and compare the results with those obtained from ab initio calculations. The results, which will be presented here, were used in a numerical model of convection in the Earth's mantle to reveal, among other things, effects of phase transitions on the degree of layering around $660 \mathrm{~km}$ depth in the Earth (Van den Berg et al., this meeting).

\section{References}

[1] M.H.G. Jacobs, H.A.J. Oonk, CALPHAD 24 (2000) 133-148.

[2] M.H.G. Jacobs, H.A.J. Oonk, Phys. Chem. Chem. Phys. 2 (2000) 2641-2646.

[3] M.H.G. Jacobs, H.A.J. Oonk, Phys. Chem. Minerals 28 (2001) 572-585.

[4] M.H.G. Jacobs, H.A.J. Oonk, Phys. Chem. Chem. Phys. 3 (2001) 1394-1395. 
[5] M.H.G. Jacobs, B.H.W.S. de Jong, H.A.J. Oonk, Geochim. Cosmochim. Acta 65 (2001) 4231-4242.

[6] M.H.G. Jacobs, B.H.W.S de Jong, Phys. Chem. Chem. Phys. 5 (2003) 2056-2065.

[7] S.W. Kieffer, Rev. Geophys. Space Physics 17 (1979) 35-59.

\section{Thermal convection models for planetary mantles based on self-consistent thermodynamics}

A.P. van den Berg, M.H.G. Jacobs and B.H.W.S. de Jong

Thermal convection by high viscosity creeping flow processes in solid-state mantle silicates accommodates the bulk of the thermal energy transport from the Earth's interior, resulting in a total estimated present day heat output of some $44 \times 10^{12} \mathrm{~W}$ through the Earth's surface.

This mantle convection process has been investigated extensively by means of numerical modeling, based on numerical solution of the governing equations for massmomentum and energy conservation. The energy transport equation involved in such models contains several thermophysical parameters, such as density, specific heat and thermal expansivity, which are typically parameterized or taken as uniform constants in most numerical models in use in geophysical studies of mantle convection today.

As a result of the inherent complexities of these models, containing several non-linear process interactions, detailed sensitivities in the model response could be artifacts from inconsistent parameterizations used, rather than truly physical effects.

To remediate this problem we have used a different approach towards mantle convection modeling. Instead of parameterizing the relevant physical parameters we directly apply thermodynamic parameter values obtained from a selfconsistent thermodynamic description based on a Gibbs energy formulation, for a complete temperature and pressure range relevant for the Earth's mantle (300-4500 K, 0-140 GPa). This way our convection model calculations are based on selfconsistent thermo-physical parameters for the different solidstate phases of the magnesium-silicate mantle material. In our numerical models based on finite-element formulations of the coupled momentum and energy equations we obtain the $(P, T)$ dependent parameter values by interpolation in data tables with typical table spacing of $2 \mathrm{~K}$ and $0.06 \mathrm{GPa}$ ( $2 \mathrm{~km}$ depth spacing).

We present modeling results of convection in the Earth's mantle using a recent thermodynamic database of Jacobs et al. (2005) (this meeting) for magnesium silicate, representing the olivine fraction of the representative pyrolitic mantle composition. This includes the complete subset of corresponding mantle mineral phases (olivine, wadsleyite, ringwoodite, characteristic for the earth's upper mantle $(P<$ $25 \mathrm{GPa}$ ). For higher pressures the model lower mantle consists of a mineral assemblage of post-spinel with magnesium perovskite and magnesiowüstite. The model also includes a high pressure post-perovskite phase which was recently discovered at pressure values of around $125 \mathrm{GPa}$ representative for the bottom of the Earth's mantle at about $2500 \mathrm{~km}$ depth.
We focus in particular on the role of phase transitions in regulating the degree of layering around a depth of $660 \mathrm{~km}$ or $24 \mathrm{GPa}$ pressure and on the occurrence of the high-pressure $(>125 \mathrm{GPa}$ ) post-perovskite phase in the bottom D" zone of the mantle near the core-mantle boundary.

\section{Modelling and experiments}

\section{Thermodynamic modeling and key experiments in Mg-Al-Mn-Zn alloys}

Rainer Schmid-Fetzer, Munekazu Ohno, and Djordje Mirkovic

Proper interpretation of experimental data is the focus of this presentation. For example, the calculated $\mathrm{Mg}-\mathrm{Al}-\mathrm{Zn}$ phase diagram section in Fig. 1 appears to disagree with recent thermal analysis "solidus" data [2]. We performed our own key experiments. For the MgA19.4Zn1.2 (wt.\%) alloy they indicate virtually the same thermal signals, even though we have used a more elaborated DTA setup and a much lower cooling rate. However, our metallographic analysis reveals the precipitation of $\gamma-\mathrm{Mg}_{17} \mathrm{Al}_{12}$ from the liquid. This is easily explained by performing Scheil calculations, which show that for all samples in Fig. 1 the second signal is related to the $\mathrm{L}+\mathrm{hcp} / \mathrm{L}+$ hcp $+\gamma-\mathrm{Mg}_{17} \mathrm{Al}_{12}$ transition, proven by the solidification microstructure. Now all the "second signals" are in much better agreement with the calculation compared to the assumption of equilibrium, see Fig. 2. The claimed "solidus" data [2] are thus the start of a monovariant eutectic solidification reaction that ranges down to much lower temperature. It is stunning that even with our DTA cooling rates as low as $1 \mathrm{~K} / \mathrm{min}$ the solidification path is far from equilibrium and close to Scheil conditions.

Phase equilibria of the $\mathrm{Mg}-\mathrm{Al}-\mathrm{Mn}-\mathrm{Zn}$ quaternary system will also be shown. They provide crucial information in development and designing of most important $\mathrm{Mg}$ alloys like the AZ and AM series.

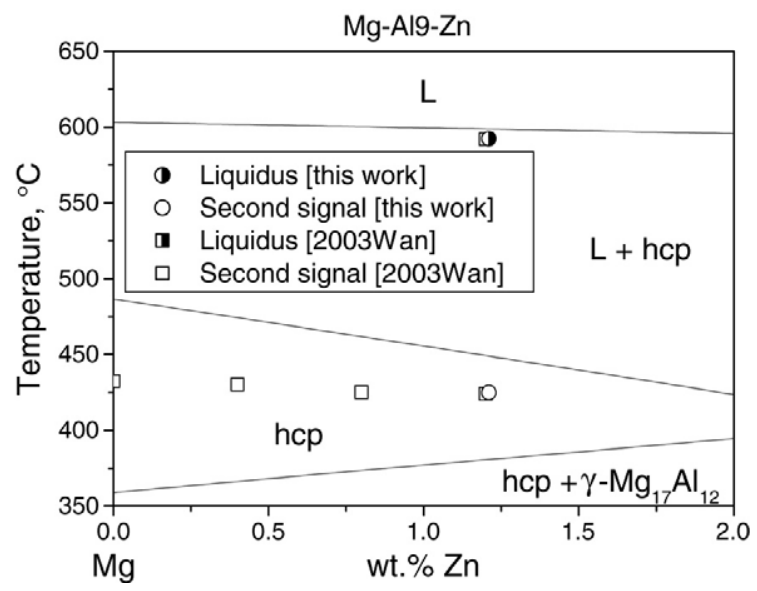

Fig. 1. $\mathrm{Mg}-\mathrm{Al}-\mathrm{Zn}$ phase diagram section at $9 \mathrm{wt} \% \mathrm{Al}$, calculated from the parameters of Liang et al. [1]. 


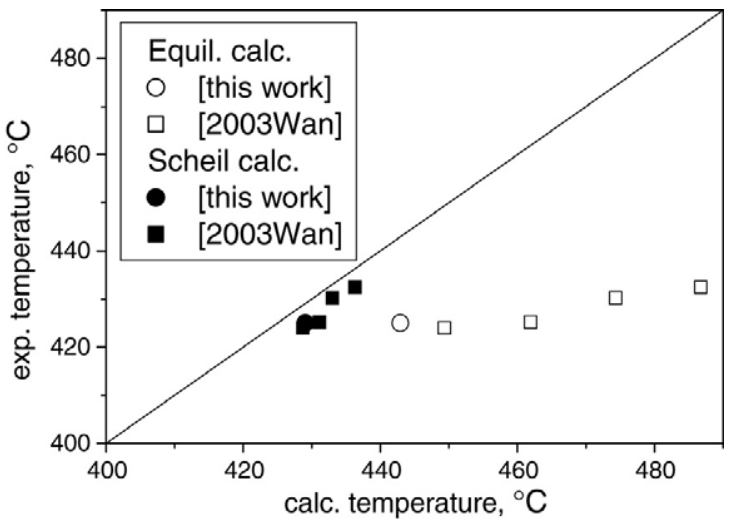

Fig. 2. Comparison between the calculated and the experimental results.

\section{Acknowledgement}

This work is supported by the German Research Foundation (DFG) in the Priority Programme "DFG-SPP 1168: InnoMagTec".

\section{References}

[1] P. Liang, H.-L. Su, P. Donnadieu, M.G. Harmelin, A. Quivy, P. Ochin, G. Effenberg, H.-J. Seifert, H.L. Lukas, F. Aldinger, Z. Metallkd. 89 (1998) 536.

[2] Y. Wang, Q. Wang, C. Ma, W. Ding, Y. Zhu. Mater. Sci. Eng. A 342 (2003) 178.

\section{Experimental investigation and thermodynamic modeling of magnesium alloy systems}

M. Medraj, M.A. Parvez, E. Essadiqi, A. Muntasar and G. Dénès

The phase diagrams of $\mathrm{Mg}-\mathrm{Al}-\mathrm{Sr}$ and $\mathrm{Mg}-\mathrm{Al}-\mathrm{Ca}$ systems were investigated experimentally by differential scanning calorimetry (DSC) and X-ray diffraction (XRD) techniques. The experimental work focused on the critical regions after reviewing the phase diagrams developed by thermodynamic modeling. DSC has permitted real time measurement of the phase changes involved in these systems. The temperature ranges for the phase change peaks have been determined. Enthalpy of melting and enthalpy of formation of the compounds are also reported. Comparison between these results and the thermodynamic findings will be discussed. These results along with the XRD analysis are used to establish the equilibria in $\mathrm{Mg}-\mathrm{Al}-\mathrm{Sr}$ and $\mathrm{Mg}-\mathrm{Al}-\mathrm{Ca}$ systems. XRD was used to identify the phases in the studied samples. $\mathrm{Al}_{4} \mathrm{Sr}$ and $\mathrm{Al}_{2} \mathrm{Ca}$ were found to be the dominating phases in $\mathrm{Mg}-\mathrm{Al}-\mathrm{Sr}$ and $\mathrm{Mg}-\mathrm{Al}-\mathrm{Ca}$ systems, respectively.

Four new phase fields have been identified in the $\mathrm{Mg}-\mathrm{Al}-\mathrm{Sr}$ system and the phases were tentatively designated as $\mathrm{T}_{\mathrm{Sr}} 1$, $\mathrm{T}_{\mathrm{Sr}} 2, \mathrm{~T}_{\mathrm{Sr}} 3$ and $\mathrm{T}_{\mathrm{Sr}} 4$; the new phases may be ternary intermetallics or solid solutions. Comparison with the pertinent thermodynamic calculation and the available experimental results were made that suggests the $\mathrm{Mg}-\mathrm{Al}-\mathrm{Sr}$ system should be remodeled. In most of the studied samples in the
$\mathrm{Mg}-\mathrm{Al}-\mathrm{Ca}$ system, good agreement was observed between the experimental results and thermodynamic calculations.

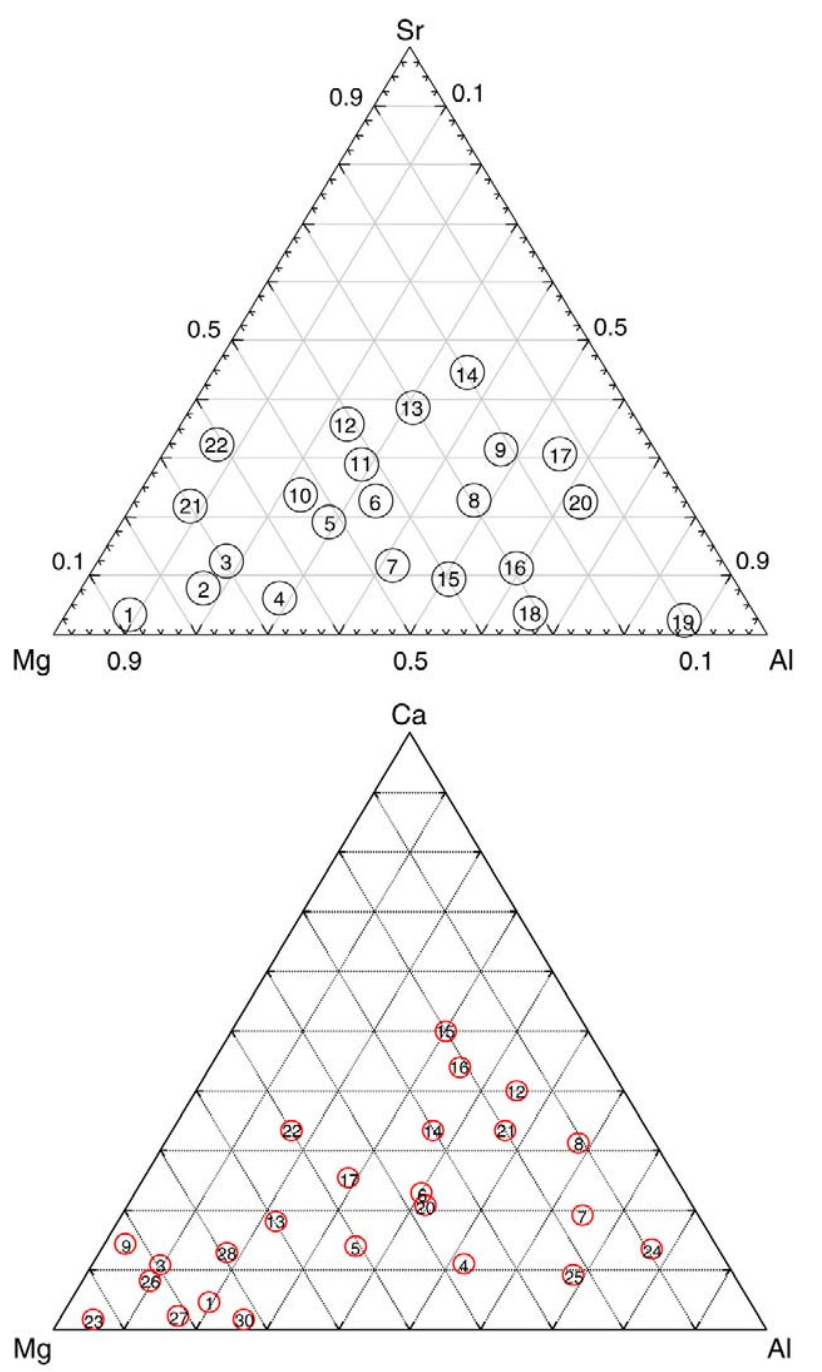

Ternary diagrams showing investigated compositions in $\mathrm{Mg}-\mathrm{Al}-(\mathrm{Sr}, \mathrm{Ca})$ systems in wt.\%.

\section{On the stability of the $\alpha$-phase in aluminum alloys}

\section{Mohamed Abou Khatwa and Dmitri V. Malakhov}

Since precipitation of tiny plate-like particles of $\mathrm{Mg}_{2} \mathrm{Si}$ is the major strengthening mechanism in the 6xxx series aluminum alloys, temperature and time used for artificial aging are the most important technological parameters determining the mechanical properties of these alloys. However, the presence of particles different from $\mathrm{Mg}_{2} \mathrm{Si}$ cannot be discarded when not only the last stage, but all stages of thermomechanical processing are considered. In particular, these particles, which are usually rich in iron, manganese and silicon, may significantly affect the kinetics of recrystallization of coldrolled alloys as well as a post-recrystallization grain structure.

As-cast alloy (alloy A) containing $0.55 \% \mathrm{Mg}, 0.34 \% \mathrm{Fe}$, $0.56 \% \mathrm{Si}, 0.25 \% \mathrm{Mn}$ and $0.5 \% \mathrm{Cu}$ was placed in boiling phenol, which selectively dissolves the FCC matrix thus allowing 


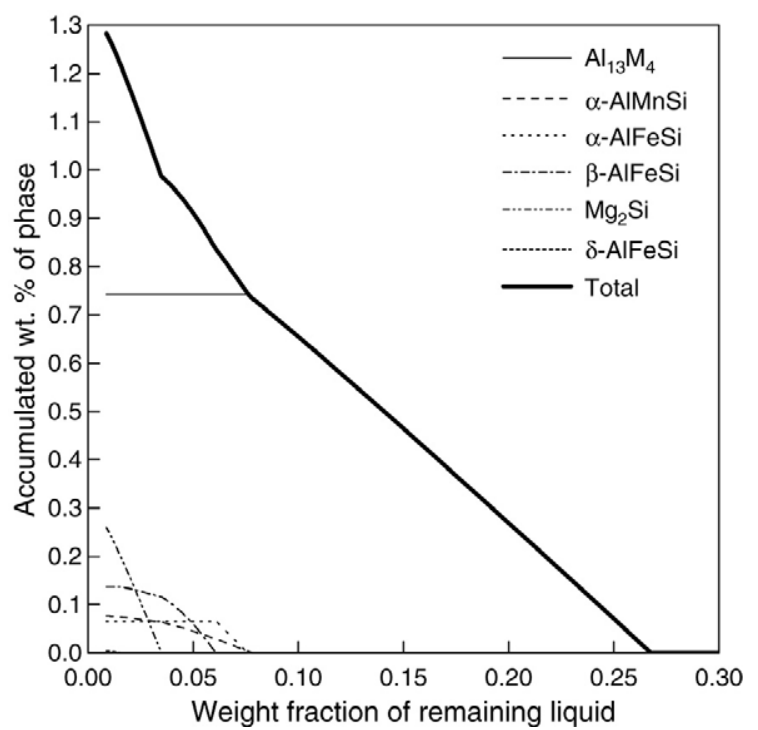

Fig. 3.

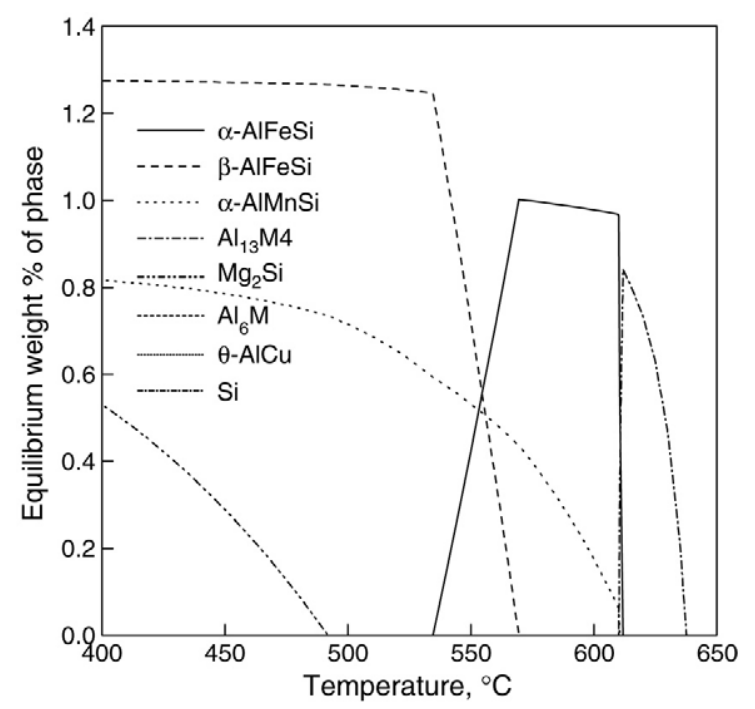

Fig. 4.

the extraction of intermetallic particles. The experimentally determined fraction of second-phase particles was equal to $2.4 \pm 0.2$ wt.\%, which, as Fig. 3 demonstrates, is much higher than that predicted by the Scheil-Gulliver formalism. It is worth emphasizing that according to this formalism, $\mathrm{Al}_{13} \mathrm{M}_{4}$ should dominate in the mixture of intermetallics. In contrast to this prediction, it was found by means of the XRD analysis that the dominating phase in the mixture is the $\alpha$-phase, a cubic phase containing both $\mathrm{Fe}$ and $\mathrm{Mn}$.

The same technique was used for extracting intermetallics from two heat-treated alloys fabricated from the as-cast alloy (alloy B: $450{ }^{\circ} \mathrm{C}, 168 \mathrm{~h}$; alloy C: $600{ }^{\circ} \mathrm{C}, 47 \mathrm{~h}$ ). It was found that the fraction of the particles in alloy $\mathrm{B}, 2.5 \pm 0.2 \mathrm{wt} . \%$, was very similar to that in alloy $\mathrm{A}$, and that alloy $\mathrm{C}$ contained $2.1 \pm 0.2 \mathrm{wt} . \%$ of intermetallics. According to the results of the XRD analysis, $\alpha$-phase again dominated in both cases. As Fig. 4 stipulates, those findings did not conform to an estimation of the equilibrium amounts of phases at 450 and $600^{\circ} \mathrm{C}$, which were calculated by using the Thermochemical Database for Light Metal Alloys.

The results of the investigation suggest that the thermodynamic stability of the $\alpha$-phase is likely underestimated in the literature. One of the possible explanations is based on the fact that in many intermetallic compounds having several sublattices, Fe can readily mix with $\mathrm{Mn}$ on the same sublattice. For an arbitrary phase, it cannot be said in advance whether such interaction results in a greater stability since enthalpic and entropic terms may act in different directions.

The thermodynamic properties of the $\alpha$-phase were described by using the following sublattice model $\mathrm{Al}_{16}(\mathrm{Fe}, \mathrm{Mn})_{4}$ $(\mathrm{Si})(\mathrm{Al}, \mathrm{Si})_{2}$. De facto, by using this model we assumed that the cubic $\alpha$-AlMnSi phase, $\mathrm{Al}_{16}(\mathrm{Mn})_{4}(\mathrm{Si})(\mathrm{Al}, \mathrm{Si})_{2}$, can dissolve Fe. This debatable assumption will be discussed in the presentation. Experimental data reported by Zakharov et al. were employed for evaluating the thermodynamic properties of the phase. It was attempted to carry out this mini-optimization in such a way that temperatures of nonvariant equilibria are reproduced without altering the descriptions of the ternary $\mathrm{Al}-\mathrm{Fe}-\mathrm{Si}$ and $\mathrm{Al}-\mathrm{Mn}-\mathrm{Si}$ systems adopted in the Thermochemical Database for Light Metal Alloys.

\section{References}

[1] A.M. Zakharov, I.T. Guldin, A.A. Arnold, Yu.A. Matsenko Izvestiya Akademii Nauk SSSR, Seriya Metally (4) (1989) 214-218.

[2] A.M. Zakharov, I.T. Guldin, A.A. Arnold, Yu.A. Matsenko Izvestiya Vysshikh Uchebnykh Zavedenii, Tsvetnye Metally (4) (1988) 89-94.

[3] A.M. Zakharov, I.T. Guldin, A.A. Arnold, Yu.A. Matsenko Izvestiya Vysshikh Uchebnykh Zavedenii, Tsvetnye Metally (4) (1989) 78-81.

\section{Formation and stability of complex intermetallic phases in the Al-rich region of Al-Pd-Re and Al-Pd-Mn}

Balanetskyy S., Velikanova T.Ya., Grushko B., Feuerbacher M. and Urban K.

Structurally complex alloy phases are exceptional metallic systems based on crystal structures with giant unit cells comprising up to more than a thousand atoms per unit cell. They have long since been studied in crystallography and metallurgical materials science (see [1,2] and references therein). However physical properties of this class of intermetallic phases have hardly been investigated. Correct interpretation of the physical properties requires knowledge of the stability conditions of the phases, their atomic structure, phase transition mechanisms etc., but this is impossible without systematic investigations of the corresponding phase diagrams. Up to now, many binary and ternary alloy systems, where complex intermetallics were revealed or their formation is expected, are not systematically investigated.

The present work continues the study of formation conditions, structure and stability of complex intermetallics, including quasicrystals, in ternary Al-Pd-TM alloy systems ([3-6] and references therein) which belong to the Al-based complex intermetallics-forming alloy systems (CIFAS). 
While Al-Pd-Mn belongs to the most intensively investigated CIFASs [7], the Al-Pd-Re alloy system was much less known as yet. Since Mn and Re belong to the same column of the periodic table some similarities in constitution of $\mathrm{Al}-\mathrm{Pd}-\mathrm{Mn}$ and Al-Pd-Re phase diagrams as well as some differences governed by the difference of size and electronic structure of their atoms are expected.

In our work, we consider the AlPd-Al- $\mathrm{Al}_{11} \mathrm{TM}_{4}(\mathrm{TM}=$ $\mathrm{Mn}, \mathrm{Re})$ compositional region. In this region, thermodynamically stable binary $l-\mathrm{Al}_{11} \mathrm{Mn}_{4}$ and $\mathrm{Al}_{11} \mathrm{Re}_{4}, \mathrm{Al}_{6} \mathrm{Mn}$ and $\mathrm{Al}_{6} \mathrm{Re}$ as well as ternary $\mathrm{I}-\mathrm{Al}_{70} \mathrm{Pd}_{20} \mathrm{Mn}_{10}$ and $\mathrm{I}-\mathrm{Al}_{70} \mathrm{Pd}_{20} \mathrm{Re}_{10}$ are isostructural phases. No phases isostructural with orthorhombic $\mathrm{Al}_{3} \mathrm{Mn}$, and hexagonal $\mu$ and $\lambda$ with stoichiometry close to $\mathrm{Al}_{4} \mathrm{Mn}$ in $\mathrm{Al}-\mathrm{Re}$ exist. In contrast, $l-\mathrm{Al}_{4} \mathrm{Re}$ has triclinic structure and that of $h-\mathrm{Al}_{4} \mathrm{Re}$ is unclear but rather related to monoclinic $\mathrm{Al}_{4} \mathrm{~W}$. No phase isostructural with cubic $\mathrm{Al}_{12} \mathrm{Re}$ was revealed in $\mathrm{Al}-\mathrm{Mn}$.

Ternary decagonal (D) phases are thermodynamically stable in both systems but they are not isostructural. While $\mathrm{D}_{3}$ has periodicity $\sim 1.24 \mathrm{~nm}$ and composition $\sim \mathrm{Al}_{69.0} \mathrm{Pd}_{11.8} \mathrm{Mn}_{19.2}$, $\mathrm{D}_{6}$ has $-\sim 25.7 \mathrm{~nm}$ and composition $\sim \mathrm{Al}_{78.0} \mathrm{Pd}_{7.8} \operatorname{Re}_{14.2}$.

The stabilization effect of the replacement of Pd atoms by Re in the structure of the metastable binary Al-Pd $\chi$-phase ( $a \approx 1.24$ and $c \approx 2.78 \mathrm{~nm}[8]$ ) was not observed in the case of Mn. Thus, no phase isostructural with thermodynamically stable ternary $\mathrm{Al}-\mathrm{Pd}-\mathrm{Re} \chi$ was revealed in $\mathrm{Al}-\mathrm{Pd}-\mathrm{Mn}$.

The maximum of solubility of both $\mathrm{Mn}$ and $\mathrm{Re}$ in the binary Al-Pd $\varepsilon$-phase(s) approximately amounts to $\sim 5$ at. $\%$. No T-phase related (based on $\mathrm{Al}_{3} \mathrm{Mn}$ ) complex orthorhombic structures [7] typical for as-cast or partially annealed $\mathrm{Al}-\mathrm{Pd}-\mathrm{Mn}$ samples were observed in Al-Pd-Re. Instead of this the metastable orthorhombic O-phase (B-centred, $a \approx 3.90$, $b \approx 2.57, c \approx 5.40 \mathrm{~nm}$ ) was revealed by TEM during in-situ decomposition of $\mathrm{D}_{6}$ under the electron beam.

\section{References}

[1] K. Urban, M. Feuerbacher, Structurally complex alloy phases, J. NonCryst. Solids 334-335 (2004) 143-150.

[2] B. Grushko, T.Ya. Velikanova, Stable and metastable quasicrystals in Albased alloy systems, J. Alloys Compounds 367 (2004) 58-63.

[3] B. Grushko, M. Yurechko, N. Tamura, A contribution to the Al-Pd-Mn phase diagram, J. Alloys Compounds 290 (1999) 164-171.

[4] M. Yurechko, B. Grushko, T. Velikanova, K. Urban, Isothermal sections of the Al-Pd-Co alloy system for 50-100 at.\% Al, J. Alloys Compounds 337 (2002) 172-179.

[5] S. Balanetskyy, B. Grushko, T.Ya. Velikanova, K. Urban, An investigation of the Al-Pd-Fe phase diagram between 50 and 100 at. $\%$ Al: phase equilibria at $750^{\circ} \mathrm{C}$, J. Alloys Compounds 376 (2004) 158-164.

[6] S. Balanetskyy, B. Grushko, T.Ya. Velikanova, Decagonal quasicrystal of a new structural type, Z. Kristall. 219 (2004) 548-553.

[7] O. Dovbenko, T. Velikanova, S. Balanetskyy, Aluminum-ManganesePalladium. G. Effenberg (Ed.), Ternary Alloy Systems. Phase Diagrams, Crystallographic and Thermodynamic Data Critically Evaluated by MSIT. Group IV: Physical Chemistry. Subvolume A-Light Metal Systems, Springer \& MSI, 2005 (in press).

[8] L. Ma, R. Wang, K.H. Kuo, Decagonal quasicrystals and related quasicrystalline phases in rapidly solidified Al-Ir, Al-Pd and Al-Pt, Scripta Metallurgica 22 (1988) 1791-1796.

\section{The experimental and theoretical study of phase equilibria in the Bi-Sn-Zn system}

Jiri Vizdal and Ales Kroupa

The ternary system Bi-Sn-Zn was studied experimentally with the aim to produce data allowing assessing the above mentioned system theoretically. Significant discrepancies were found with respect to the calculation based on the binary data only, especially concerning the solubility of other elements in terminal solid solutions. It was found that the presence of the third element influences significantly the solubility of the other element in particular terminal phase in comparison with binary systems (with the exception of HCP_Zn, where the solubility of other elements remained very low), e.g. the solubility of Bi in BCT_Sn in the ternary system is significantly lower than the reported solubility of $\mathrm{Bi}$ in BCT_Sn for the limiting Bi-Sn binary. On the other hand, the solubility of Zn in RHOMBO_Bi seems to be significantly higher than in the case of limiting binary $\mathrm{Bi}-\mathrm{Zn}$ system. The differences are of such an extent that the suspicion about the quality of experimental data for binaries was raised. Therefore not only the ternary system but also the binary systems, where the differences existed were studied experimentally and, if necessary, remodelled theoretically.

The long-term annealing and DTA analysis was used to obtained phase data necessary for the theoretical assessment. The structures, obtained after a long-term annealing, were studied by means of SEM with EDX and WDX analysis. The DTA analysis was then used to derive the temperatures of phase transitions.

\section{Acknowledgements}

This study was supported by the Ministry of Education of Czech Republic under the COST project OC 531.002, Institutional Research Plan AV0Z20410507 and Czech Research Foundation Project No. 106/05/H008.

\section{CALPHAD thermodynamics}

\section{Thermodynamic Modelling of $\mathrm{MgF}_{2}-\mathrm{MgO}$ in $\mathrm{NaF}^{-\mathrm{AlF}_{3}-}$ $\mathrm{Al}_{2} \mathrm{O}_{3}-\mathrm{CaF}_{2}-\mathrm{LiF}$}

\section{Patrice Chartrand}

A large body of experimental thermodynamic and phaseequilibrium data exists for the $\mathrm{Al}-\mathrm{Na}-\mathrm{Ca}-\mathrm{Li}-\mathrm{Mg}-\mathrm{F}-\mathrm{O}$ system. This system is of primary importance for $\mathrm{Al}_{2} \mathrm{O}_{3}$-reduction cells. A thermodynamic model and database have been proposed by the author for the $\mathrm{Al}-\mathrm{NaF}-\mathrm{AlF}_{3}-\mathrm{CaF}_{2}-\mathrm{LiF}-\mathrm{Al}_{2} \mathrm{O}_{3}$ system. In the present work, $\mathrm{MgF}_{2}-\mathrm{MgO}$ have been added to the system. All available data are critically evaluated to obtain optimized parameters of thermodynamic models of all phases. The bath model is the quasichemical model in the quadruplet approximation that evaluates 1st- and 2nd-nearest-neighbor short-range order. Other solution models are used for nonstoichiometric solid cryolite, cryolithionite, $\mathrm{Li}_{3} \mathrm{AlF}_{6}$ terminal solid solutions, the gas phase and molten Al. The models 
are then used to predict the thermodynamic properties and metal-bath-gas-oxides equilibria in the multicomponent heterogeneous system. All experimental data were reproduced within experimental error limits. The model parameters form a database that is part of the FactSage Thermochemical Software. This software can be used to predict/simulate metal-bath-gas equilibrium (phase amounts, compositions, activities/partial pressures, enthalpies, $T_{\text {liquidus, etc...) for } 25^{\circ} \mathrm{C}<T<}$ $1100^{\circ} \mathrm{C}$, for $P<4 \mathrm{~atm}$, and for bath ratios (wt.\%) from 3.0 to $\mathrm{AlF}_{3}$ saturation.

\section{(CT)The CALPHAD approach to computational thermody- namics}

\section{Larry Kaufman}

Recent conferences [1,2] presented many applications of Computational Thermodynamics. Moreover volume 26 (2002) of the CALPHAD Journal describes a variety of software for applying these methods. Several examples of recent work on $\mathrm{Nb}$ alloys [3], metallic glasses [5-7], lithium batteries [8,9], zirconia, ceramics [10], and multicomponent rhenium alloys $[11,12]$ illustrate problems that require attention and to foster future progress in these fields. At these conferences [1,2] progress since 1966 was presented. This was attributed to the development of CALPHAD THERMODYNAMICS (CT) to describe all possible phases in a system over wide ranges of conditions uncommon in classical thermodynamics. This feature grew naturally in (CT) from the realization that commercial processing always tries to increase the rate of production to become more profitable. By contrast, thermodynamic measurements are performed under equilibrium conditions! Since (CT) applies the results of measurements and observations, made under conditions where equilibrium prevails, to commercial practice where non-equilibrium or quasi-equilibrium persists, (CT) must have a broader scope than used in classical thermodynamics. The success achieved by pursuing this track is the explicit description of the stability of unstable and metastable phases and the functional descriptions of the compositional, temperature and pressure dependences of the Gibbs energies and entropies of such phases. This feature has permitted many workers worldwide to understand and apply this framework to many important problems and to communicate their results to others. The fast, powerful PC's and efficient software programs for performing such calculations have contributed to this progress. The (CT) descriptions of stable, metastable and unstable phases have also been established in interface with ab intio methods. Good agreement has been attained between these methods in many cases but some differences still exist. The discussion below will review the current applications of CT to several new systems as well as CALPHAD and ab initio lattice stabilities [17].

\section{References}

[1] L. Kaufman, Computational thermodynamics and materials design CALPHAD 25 (2001) 141.
[2] L. Kaufman, Hume-Rothery and CALPHAD thermodynamics, in: P.E.A. Turchi, A. Gonis, R.D. Shull (Eds.), CALPHAD and Alloy Thermodynamics, TMS, Warrendale PA, 2002, pp. 3-19.

[3] L. Kaufman, Calculated Multicomponent Phase Diagrams for Niobium Alloys, in: D. Howden (Ed.), Niobium 2001.

[4] M. Bamberger, A. Munitz, L. Kaufman, R. Abbaschian, CALPHAD 26 (2002) (submitted for publication).

[5] Y. He, S.J. Poon, G. Shiflet, Science 241 (1988) 1640-42

[6] R. Hackenberg, M.C. Gao, L. Kaufman, G.J. Shiflet, Acta Materialia 50 (2002) 2245-2258;

R. Ferro, G. Zanicchi and R. Marazza, in: G. Petzow, G. Effenberg (Eds.), "Al-Gd-Ni" Ternary Alloys, vol. 5, 1993, pp. 677-681.

[7] M.C. Gao, G.J. Shiflet, in: P.E.A. Turchi, A. Gonis, R.D. Shull, (Eds.) CALPHAD and Alloy Thermodynamics, Warrendale PA, 2002, pp. 215-223.

[8] M.M. Thackery, J.T. Vaughey, L.M.L. Frannson, Recent developments in anode materials for lithium batteries, J. Metals 20 (March) (2002).

[9] L. Kaufman, Research Conducted under U.S.ATP Cooperative Agreement70ANBOH3023, 2001, Polystore Corp. Livermore, CA.

[10] N.S. Jacobson, E.H. Copeland, L. Kaufman, Thermodynamic Database for the NdO1.5-YO1.5-YbO1.5-ScO1.5-ZrO1.5 System, NASA/TM2001-21073, September 2002.

[11] N. Erymenko, T.Ya. Velikanova, A.M. Kharkova, Kiev.IPM An USSR, (1981) 3-28.

[12] T.Ya. Velikanova, A.A. Bondar, A. Grystiv, O.L. Dovbenko, J. Alloys Compounds 320 (2001) 341.

[13] G.Grimvall, CALPHAD and ab initio approaches to lattice stabilities in: P.E.A. Turchi, A. Gonis, R.D. Shull (Eds.), CALPHAD and Alloy Thermodynamics, TMS, Warrendale, PA, 2002, p. 81.

[14] Q. Chen, B. Sundman, J. Phase Equilibria 22 (2001) 63.

[15] L. Kaufman, E.V. Clougherty, R.J. Weiss, Acta Met. 8 (1960) 270.

[16] H.C. Herper, E. Hoffman, P. Entel, Phys. Rev. B 60 (1999) 3839.

[17] A.E. Kissavos, S. Shallcross, V. Meded, L. Kaufman, I.A. Abrikosov, CALPHAD 29 (2005) 17-23.

\section{Thermodynamic assessment of phase diagram of Bi-Pd system}

J. Vř̌š̌t'ál, J. Pinkas, A. Kroupa, J. Houserová, A. Scott and A. Watson

Very little experimental thermodynamic and phase equilibrium data are known on the system $\mathrm{Bi}-\mathrm{Pd}$. Recently, P. Oberndorff's theses [1] present new information concerning low temperature equilibria. The reliable assessment of thermodynamic parameters for phase diagram calculation is desirable for description of this system for lead-free solder database.

Therefore, new experimental DTA, XRD, SEM, solution calorimetry and ab initio calculated results are used for reasonable assessment of thermodynamic parameters of the $\mathrm{Bi}-\mathrm{Pd}$ system, necessary for calculation of the phase diagram by the CALPHAD method. The homogeneity of prepared samples was carefully tested by SEM after alloying. High temperature solution calorimetry was used for determination of heat of solution of Pd in liquid Bi and DTA measurements have checked the phase transformation temperatures during heating of samples. XRD determination of structures of equilibrated samples after quenching to room temperature was important information for the structure evaluation of experiments. $\mathrm{Ab}$ initio electronic structure calculation complements the information of intermetallic phases energetics of the system. The calculated phase diagram was compared with phase diagrams presented in the literature [2]. 


\section{Acknowledgements}

Financial support of the ESF-COST 531 Action and of the Ministry of Education of Czech Republic Nos. AB0Z 20410507, MSM 0021622410, OC531.001 and OC531.002 is gratefully acknowledged.

\section{References}

[1] P. Oberndorff, Lead-free solder systems: Phase relations and microstructures, Theses, Tech. Univ. Eindhoven, 2001, ISBN 90-386-2862-5.

[2] T.B. Massalski, J.I. Murray, L.H. Bennet, Baker H. (Eds.), Binary Alloy Phase Diagrams, ASM, Metal Park, OH, USA, 1990.

\section{Thermodynamic modelling of the undercooled liquid by the regular associated solution model}

Taichi Abe, Masato Shimono, and Hidehiro Onodera

Since Gibbs free energy for the liquid phase, in most cases, is optimized by using only thermodynamic properties at high temperature, it may give overestimation of the driving force for crystallization at low temperatures in the glass forming systems where short range ordering in the liquid significantly affects the phase stability of liquid. In the present study, for the $\mathrm{Cu}-\mathrm{Zr}$ and the $\mathrm{Ni}-\mathrm{Zr}$ systems well known as glass forming systems, Gibbs free energy of the liquid was assessed with thermodynamic properties obtained in a wide range of temperatures such as the formation enthalpy of the amorphous phase, latent heats for crystallization from the undercooled liquid, and heat capacity. Then, the driving force, critical cooling rate and GFR were estimated using the assessed free energy.

The effect of the short range ordering in liquid was described by the regular associated solution model. $\mathrm{Cu}_{2} \mathrm{Zr}_{1}$ and $\mathrm{Ni}_{2} \mathrm{Zr}_{1}$ associates were assumed in the liquid. The glass transition was described as the second order transition with Hillert-Jarl type function [1]. The thermodynamic assessment has been done by using the PARROT module in the Thermo-Calc package. Then, TTT curves and critical cooling rates were calculated for those binary systems using the procedure proposed by Uhlmann [2] and Davis [3].

In the present assessment, the calculated driving force is decreased compared to the results of other researchers by taking account of low temperature data. Consequently, the nose of the TTT curve is shifted to longer time.

\section{References}

[1] G. Shao, J. Appl. Phys. 88 (2000) 4443.

[2] D. Uhlmann, J. Non-Cryst. Solids 7 (1972) 337.

[3] H.A. Davis, Phys. Chem. Glasses 17 (1976) 159.

\section{Thermodynamic modeling of the Mo-Pt, Pt-Si and Mo-Pt-Si systems}

T. Benlaharche, N. David, J.M. Fiorani and M. Vilasi

The Mo-Me-Si systems ( $\mathrm{Me}=$ noble metal) are of great interest for metallurgists especially because of their potential use in the elaboration of refractory alloys for the aeronautics industry. Our experimental investigations of the ternary Mo-Pt-Si have shown the existence of two new ternary intermetallic compounds $\mathrm{MoPt}_{3} \mathrm{Si}_{4}$ and $\mathrm{MoPt}_{2} \mathrm{Si}_{3}$. As a first step for the thermodynamic modeling of Mo-Pt-Si, this work presents the assessments for the Mo-Pt and Pt-Si systems, for which no similar works were previously available. All experimental information for these binaries is well reproduced by using the resulting parameters. The modeling of the Mo-Si system due to Liu et al. [1] has been directly accepted for our description of the ternary Mo-Pt-Si, which is also presented here.

\section{References}

[1] Y. Liu, G. Shao, P. Tsakiropoulos, Intermetallics 8 (2000) 953-962.

The behaviour of the $\mathrm{B8}, \mathrm{C18}$ and $\mathrm{DO}_{2}$ phases in the Co-Fe-Sb ternary system

\section{Jean-Claude Tedenac, Didier Ravot and Suzana G. Fries}

The Co-Fe-Sb ternary system was first studied in 1939 in Aachen [1]. After that, very few investigations were done on this system although a quite relevant amount of experimental data was determined for the $\mathrm{Fe}-\mathrm{Co}, \mathrm{Fe}-\mathrm{Sb}$ and $\mathrm{Co}-\mathrm{Sb}$ constituent binaries. The $\mathrm{B} 8$ phase, prototype NiAs, appears as stable phase in the $\mathrm{Fe}-\mathrm{Sb}$ and $\mathrm{Co}-\mathrm{Sb}$ binaries.

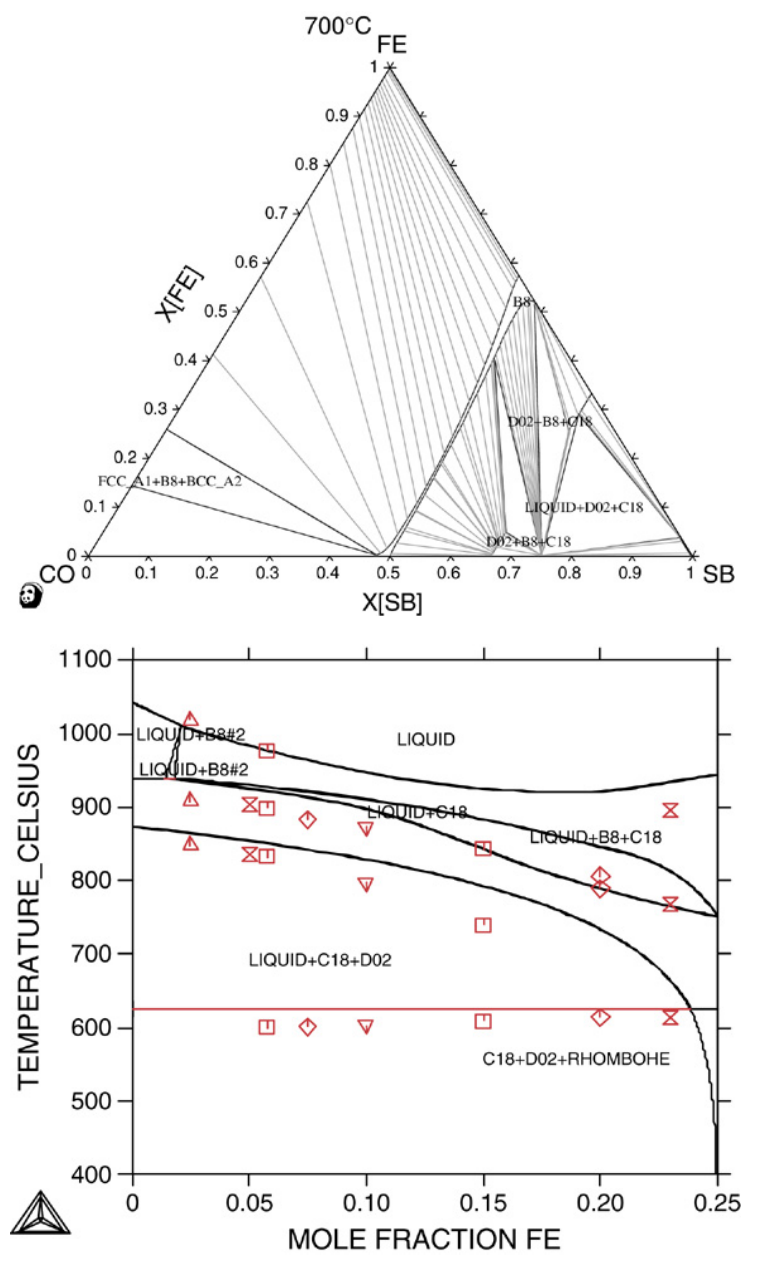


In Fe-Sb, B8 stabilizes off-stoichiometry by an excess of $\mathrm{Fe}$; in $\mathrm{Co}-\mathrm{Sb}$, however, the range of homogeneity of $\mathrm{B} 8$ spreads into both sides of the 50-50 ideal composition. The rich metal range stability is explained by $\mathrm{Fe}$ or $\mathrm{Co}$ atoms occupying interstitial sites in the hexagonal Sb sublattice. The extension to the $\mathrm{Sb}$ rich side in the case of the $\mathrm{Co}-\mathrm{Sb}$ system is explained by vacancies in the metal sublattice. Actually these defects are known in the literature as the mechanism doing the connection between $\mathrm{NiAs}, \mathrm{InNi}_{2}$ and $\mathrm{CdI}_{2}$ crystal structures: the occupation of all hexagonal interstitial sites in the $\mathrm{Sb}$ sublattice by the metal atoms leads to the $\mathrm{InNi}_{2}$ structure and the increasing ordering of the vacancies resulting in an empty layer in the metal sublattice leads to the $\mathrm{CdI}_{2}$ structure. The $\mathrm{C} 18$ phase, prototype $\mathrm{FeS}_{2}$, also appears in both binaries with a very narrow range of homogeneity. The $\mathrm{D}_{2}$ phase, prototype $\mathrm{CoAs}_{3}$, also called skuteruditte stabilizes only in the $\mathrm{Co}-\mathrm{Sb}$ system and constitutes into a relevant material for thermoelectric applications, which makes important the knowledge of the phase equilibrium in this system. The experimental investigation of the stability and defect mechanism understanding in the ternary phases applied to a Gibbs energy modelling is the objective of this study.

As a first approach, the constituent binaries, for which the Gibbs energies are already modelled in previous works $[2,3,4]$, are assembled together and by simple ternary extrapolation from the binaries, isothermal and isopleths are calculated.

The figure at the top shows the extrapolated isothermal section at $1250 \mathrm{~K}$ with a complete extension of the $\mathrm{B} 8$ phase across the ternary which seems to be experimentally observed. However its ternary homogeneity range at low temperature is not known and is being investigated, as well as the ternary extension of the phases $\mathrm{C} 18$ and $\mathrm{D}_{2}$.

In order to guide the modelling of the ternary ad hoc samples were prepared and analysis by DTA and X-ray diffraction are presented elsewhere [5]. The thermal analysis results of samples with $75 \% \mathrm{Sb}$ nominal composition are compared with the calculated isopleth obtained from the extrapolated binary descriptions and shown in the bottom figure. The comparison indicates that the extrapolation anticipates quite well the ternary equilibria. The experimental results however does not confirm the invariant equilibrium at low temperature and will be discussed during the presentation. Further comparisons will be presented and the understanding and modelling of the ternary phase's stability will be discussed.

\section{References}

[1] W. Geller, Arch. Eisenhuettenwes. 13 (1939) 263

[2] B. Pei, B. Bjoerkman, B. Sundman, B. Jansson, CALPHAD 19 (1) (1995) $1-15$.

[3] A. Fernandez-Guillermet, High Temp. High Press. 19 (1988) 477-499.

[4] H. Li, J.C. Tedenac, S.G. Fries (2005) (in press).

[5] P. Amornpitosuk, J.C. Tedenac, D. Ravot (2005) (in press).

\section{Thermodynamic analysis of the Fe-Ti-P ternary system}

Ohtani Hiroshi, Hanaya Naoko, Teraoka Shin-ichi, Abe Masayuki, and Hasebe Mitsuhiro

The addition of Ti plays a crucial role in controlling the desired properties of interstitial free (IF) steels by an extensive removal of interstitials from the solid solutions and formation of very fine precipitates. It was reported that a strain ageing appeared in Ti-containing IF steels due to the effect of $\mathrm{P}$ added as solid-solution strengthening element. This is attributed to the exhaustion of Ti during the formation of ternary phosphide FeTiP, and therefore it is essential to comprehend precipitation behavior of this phosphide in the annealing stage. Knowledge on phase equilibria of the $\mathrm{Fe}-\mathrm{Ti}-\mathrm{P}$ system, however, is very restricted. The $\mathrm{Fe}-\mathrm{P}$ and Ti-P binary systems were studied only for metal-rich regions, which is mainly due to high volatilisation of $\mathrm{P}$. Although some isothermal and vertical section diagrams of the ternary system were experimentally investigated, no thermodynamic information on the FeTiP phase is available.

In the present work, a thermodynamic analysis of the $\mathrm{Fe}-\mathrm{Ti}$-P ternary system has been performed by combining first-principles calculation with the CALPHAD approach. Because of the lack of experimental information available, the enthalpies of formation of the $\mathrm{Fe}-\mathrm{P}$ and Ti-P based binary phosphides were evaluated using the Full Potential Linearized Augmented Plane Wave method, and the estimated values were introduced into a CALPHAD-type thermodynamic analysis. The same procedure was also applied to the FeTiP compound with an orthorhombic structure of the anti- $\mathrm{PbCl}_{2}$ type. The calculated phase diagrams were in good agreement with previous experimental results. In this contribution, we will also discuss the precipitation behavior of the FeTiP phase in the ferritic stainless steels.

\section{Phase equilibria modelling in $\mathrm{Bi}-\mathrm{Sr}-\mathrm{Mn}-\mathrm{O}$ system}

\section{Sedmidubský, J. Leitner, A. Strejc, O. Beneš and M. Nevřiva}

The mixed valence manganites with a perovskite structure and a general formula $\mathrm{Bi}_{1-x} \mathrm{Sr}_{x} \mathrm{MnO}_{3}$ attracted recently attention due to a metal-insulator transition provoked by charge/orbital ordering which has been observed at unusually high temperature, $T_{\mathrm{CO}}$, compared to analogous $\mathrm{Ln}_{1-x}^{3+} \mathrm{A}_{x}^{2+} \mathrm{MnO}_{3}$ systems $\left(\mathrm{Ln}^{3+}=\right.$ lanthanide, $\mathrm{A}^{2+}=$ alkaline earth). The charge ordering temperature reaches a maximum value $T_{\mathrm{CO}} \sim 530 \mathrm{~K}$ for the composition $x=0.5$, where the ratio $\mathrm{Mn}^{3+} / \mathrm{Mn}^{4+}$ corresponds to a commensurate superstructure with respect to the parent perovskite lattice. The ordering effect, which is accompanied by a pronounced broad peak on the heat capacity curve, is to be attributed to a peculiar role of $\mathrm{Bi}^{3+}$ lone pair, whose stereoactivity and polarizability gives rise presumably to a softening of the corresponding phonon modes and a subsequent cooperative lattice distortion.

Although the transition has been identified on both the Bi- and Sr-rich part of the above pseudobinary system, the detailed study was complicated by technological problems due 
to a limited stability of the $\mathrm{Bi}_{1-x} \mathrm{Sr}_{x} \mathrm{MnO}_{3}$ solid solution. Unfortunately, at normal conditions both end members adopt different structure modifications. While the perovskite $\beta-\mathrm{SrMnO}_{3}$ can be stabilized at the expense of the more stable hexagonal $\alpha-\mathrm{SrMnO}_{3}$ by lowering the partial pressure of oxygen, $P_{\mathrm{O} 2}$, and a subsequent non-equilibrium annealing of the sub-stoichiometric $\beta-\mathrm{SrMnO}_{3-\delta}$ in oxygen at low $T$, the perovskite $\mathrm{BiMnO}_{3}$ is not known and the reported monoclinic $\mathrm{BiMnO}_{3}$ represents a high pressure form. At normal pressures, the Bi-rich utmost composition $x \sim 0.3$ is in equilibrium with $\mathrm{Bi}_{2} \mathrm{Mn}_{4} \mathrm{O}_{10}$ and $\mathrm{Bi}_{12} \mathrm{MnO}_{20}$.

It follows that for a controlled and reproducible synthesis of $\mathrm{Bi}_{1-x} \mathrm{Sr}_{x} \mathrm{MnO}_{3}$ in a wide compositional range the knowledge of the thermodynamic stability in the subsolidus region as a function $T$ and $P_{\mathrm{O} 2}$ is of primary importance. Moreover, for the accurate structure determination including the refinement of oxygen positions neutron diffraction experiments on relatively large single crystals are necessary. These have been already grown using a self-flux method from a Bi-rich melt, however, the prepared single crystals revealed only a narrow compositional range close to $x \sim 0.5$. The growth of Sr-rich single crystals has not been successful as yet. Consequently, the modelling of solid-liquid equilibrium and the delimitation of the primary crystallization field including its evolution with $P_{\mathrm{O} 2}$ would be very useful for drawing up the crystal growth experiments.

In the present study we propose a thermodynamic model of phase equilibria in the $\mathrm{Bi}-\mathrm{Sr}-\mathrm{Mn}-\mathrm{O}$ system with a focus on the pseudobinary section $\mathrm{BiMnO}_{3-\delta}-\mathrm{SrMnO}_{3-\delta}$. The dependence of phase equilibria on the activity of oxygen $\left(P_{\mathrm{O} 2}\right.$ in the surrounding atmosphere considered as ideal gas) is also involved. For the description of the adjacent binaries $\mathrm{BiO}_{1.5}-$ $\mathrm{SrO}$ and $\mathrm{SrO}-\mathrm{MnO}_{x}$ the previously reported assessments [1-3] were employed. Since only a few experimental thermochemical data are available in the system under study, we use the density functional theory calculations to obtain the total energies of solid mixed and unary oxide phases from which the unknown enthalpies of formation are evaluated. The APW+lo basis set and the general gradient approximation for treating the exchange-correlation potential (implemented in WIEN2k program package) are used for electronic structure calculations. All calculations involving $\mathrm{Mn}$ as a component are performed as spin-polarized and ferromagnetic, although most $\mathrm{Mn}$-compounds in question reveal an AF ground state. The F-AF energy difference is neglected. The entropies and heat capacities are approximated by Neumann-Kopp rule in those cases where the experimental $C_{p}(T)$ data are not available.

The thermodynamic model for high temperature melt is based on the analysis of $\mathrm{Mn}-\mathrm{O}$ liquid which is treated as a non-ideal (Redlich-Kister) ternary mixture of liquid $\mathrm{Mn}, \mathrm{MnO}$, and $\mathrm{Mn}_{2} \mathrm{O}_{3}$. In fact, only $\mathrm{Mn}-\mathrm{MnO}$ or $\mathrm{MnO}-\mathrm{Mn}_{2} \mathrm{O}_{3}$ pairs are essentially present in the melt depending on its overall oxygen content. The complex $\mathrm{Bi}-\mathrm{Sr}-\mathrm{Mn}-\mathrm{O}$ melt is considered as a mixture of $\mathrm{Mn}(\mathrm{l}), \mathrm{MnO}(\mathrm{l}), \mathrm{Mn}_{2} \mathrm{O}_{3}(\mathrm{l}), \mathrm{SrO}(\mathrm{l})$ and $\mathrm{Bi}_{2} \mathrm{O}_{3}(\mathrm{l})$, where the binary $\mathrm{R}-\mathrm{K}$ interaction coefficients are adjusted from experimental equilibrium data in $\mathrm{SrO}-\mathrm{MnO}_{x}, \mathrm{Bi}_{2} \mathrm{O}_{3}-\mathrm{MnO}_{x}$ and $\mathrm{Bi}_{2} \mathrm{O}_{3}-\mathrm{SrO}$ subsystems.

\section{References}

[1] A.N. Grundy, B. Hallstedt, L.J. Gauckler, Journal of Phase Equilibria and Diffusion 25 (2004) 311.

[2] D. Sedmidubský, A. Strejc, M. Nevřiva, J. Leitner, C. Martin, Solid State Phenomena 90-91 (2003) 427.

[3] B. Hallstedt, D. Risold, L.J. Gauckler, Journal of the American Ceramic Society 80 (1997) 1085.

\section{Phase diagram calculation of the Al-Mg-Sr system}

\section{Onderka Boguslaw and Zakulski Wojciech}

Basing on own results from the $\mathrm{Al}-\mathrm{Mg}$ [1], $\mathrm{Al}-\mathrm{Sr}$ [2] and $\mathrm{Mg}-\mathrm{Sr}$ [3] binary systems, together with existing thermodynamic and phase equilibrium data from the literature, the phase diagram of ternary $\mathrm{Al}-\mathrm{Mg}-\mathrm{Sr}$ system has been calculated with the aid of a binary model.

As the second step, magnesium activities determined by the EMF method in ternary $\mathrm{Al}-\mathrm{Mg}-\mathrm{Sr}$ [4] liquid solutions were used for the estimation of ternary term and subsequent calculation of phase equilibria in that system.

\section{References}

[1] W. Zakulski, T. Czeppe, Experimental investigations on the Al-Mg gamma phase, in: Proceedings of the conference "Progress in Computing of Physicochemical Properties", 18-20 November 1999, Warszawa, Poland, pp. 417-423.

[2] W. Zakulski, Experimental studies in the Al-Sr system, in: Proceedings of the VIII Seminar - "Diffusion and Thermodynamics of Materials", 4-6 September, Brno, The Czech Rep., 2002, pp. 256-259.

[3] W. Zakulski, Experimental studies in magnesium-strontium system, in: Proceedings of Seminar on thermodynamics of materials, November 19, Brno, The Czech Rep., 2001, pp. 18-23.

[4] W. Zakulski, Thermodynamics of the Al-Mg-Sr Liquid Solutions, CALPHAD XXXIII, May 30-June 4, Krakow, Poland, p. 64. Program\&Abstracts.

\section{Kinetic matters}

\section{Melting of alloys}

\section{Bengt Hallstedt}

We have studied the melting behaviour of the tool steel $\mathrm{X} 210 \mathrm{CrW} 12(\mathrm{Fe}-2 \mathrm{w} \% \mathrm{C}-12 \mathrm{w} \% \mathrm{Cr}-0.8 \mathrm{w} \% \mathrm{~W})$ by diffusion simulation using the DICTRA software. It is believed that the conclusions regarding the melting behaviour of this material are quite general and applicable to a large variety of materials. The primary conditions being that the alloy is ternary or higher order and that it has an at least two-phase microstructure below the solidus temperature at equilibrium.

In contrast to the solidification process, the melting process is rarely studied. To our knowledge the subject matter addressed in this work has so far not been treated in the open literature. The only study so far lightly touching the subject of the present study appears to be by Boettinger and Kattner [1] where they model differential thermal analysis (DTA) curves during melting of homogeneous single phase alloys. The melting process is of importance for semi-solid processing, in order to determine the maximum temperature for homogenisation and to design and interpret DTA measurements. 


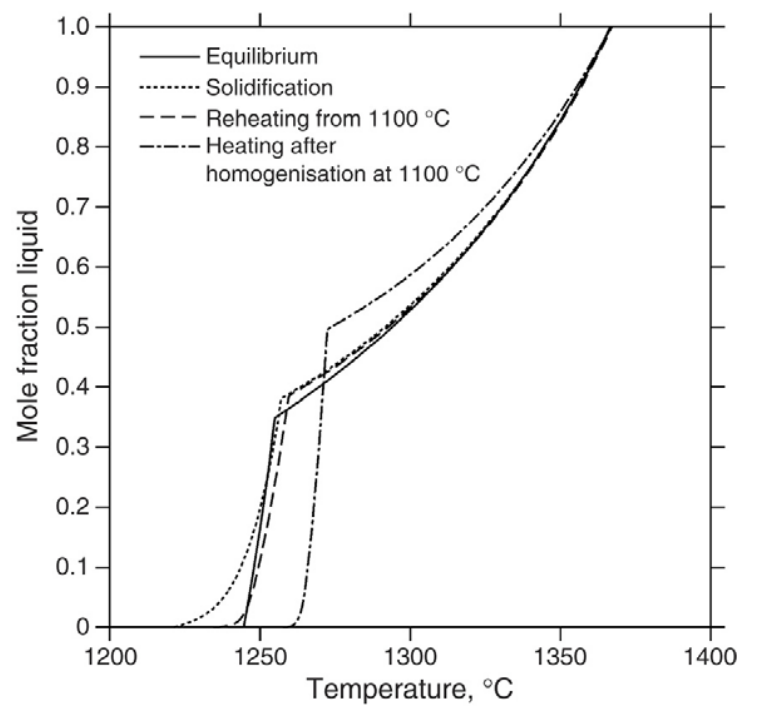

The steel X210CrW12 solidifies austenitically, and the last $30 \%-40 \%$ liquid forms an austenite $+\mathrm{M}_{7} \mathrm{C}_{3}$ eutectic. The microstructure (at high temperature) typically consists of coarse $\mathrm{M}_{7} \mathrm{C}_{3}$ particles surrounded by some amount of eutectic in an austenite matrix. During heating liquid will start to form at the austenite $-\mathrm{M}_{7} \mathrm{C}_{3}$ interfaces, and the characteristic diffusion distance is determined by the distance between the coarse carbide particles (around $40 \mu \mathrm{m}$ in this case).

The most astonishing finding is that melting starts considerably above the equilibrium solidus in a homogenised material. Melting starts at a higher temperature, the lower the homogenisation temperature is. The major reason for this behaviour is that the operating tieline when heating through the solidus is different from the equilibrium tieline. Furthermore, the influence of heating rate within the investigated range $(5-500 \mathrm{~K} / \mathrm{min})$ is fairly small and melting is complete very close to the liquidus temperature. At very high heating rates or coarser microstructure, where concentration gradients in the liquid can build up, the melting curve can change considerably, and melting is complete some distance above the liquidus. The solidus of this alloy cannot be determined by thermal analysis.

\section{References}

[1] W.J. Boettinger, U.R. Kattner, Metall. Mater. Trans. A 33A (2002) 1779-1794.

Diffusion simulations of $\mathrm{MC}$ and $\mathrm{M}_{7} \mathrm{C}$ carbide coarsening in bec and fec matrix using a new thermodynamic and kinetic description

Johan Bratberg, John Ågren and Karin Frisk

The coarsening of $\mathrm{MC}$ and $\mathrm{M}_{7} \mathrm{C}_{3}$ carbides in a bcc and fcc matrix using a new thermodynamic database and an existing kinetic database was simulated. Calculations in ternary systems including $\mathrm{MC}$ respective $\mathrm{M}_{7} \mathrm{C}_{3}$ carbide in a fcc matrix showed that the kinetic description needed revision. New experimental information in the $\mathrm{Fe}-\mathrm{Cr}-\mathrm{V}-\mathrm{C}$ system described in the present work was also taken into consideration. After the revision the agreement of the calculated coarsening rates with the experimental values was satisfying. The input variables, especially the values of the interfacial energies of the different carbides, have physically correct values. It was shown that the $\mathrm{MC}$ and the $\mathrm{M}_{7} \mathrm{C}_{3}$ carbide have different interfacial energies. The $\mathrm{M}_{7} \mathrm{C}_{3}$ carbide has more than twice as large an interfacial energy value than the MC carbide in an fcc matrix.

Satisfying results were shown when going to higher order systems using the same values of the interfacial energies. The calculations were compared to new experimental measurements in higher order systems. All the coarsening simulations using the old thermodynamic and kinetic description are compared in figures together with the present results and experimental values. The present calculations using the DICTRA software showed significantly improved agreement with the experimental data.

Thermodynamic and kinetic modelling of the Fe-B and Al-Ni-Ce amorphous and nanocrystalline alloys

\section{Mauro Palumbo, Marcello Baricco and Livio Battezzati}

Amorphous alloys have attracted much interest for both their remarkable mechanical and magnetic properties $[1,2]$. The formation of nanosized crystals by controlled crystallization in the amorphous matrix may further improve such properties. The development of proper models to describe both the formation of amorphous phases and the crystallization process is thus of considerable importance. A possible modelling approach relies on the coupling of classical thermodynamics and kinetic theory, as the nucleation and growth theory. Extensions to describe metastable phases are also necessary, so being the nature of the amorphous phase.

In this work, modelling of the amorphous phase and of its crystallization in the binary $\mathrm{Fe}-\mathrm{B}$ and the ternary $\mathrm{Al}-\mathrm{Ni}-\mathrm{Ce}$ systems has been proposed in the framework of the CALPHAD methodology. The former system is the ancestor of a family of commercial magnetic amorphous and nanocrystalline multicomponent Fe-based alloys such as Finemet and Nanoperm, whereas the latter belongs to the wide group of Al-TM-RE $(\mathrm{TM}=$ Transition Metal, $\mathrm{RE}=$ Rare Earth) systems which show interesting mechanical properties.

A comprehensive thermodynamic assessment of the $\mathrm{Fe}-\mathrm{B}$ system has been performed [3,4], including the amorphous phase and the metastable $\mathrm{Fe}_{3} \mathrm{~B}$ stoichiometric compound, using the ThermoCalc software. Experimental data on these metastable phases have been used to this purpose. Assessed thermodynamic parameters have been used to calculate quantities such as the driving force for nucleation. By coupling thermodynamics and diffusion theory, a kinetic simulation of crystal growth has been carried out using the DICTRA software [5]. The parameters necessary for the simulations have been taken both from the assessment and from the literature. Composition profiles in the amorphous matrix in the surroundings of the growing crystal can be calculated, both in isothermal and continuous heating modes. A comparison between calculated and experimental DSC traces has also been attempted. 
The same modelling approach has been applied to the ternary $\mathrm{Al}-\mathrm{Ni}-\mathrm{Ce}$ system [6], but limiting our analysis to aluminium rich alloys, where a significative glass forming ability has been reported. Metastable phase diagrams and driving forces have been calculated. The prediction of the glass forming range has been attempted and results are in good agreement with experimental achievements. Kinetic simulations have been also performed and results of composition profiles compared to APFIM data for some alloys.

\section{References}

[1] A. Inoue, Progress in Materials Science 43 (1998) 365.

[2] M.E. McHenry, M.A. Willard, D.E. Laughlin, Progress in Materials Science 44 (1999) 291.

[3] M. Palumbo, G. Cacciamani, E. Bosco, M. Baricco, CALPHAD 25 (2001) 625.

[4] M. Palumbo, G. Cacciamani, E. Bosco, M. Baricco, Intermetallics 11 (2003) 1293

[5] M. Palumbo, M. Baricco, Acta Materialia (in press).

[6] M. Baricco, M. Palumbo, Journal of Metastable and Nanocrystalline Materials 20-21 (2004) 415 .

\section{Phase field simulations of grain growth in materials containing a finely dispersed second phase}

\section{Nele Moelans, Bart Blanpain and Patrick Wollants}

Small second-phase particles have the ability to pin grain boundaries, also called Zener pinning. They considerably reduce the mobility of the grain boundaries and eventually stop grain growth. This possibility to stop grain growth is of great practical importance as it allows controlling the grain size of a material. For example in the production of steels for structural application or thin films for electronic devices, impurity elements that lead to the precipitation of a second phase are added to the material as its properties and reliability highly depend on the grain size.

The pinning effect is based on the fact that when a particle is located on a grain boundary, the grain boundary area is reduced with an amount that equals the intersection area of the particle and the grain boundary, resulting in a decrease of the free energy. Therefore particles exert a backward force on grain boundaries. When the pinning force of the particles exceeds the driving force for grain growth, further grain growth is inhibited by the particles. In general, it is assumed that the final grain size is proportional to the size of the second phase particles and inversely proportional to the volume fraction of the second phase in three dimensions or the square root of the volume fraction in two dimensions [1]. However, this relation is not always experimentally observed [2]. The pinning effect of particles depends on many more parameters, such as grain boundary properties, properties of the particle-matrix interface and the chemical stability of the second phase.

Phase field simulations for grain growth in materials containing second-phase particles were performed. An existing phase field model for grain growth in single-phase materials was extended to incorporate the presence of the particles [3]. The interaction between a particle and a grain boundary is studied at a small scale as a function of particle size and grain boundary energy in two and three dimensions. From largescale simulations for two dimensional polycrystalline systems the dependence of the final grain size on the volume fraction and particle size of the second phase is determined, and the role of the initial grain size of the matrix phase is studied. Further the local interaction between a moving grain boundary and a particle was in-situ observed using a Confocal Scanning Laser Microscope in combination with an infrared furnace. The simulation results are compared with the in-situ observations and experimental data from the literature.

\section{References}

[1] M. Hillert, Acta Metall. 36 (1988) 3177.

[2] M. Guo, H. Suito, ISIJ International 39 (1999) 1289.

[3] N. Moelans, B. Blanpain, P. Wollants, Acta Mater. 53 (2005) 1771.

\section{Aging behavior of a $2.25 \mathrm{Cr}-1 \mathrm{Mo}$ steel}

\section{R.R. de Avillez, F.C. Rizzo Assunção and B. Marinkovic}

The $2.25 \mathrm{Cr}-1.0 \mathrm{Mo}$ steel is widely used in petroleum refining units, for example, in pressure vessels, working under severe operational conditions. Due to the high temperatures of some processes, many phenomena such as precipitation of carbides and their coarsening occur during service, resulting in changes of material microstructure. Such changes may modify the mechanical properties, which are responsible for the performance of the pressure vessels.

Using a software for thermodynamic calculations, the thermodynamically stable carbides and the theoretical carbide nucleation sequence were established over the temperature range of interest (700-1040 K), supposing ferrite as the original microstructure. The evolution of the carbide precipitation along a period up to 20 years was calculated using the software DICTRA. The $\mathrm{M}_{2} \mathrm{C}$, the carbide with the highest nucleation energy, was used as the starting condition in a system consistent of several diffusion cells, one for each carbide considered.

The initial carbide disappears over a period of about a year while the thermodynamically stable carbide steadily grows. The results were compared with the experimental data available from the literature. These results are important for the evaluation of the microstructural degradation of $2.25 \mathrm{Cr}-1 \mathrm{Mo}$ steel with original ferrite microstructure and, therefore, the determination of the remaining useful service life of these materials under operational conditions.

\section{Carburisation of diffusion couples}

\section{R. Bernst, G. Inden and A. Schneider}

The diffusion couple technique was applied in this work to determine the solubility of $\mathrm{X}=\mathrm{Si}, \mathrm{V}$ and Mo in cementite at $700{ }^{\circ} \mathrm{C}$. Diffusion couples of $\mathrm{Fe} / \mathrm{Fe}-4 \mathrm{Si}, \mathrm{Fe} / \mathrm{Fe}-7 \mathrm{Mo}$, and $\mathrm{Fe} / \mathrm{Fe}-20 \mathrm{~V}$ (at.\%) were prepared and heat treated at $900^{\circ} \mathrm{C}$ or $1200^{\circ} \mathrm{C}$ for 1 month. Then they were carburised at $700{ }^{\circ} \mathrm{C}$ in a $\mathrm{CO}-\mathrm{H}_{2}-\mathrm{H}_{2} \mathrm{O}$ gas mixture with $10 \mathrm{ppm} \mathrm{H}_{2} \mathrm{~S}$ with a carbon activity of $a_{\mathrm{C}}=100$ for 10 hours. The $\mathrm{H}_{2} \mathrm{~S}$ was added to prevent graphite formation and the onset of cementite 
decomposition (metal dusting). The growth of a cementite layer was observed for all diffusion couples. Generally, these cementite layers extend laterally from the pure Fe side up to a position in the diffusion couple corresponding to concentration of $\mathrm{X}$ which is assumed to represent their solubility limits in $(\mathrm{Fe}, \mathrm{X})_{3} \mathrm{C}$. The cross-sections of the carburised samples were characterised by means of light optical microscopy (LOM). The profiles of the alloying elements in the matrix after the first heattreatment and their content in cementite after the carburisation treatment were measured by electron probe microanalysis (EPMA). The identification of the precipitated phases was performed by using electron backscatter diffraction (EBSD). The experimental work was supported by calculations of stable and metastable phase equilibria using Thermo-Calc and by simulations of diffusion controlled phase transformations using DICTRA.

\section{Observed reaction paths and corresponding diffusion paths in ternary metallic phase diagrams}

\section{Myriam Sacerdote-Peronnet and Jean Claude Viala}

The present contribution deals with the chemical reactivity in couples resulting from the association of molten metals (Al and $\mathrm{Mg}$ alloys) and solid substrates (Fe base metals). The applied background of this study concerns the development of various metallic products that can be used in the automotive and aeronautics industries. The ternary Al-Fe-Si phase diagram is a key system to obtain products such as hot dip aluminized steel sheets, laser beam welded aluminium/steel structures or aluminium alloy parts locally reinforced with iron base inserts.

-The ternary $\mathrm{Fe}-\mathrm{Mg}-\mathrm{M}$ systems ( $\mathrm{M}$ is an alloying element of magnesium) are also very interesting in the scope of manufacturing lower-weight components.

To obtain Fe/Al-Si and Fe/Mg-M bimetallic joints with optimized properties, it is necessary to acquire a thorough understanding of the interface chemistry of the corresponding systems. It is needed to study thermodynamics, kinetics and reaction mechanisms likely to develop between the ferrous substrate and the metallic matrix ( $\mathrm{Al}$ or $\mathrm{Mg})$ :

- Concerning $\mathrm{Fe} / \mathrm{Mg}-\mathrm{M}$ couples [1], the interface reactivity was studied by two complementary approaches: on the one hand, we determined the phase equilibria in the $\mathrm{Fe}-\mathrm{Mg}-\mathrm{M}$ systems at $730^{\circ} \mathrm{C}$. On the other hand, ferrous metal/magnesium alloy interfaces were characterized. We used synthetic $\mathrm{Mg}-\mathrm{M}$ alloys and four ordinary commercial magnesium alloys: GA6Z1 with aluminium, GM2 with manganese and the two alloys M2 and RZ5 containing zirconium. From all the results obtained, it has been possible to precisely determine the growth kinetics and mechanism at these interfaces.

- Concerning Fe/Al-Si bimetallic joints [2-3], an experimental study has been undertaken using the same methodology: refinement of the phase equilibria in the ternary $\mathrm{Al}-\mathrm{Fe}-\mathrm{Si}$ system at $730^{\circ} \mathrm{C}$ [4-6], dipping ferrous substrates in Al-Si alloys at temperatures ranging from 600 to $800^{\circ} \mathrm{C}$. The nature, thickness, morphology and sequences of the different phases formed at the interfaces were thus determined. Different types of reaction zones were characterized depending on the temperature and on the silicon content of the aluminium alloy. For each of them, the results were interpreted in terms of kinetics and reaction mechanism.

Based on examples chosen in both $\mathrm{Fe} / \mathrm{Mg}-\mathrm{M}$ and $\mathrm{Fe} / \mathrm{Al}-\mathrm{Si}$ systems, we will point out that it is possible to use the diffusion path concept to relate the phase diagram of the relevant systems with the composition and sequence of the reaction layers observed at the interfaces [7].

Initially developed for solid/solid couples with interface layers growing by solid state volume diffusion according to a parabolic growth law, we will describe examples showing that it is possible to extend the diffusion path concept to solid/liquid interfaces.

In some cases, however, deviations to parabolic growth have been identified: dissolution, interface reaction that proceeds by dissolution-crystallization, liquid metal that permeates the reaction zone.... We will explain why, in such cases, differences may appear between the observed reaction path and the theoretical diffusion path [8-10].

\section{References}

[1] D. Pierre, Thesis, University Lyon I, 1999.

[2] F. Barbeau, Thesis, University Lyon I, 1999.

[3] S. Pontevichi, Thesis, University Lyon I, 2004.

[4] V.G. Rivlin, G.V. Raynor, Int. Met. Rev. 3 (1981) 133

[5] G. Petzow, G. Effenberg, Ternary Alloys, VCH Publishers, USA, 1992.

[6] S. Pontevichi, F. Bosselet, F. Barbeau, M. Peronnet, J.C. Viala, J. Phase Equilib. Diff. 25 (2004) 528.

[7] F.J.J. Van Loo, Prog. Solid. State. Chem. 20 (1990) 47

[8] V.I. Dybkov, Growth Kinetics of Chemical Compound Layers, Cambridge, England, 1998.

[9] F.M. d'Heurlé, P. Gas, J. Mater. Res. 1 (1986) 205.

[10] F.M. d'Heurlé, Mater. Sci. Forum, 155-156 (1994) 1.

\section{Use of the Au-Zn-O phase diagram for $\mathrm{ZnO}$ nanowhisker growth}

Albert Davydov, Kil-Won Moon, William Boettinger and Ursula Kattner

Semiconductor single-crystal whiskers that are nanometers in diameter and known as "nanowhiskers" or "nanowires" (NW) show great potential for use in integrated optoelectronic and electronic devices including nano-lasers and biochemical detectors. NWs are often grown by the Vapor-Liquid-Solid (VLS) method using a nano-sized metal droplet (catalyst) [1]. It is attractive to employ metal/semiconductor phase diagrams to facilitate understanding of the NW growth mechanism and to optimize the growth temperature as well as catalyst selection. This paper presents application of $\mathrm{Au}-\mathrm{Zn}-\mathrm{O}$ phase diagram to describe growth of $\mathrm{ZnO}$ semiconductor NWs using $\mathrm{Au}$ as a catalyst. The $\mathrm{Au}-\mathrm{Zn}-0$ diagram has not previously been examined.

The initial step in evaluating the ternary $\mathrm{Au}-\mathrm{Zn}-\mathrm{O}$ diagram was to study the $\mathrm{Au}-\mathrm{ZnO}$ section. A set of $\mathrm{Au}_{1-x}(\mathrm{ZnO})_{x}$ samples with $x=0.03,0.05,0.1,0.2,0.4$, and 0.8 was prepared by sintering pelletized mixtures of $\mathrm{Au}$ and $\mathrm{ZnO}$ powders at $900{ }^{\circ} \mathrm{C}$ in air for $72 \mathrm{~h}$ followed by air quenching. The T- $x$ diagram was constructed using the results of XRD, SEM/EDS and DTA. The $\mathrm{Au}-\mathrm{ZnO}$ section was determined to be a 
quasi-binary section of the eutectic type with no intermediate phase. The eutectic temperature was measured by DTA as $1044 \pm 1{ }^{\circ} \mathrm{C}$ with a eutectic composition close to pure Au. Liquidus temperatures were not detected up to the DTA limit of $1400^{\circ} \mathrm{C}$. This indicates that the $\mathrm{ZnO}$ liquidus line is likely to be very steep. Consequently, and by analogy with similar metal-oxide systems such as $\mathrm{Ag}-\mathrm{Cu}_{2} \mathrm{O}$ [2], the formation of a high-temperature liquid miscibility gap in the $\mathrm{Au}-\mathrm{ZnO}$ system is probable. The experimental information on the $\mathrm{Au}-\mathrm{ZnO}$ section and preliminary thermodynamic evaluation was used to construct the entire $\mathrm{Au}-\mathrm{Zn}-\mathrm{O}$ diagram under the assumption of no ternary phase formation.

Finally, we analyze the growth of $\mathrm{ZnO} \mathrm{NWs}$ from an $\mathrm{Au}$ catalyst by mapping the spatial concentration profile during VLS growth onto the $\mathrm{Au}-\mathrm{Zn}-\mathrm{O}$ phase diagram. Visualizing VLS growth on a phase diagram allows us to explain the critical steps of ZnO NW growth; this approach can further be used for optimization of nanowhisker fabrication of other materials.

\section{References}

[1] Y. Xia et al., One-dimensional nanostructures: synthesis, characterization and applications, Adv. Mater. 15 (2003) 353.

[2] H. Nishiura, R.O. Suzuki, K. Ono, Experimental phase diagram in the Ag- $\mathrm{Cu}_{2} \mathrm{O}-\mathrm{CuO}$ system, J. Am. Chem. Soc. 81 (1998) 2181.

\section{Development of prediction model for precipitates kinetics and austenite grain growth in the weld heat affected zone}

Joonoh Moon, Jonggeun Ryu, Changhee Lee, Youngho An and Jongbong Lee

A metallurgical model of the particle behavior below the dissolution temperature was considered. Unlike the conventional approach, where the mean-sized particle continues to grow, the proposed model considered the critical particle size which can be derived from Gibbs-Thomson equation. In this study, the proposed particle coarsening model was applied to study the behavior of titanium nitride (TiN) in low carbon steel during welding and heat treatment. The size distribution of the TiN particles showed that typical log-normal distribution and predicted particle size distributions from the proposed model were in agreement with the experimental results. Finally, predicted mean particle sizes also showed agreement with experimental results compared to the conventional model.

Keywords: Critical particle size, Solubility product, GibbsThomson equation

\section{Miscellaneous}

\section{Models for multicomponent liquid solutions}

Arthur D. Pelton

Thermodynamic models for liquid solutions will be discussed with particular regard to their ability to predict the properties of multicomponent solutions from the properties of their binary sub-systems. "Associate" models, quasichemical and cluster models and "sublattice" models will be compared with a view to showing which are the most appropriate for various classes of solutions. Examples will be given from solutions of molten ordered alloys, salts, sulphides and oxides.

\section{Hydrogen adsorption and desorption mechanism in carbon nanotubes}

Sang Soo Han, Jeung Ku Kang, Hyun Seok Kim, Jai Young Lee, Adri C.T. van Duin, William A. Goddard III, and Hyuck Mo Lee

We have synthesized open-tip multi-walled carbon nanotubes (MWCNTs) by plasma enhanced chemical vapor deposition (PECVD) to investigate their hydrogen adsorption and desorption properties. Our thermal desorption spectrum (TDS) analysis finds two desorption peaks at the temperature ranges of 100-200 K and 300-350 K. The total amounts of hydrogen integrated from these two peaks are 1.8 and $2.0 \mathrm{wt} \%$, respectively. In addition density functional theory (DFT) and molecular dynamics (MD) simulation determine that the first TDS peak is attributed to hydrogen physically adsorbed on the walls of the MWCNT, while the second one is attributed to hydrogen physically adsorbed inside the nanopores with about $1 \mathrm{~nm}$ diameter in the MWCNT walls. Moreover, hydrogen is also found to dissociatively bond to carbon atoms at the vacancy sites and opentip edge sites and it becomes thermodynamically stable in the intertube of MWCNT if the intertube distance would increase to the $1 \mathrm{~nm}$ size.

\section{Calculation of constrained equilibria by Gibbs energy minimisation}

\section{Pertti Koukkari, Risto Pajarre and Karri Penttilä}

The multi-phase analysis of complex systems by Gibbs energy minimisation has gained increasing popularity with the development of efficient computers. The advantages of the multi-phase methods have been widely recognised and they are becoming accepted in different applications, ranging from chemistry and metallurgy to materials processing, steelmaking, pulp and paper production and energy and environment technologies.

The Gibbs energy minimisation requires the use of the chemical potentials (partial molar Gibbs energies) of the constituents of the system. Usually, these appear at their equilibrium values as a result of the minimisation calculation, the mass balance constraints being the necessary subsidiary conditions. Yet, there are several such physical circumstances, where chemical potentials appear constrained also by other factors. In this paper a method will be presented, by which constrained chemical potentials can be applied in a multiphase Gibbs energy minimisation. The constrained potentials arise typically due to a displacement in a generalised workcoefficient in the system or they are due to a pre-defined affinity. In the Gibbs energy minimisation performed by the Lagrange method, the said constraints are set as additional Lagrangian coefficients. Examples of the constrained potential method will be presented in terms of the electrochemical Donnan equilibria 
in aqueous systems containing semi-permeable interfaces [1], the phase formation in surface-energy controlled systems [2] and in systems with affinities controlled by chemical reaction kinetics [3]. The methods have been successfully applied in calculating distribution coefficients for metal ions together with $\mathrm{pH}$-values in pulp suspensions, in calculation of surface tension of alloys and in thermochemical process modelling involving chemical reaction rates

\section{References}

[1] P. Koukkari, R. Pajarre, H. Pakarinen, H., J. Solution Chem. 31 (2002) 627.

[2] R. Pajarre, P. Koukkari, T. Tanaka, J. Lee (in press).

[3] P. Koukkari, R. Pajarre, K. Hack, Z. Metallkd. 92 (2001) 1151.

The qualitative structure of phase diagrams: From the works of Schreinemakers (The Netherlands, beginning of the XXth century) to present day

\section{Bernard Guy}

One century ago, a scientist from the Netherlands, Franciscus Antonius Hubertus Schreinemakers (1864-1945), published a series of papers dedicated to phase diagrams. These appeared both in Dutch and English in the Proceedings of Koninklijke Akademie van Wetenschappen Te Amsterdam. It is the purpose of this paper to give a short review of the contribution of Schreinemakers to the qualitative understanding of phase diagrams and to make one understand his way of reasoning and his principal results. The work of Schreinemakers will be compared to the numerous qualitative rules for phase diagrams that have been proposed, either by the Dutch school or abroad (USA, Canada, China, former USSR and Russia, Europe), in a number of scientific fields from Chemistry to Earth Sciences, and by many researchers, among which are several Calphad people. The rules will also be discussed in the light of recent work made by the author (BG) on the "affigraphy" concept and on matroïd theory (preliminary results).

\section{References}

[1] B. Guy, J.M. Pla, Structure of phase diagrams for n-component (n+k)-phase chemical systems: the concept of affigraphy, C. R. Acad. Sci. Paris 324 II-a (1997) 337-343.

[2] F.A.H. Schreinemakers In-, mono- and divariant equilibria, in: Proceedings of the Koninklijke Akademie van Wetenschappen te Amsterdam (I to XXIX) (1915-1925).

On the statistical thermodynamics of solutions with variable valence states of one of the components

A.Yu. Zakharov, M.A. Zakharov, A.L. Udovsky and H.A.J. Oonk

The aim of the report is development of a generalized lattice model [1] to condensed systems with variable valence states of one of the components (such as uranium-oxygen system). The problem consists in the correct account for the following peculiarities of such systems:
- Short-range parts of interatomic potentials. They are taken into account by means of dense packing principle, which connects local densities of components.

- Long-range parts of the interatomic potentials, which are smooth functions of space variables and taken into account by means of effective field approximation.

- Existence of thermal defects such as vacancies in condensed systems. The vacancies are considered as a disparate component of the system, which is characterized by its specific "atomic" volume.

- Existence of "complexes" with variable compositions in the system.

Model expression for the Helmholtz free energy functional is suggested. The conditional extremum of the Helmholtz functional and the system of integral equations for equilibrium distributions of components are obtained. Qualitative properties of solutions of these equations are investigated. The conditions of multiphase solutions are established. Reduction of Helmholtz free energy to Ginzburg-Landau-like functional is reduced. Connections between parameters of this functional and characteristics of interatomic potentials are established. The conditions of mathematical well-posedness of the approximations are obtained. The system of equations, connecting compositions of coexisting phases with characteristics of interatomic potentials, is deduced. The ways of inverse problem solution and related problems of phase diagram predictions are discussed.

\section{Acknowledgements}

The work supported by Scientific Program "Universities of Russia” (Project No.UR.01.01.183), Dutch-Russian Program RFBR-NWO (Project No.047.011.2001.011), and Russian Target Program "Integration” (Project No. B0056).

\section{References}

[1] A.Yu. Zakharov, M.A. Zakharov, O.V. Loginova, International Journal of Quantum Chemistry 100 (2004) 435-441.

\section{$\mathrm{Ni}_{3} \mathrm{Ga}$-Defect structure and changes in degree of long range order}

\section{Olga Semenova, Hiroshi Numakura and Herbert Ipser}

In the last years, intermetallics with $\mathrm{L}_{1}$-structure were of particular interest, both from the point of view of their fundamental properties and their practical application as materials with excellent chemical, mechanical and physical properties.

In the present investigation, we have chosen $\mathrm{Ni}_{3} \mathrm{Ga}$ as a model $\mathrm{L}_{2}$ compound and measured the electrical resistivity to study (1) the equilibrium degree of order at various temperatures and (2) the kinetics of ordering and disordering [1]. In this paper we report the method of estimating the longrange order parameter from the resistivity data and derive the effective pair interaction (EPI) energy. It is then compared with those evaluated from thermodynamic activity measurements [2-6] and also with those converted from the parameters in 
Calphad modelling [7]. Such adequately-evaluated EPI energy values can be conveniently employed for calculating point defect concentrations at various temperatures and compositions using common statistical-thermodynamic methods, e.g. the Bragg-Williams model and Monte-Carlo simulations.

\section{References}

[1] O. Semenova, J. Alloys Compounds 386 (1-2) (2005) 290-295.

[2] I. Katayama, S. Igi, Z. Kouzuka, J. Japan. Inst. Met. 38 (1974) 332-338.

[3] I. Katayama, S. Igi, Z. Kouzuka, Trans. JIM 15 (1974) 447-453.

[4] J. N. Pratt, J.M. Bird, J. Phase Equilibria 14 (1993) 465-472.

[5] W. Yuan, O. Diwald, A. Mikula, H. Ipser, Z. Metallkd. 91 (6) (2000) 448-454.

[6] A. Kushida, T. Ikeda, H. Numakura, M. Koiwa, Mater. Trans. 42 (3) (2001) 514-519.

[7] W.X. Yuan, Z.Y. Qiao, H. Ipser, G. Eriksson, J. Phase Equilib. Diff. 25 (1) (2004) 68-74.

\section{Crystallochemistry and Calphad modelling of the $\sigma$ phase}

\section{J.-M. Joubert}

The $\sigma$ phase shows up in most intermetallic A-B systems where $\mathrm{A}$ is an element pertaining to $\mathrm{V}-, \mathrm{Cr}$ - or Mn-groups and $\mathrm{B}$ an element pertaining to $\mathrm{Mn}-$, Fe-, Co- or Ni-groups, $\mathrm{Au}$ or Al. It appears consequently in higher order systems including technologically crucial ones emphasizing the need for a convenient Calphad modelling.

The $\sigma$ phase is characterized by a considerable nonstoichiometry. It may be formed, depending on the system, between 10 at.\% and 80 at.\% A. The non-stoichiometry is accommodated by substitutional disorder on the five non-equivalent sites of the crystal structure $(2 \mathrm{a}, 4 \mathrm{f}, 8 \mathrm{i}$, $8 \mathrm{i}$ and $8 \mathrm{j}$ in space group $\left.P 4_{2} / \mathrm{mnm}\right)$. These sites have different coordination numbers $(12,15,14,12$ and 14). The characterization of the disorder is therefore of primary importance and is the aim of this paper.

After a thorough critical review of the available literature data, complementary key experiments have been performed in several systems ( $\mathrm{Ta}-\mathrm{Al}, \mathrm{Nb}-\mathrm{Al}, \mathrm{Mo}-\mathrm{Co}$, Re based systems...). Intermetallic compounds have been synthesized and the site occupancies have been obtained by Rietveld refinement of Xray or neutron powder diffraction data. A systematic analysis of the site occupancies has been performed as a function of the $\mathrm{A}$ atom composition. It shows in particular that the only coordination number criterion is unable to predict which sites are progressively occupied by A atoms.

In the frame of a Calphad modelling, several sublattice models have been proposed so far assuming different substitution schemes for A and B atoms. Our analysis shows that none of them describe satisfactorily the $\sigma$ phase. They describe only approximately and sometimes wrongly the crystallography and therefore the configurational entropy because a wrong assignment is made of the sublattices in which atom mixing occurs.

Conclusions are drawn concerning the most suitable way to model the $\sigma$ phase in the frame of a unique sublattice model able to describe it in all systems.

\section{Phase behavior of a diblock copolymer in the presence of two solvents}

\author{
Ching-I Huang, Yu-Cheng Chiu and Yu-Chien Hsu
}

Block copolymers continue to be an attractive area of research due to their numerous potential applications with characteristic domain dimensions in the range of $1 \sim 100 \mathrm{~nm}$ by self-organization [1-3]. One of the major methods in controlling the length scale of microstructures is by diluting a block copolymer with solvents. Most of the theoretical research has focused on the effects of adding one solvent into a diblock copolymer [4]. There exist few theoretical studies of a block copolymer in the presence of two solvents. Indeed, understanding both the phase behavior and the microdomain length control of a block copolymer in two solvents become very important as more and more experimental systems involve two types of solvents. We therefore employ self-consistent mean-field (SCMF) theory to study the phase behavior as well as the structural sizes of a block copolymer in the presence of two solvents. In particular, the effects of copolymer volume fraction, cosolvent ratio, and the incompatibility between cosolvents are examined.

We consider an asymmetric A/B diblock copolymer in the presence of two solvents, $\mathrm{X}$ and $\mathrm{Y}$, which are selective for A block and B block, respectively. We set the A-monomer fraction in the copolymer $f=0.16$, degree of copolymerization $N=300$, and the net interaction parameter between $\mathrm{A}$ and $\mathrm{B}, \chi_{\mathrm{AB}}$, multiplied by $N$ (i.e., $\chi_{\mathrm{AB}} N$ ) equal to 41.4. As such, the most stable phase for this diblock copolymer in the melt is body-centered cubic spheres of $\mathrm{A}$ in the matrix of B $\left(S_{\mathrm{A}}^{\mathrm{BCC}}\right)$. When the solvent selectivity for both blocks is small, for example, the net interaction parameters $\chi_{\mathrm{AX}}=0.4$, $\chi_{\mathrm{BX}}=0.45, \chi_{\mathrm{AY}}=0.45$, and $\chi_{\mathrm{BY}}=0.4$, we find that only the transition from the ordered phase $S_{\mathrm{A}}^{\mathrm{BCC}}$ to the disordered phase occurs with decreasing the copolymer volume fraction $\phi$. Furthermore, the order-disorder transition line is not affected much by increasing the incompatibility between solvents $\mathrm{X}$ and $\mathrm{Y}, \chi_{\mathrm{XY}}$. While when the solvent selectivity increases, such as $\chi_{\mathrm{AX}}=0.4, \chi_{\mathrm{BX}}=0.6, \chi_{\mathrm{AY}}=0.6$, and $\chi_{\mathrm{BY}}=0.4$, both the phase behavior and the microstructural sizes are greatly influenced by increasing $\chi \mathrm{XY}$. In particular, various ordered phases and even macroscopic phase separation are induced with increasing the incompatibility between cosolvent. For a fixed ratio between cosolvent concentrations, the characteristic microdomain length $\mathrm{L}$ decreases with $\psi$ decreasing when $\chi_{\mathrm{XY}}$ is small. However, when $\chi \mathrm{XY}$ becomes large, due to the fact that $\mathrm{X}$ and $\mathrm{Y}$ don't like each other, each domain size and the characteristic microdomain length $\mathrm{L}$ increase as $\psi$ decreases further. For a fixed and large value of $\chi_{\mathrm{XY}}$, we observe that $\mathrm{L}$ reaches a maximum when both solvent concentrations are comparative.

\section{References}

[1] T.P. Lodge, Macromol. Chem. Phys. 204 (2003) 265.

[2] N. Hadjichristidis, S. Pispas, C.A. Floudas, Block Copolymers, Wiley, New Jersey, 2003. 
[3] S. Förster, T. Plantenberg, Angew. Chem. Int. Ed. 41 (2002) 688; S. Förster, M. Antonietti Adv. Mater. 10 (1998) 195.

[4] C.I. Huang, T.P. Lodge, Macromolecules 31 (1998) 3556.

Influence of antimony additions on surface tension and density of $\mathrm{Sn}-\mathrm{Sb}$, $\mathrm{Sn}-\mathrm{Ag}-\mathrm{Sb}$ and $\mathrm{Sn}-\mathrm{Ag}-\mathrm{Cu}-\mathrm{Sb}$ alloys. Experiment vs. modeling

\section{Z. Moser, W. Gsior and J. Pstruś}

It was shown in agreement with previously published results on $\mathrm{Sn}-\mathrm{Sb}$ [1], $\mathrm{Sn}-\mathrm{Ag}-\mathrm{Cu}$ [2] and on small additions of $\mathrm{Sb}$ to quaternary tin based alloys $\mathrm{Sn}-\mathrm{Ag}-\mathrm{Cu}-\mathrm{Sb}$ [3] $\left(X_{\mathrm{Sb}}=\right.$ $0.03,0.06,0.09,0.12)$ that the addition of antimony decreases the surface tension and density, while it increases the molar volume. Recently, the surface tension and density for remaining quaternary alloys on tin base $\left(X_{\mathrm{Sb}}=0.4\right.$ and 0.7$)$ were completed starting from ternary alloy $\mathrm{Sn}-3.3 \mathrm{Ag}-0.76 \mathrm{Cu}$. In addition, one alloy of equal composition in quaternary alloy $X_{\mathrm{Sn}}=X_{\mathrm{Cu}}=X_{\mathrm{Ag}}=X_{\mathrm{Sb}}=0.25$ was tested and a limited number of binary alloys : $\mathrm{Ag}-\mathrm{Sb}\left(X_{\mathrm{Sb}}=0.5\right), \mathrm{Cu}-\mathrm{Sb}$ $\left(X_{\mathrm{Sb}}=0.0,0.2\right.$ and 0.5$)$ and $\mathrm{Cu}-\mathrm{Sn}\left(X_{\mathrm{Sn}}=0.5\right.$ and 0.25$)$ to work out the relation of the surface tension on concentration in the quaternary system $\mathrm{Sn}-\mathrm{Ag}-\mathrm{Cu}-\mathrm{Sb}$. The calculations of the surface tension of the investigated alloys were performed also by Butler's model based on excess Gibbs energies of components of investigated alloys and surface tension of pure components.

Results reported in this abstract and previously published surface tension and density data for several pure components, binary, ternary, quaternary and one quinary alloys were used for creation of the SURDAT data base of Pb-free solders [4] comprising in addition to physical properties, modeling of the surface tension by Butler's method.

\section{References}

[1] W. Gasior, Z. Moser, J. Pstruś, Surface tension and density of liquid Sn-Sb alloys, J. Phase Equilibria 24 (2003) 504-510.

[2] Z. Moser, W. Gasior, J. Pstruś, S. Ishihara, X.J. Liu, I. Ohnuma, R. Kainuma, K. Ishida, Surface tension and density measurements of $\mathrm{Sn}-\mathrm{Ag}-\mathrm{Sb}$ liquid alloys and phase diagram calculations of the $\mathrm{Sn}-\mathrm{Ag}-\mathrm{Sb}$ ternary system, Mater. Trans. 45 (2004) 652-660.

[3] W. Gasior, Z. Moser, J. Struś, Measurements of the surface tension and density of liquid tin based $\mathrm{Sn}-\mathrm{Ag}-\mathrm{Cu}-\mathrm{Sb}$ alloys, Archs. Metall. 49 (2004) $155-167$.

[4] Z. Moser, W. Gąsior, A. Dębski., Experimental results of the surface tension and density for data base of $\mathrm{Pb}$-free soldering materials, in: 19th International CODATA Conference, The Information Society : New Horizons for Science, Berlin, Germany, 7-10 November 2004 (to be published in Proceedings in 2005)

\section{Experimental thermodynamics}

The standard enthalpies of formation of some intertransition metal compounds by high temperature direct synthesis calorimetry

\section{S.V. Meschel and O.J. Kleppa}

The standard enthalpies of formation of some inter-transition metal compounds have been measured by high temperature direct synthesis calorimetry at $1372 \pm 2 \mathrm{~K}$. The following results (in $\mathrm{kJ} / \mathrm{mol}$ of atoms) are reported:

$$
\begin{gathered}
\mathrm{ScMn}_{2}(-26.1 \pm 1.9) ; \mathrm{Sc}_{4} \mathrm{Os}_{11}(-22.6 \pm 3.0) \\
\operatorname{TiMn}_{2}(-8.6 \pm 1.6) ; \mathrm{V}_{2} \mathrm{Hf}(-16.7 \pm 1.7) ; \\
\operatorname{VIr}(-28.1 \pm 1.7) ; \mathrm{Fe}_{2} \mathrm{Hf}(-12.3 \pm 1.1) ; \\
\mathrm{Fe}_{7} \mathrm{Nb}_{6}(-6.2 \pm 1.8) ; \mathrm{Fe}_{2} \mathrm{Y}(0 \pm 1.9) ; \\
\mathrm{Co}_{3} \mathrm{Nb}(-7.4 \pm 1.9) ; \mathrm{NiY}(-32.9 \pm 1.7)
\end{gathered}
$$

The values are compared with some earlier experimental results obtained by EMF and by calorimetry. They are also compared with the predicted values of Miedema and coworkers. We will present a systematic picture of how the enthalpies of formation may be related to the atomic number of the transition metals.

Enthalpies of formation of intermetallic phases of the Ti-Si, Ti-B and Ti-Si-B systems measured by direct synthesis calorimetry

G.C. Coelho, J.C. Gachon, C.A. Nunes, J.M. Fiorani and M. Vilasi

Alloys of the $\mathrm{Ti}-\mathrm{Si}-\mathrm{B}$ and related systems are potential candidates for high-temperature applications. A thermodynamic database based on $\mathrm{Me}-\mathrm{Si}-\mathrm{B}$ systems $(\mathrm{Me}=$ metal $)$ will serve as a powerful tool for the development of these alloys. The enthalpy of formation is one of the most important experimental values for the optimization of these systems because it gives the largest contribution to the Gibbs energy of each phase. Several and scattered data are available for the silicides and borides of the Ti-Si and Ti-B binaries, as reviewed by [1] and [2], respectively. Recently, a new ternary phase, with stoichiometry $\mathrm{Ti}_{6} \mathrm{SiB}_{2}$, was reported to be stable in the Ti-Si-B system [3]. In the present work, the enthalpies of formation of intermetallic phases of the Ti-Si and Ti-B binaries as well as of the $\mathrm{Ti}_{6} \mathrm{SiB}_{2}$ were measured by high-temperature, direct synthesis calorimetry. After measurement, the samples were characterized by $\mathrm{X}$-ray diffraction, electron microprobe and back-scattered electron images.

\section{References}

[1] S.V. Meschel, O.J. Kleppa, Journal of Alloys and Compounds 267 (1998) $128-135$

[2] J.L. Murray, P.K. Liao, K.E. Spear, Bulletin of Alloy Phase Diagrams 7 (1986) 550-555.

[3] A.S. Ramos, C.A. Nunes, G. Rodrigues, P.A. Suzuki, G.C. Coelho, A. Grytsiv, P. Rogl, Intermetallics 12 (2004) 487-491.

\section{Phase equilibria in the Ag-Cu-Sn LEAD-Free solder alloys}

M. Kopyto, B. Onderka, A.T. Dinsdale and L.A. Zabdyr

A method for measuring the Electro-Motive Force was employed to determine the thermodynamic properties of liquid $\mathrm{Ag}-\mathrm{Cu}-\mathrm{Sn}$ alloys using solid electrolyte galvanic cells as summarized below:

$\mathrm{Pt}$, air | yttria stabilized zirconia $\mid \mathrm{Ag}-\mathrm{Cu}-\mathrm{Sn}, \mathrm{SnO}_{2}$,

Re, kanthal. 
Measurements were carried out for three cross-sections with constant $\mathrm{Ag} / \mathrm{Cu}$ ratio equal to: $1 / 3,1$ and 3 and for tin compositions ranging every $10 \%$, from 10 up to 80 at. $\%$, resulting in a total of 24 different alloy compositions. The temperature of the measurements varied from near the liquidus temperature up to $1075^{\circ} \mathrm{C}$. A linear dependence of the emf on temperature was observed for all alloy compositions and the appropriate line equations were derived. Tin activities were calculated as a function of composition and temperature and a full thermodynamic description was then derived using MTDATA and ThermoCalc using the most recent calorimetric data and experimental studies of the phase diagram.

Calculations were split into three stages: first ternary experimental data were compared to those calculated from binary COST 531 database, then the same experimental values were compared to the quantities calculated from the most recent $\mathrm{Ag}-\mathrm{Cu}-\mathrm{Sn}$ assessment (NPL 2002), and finally the system was re-optimized employing all the available experimental information, and phase diagram calculations were carried out. The experimental phase diagram data were plotted on the number of calculated isopleths displaying the good agreement with the calculated phase boundaries.

\section{Thermodynamic activity measurements and assessment of the system $\mathrm{NaI}-\mathrm{CeI}_{3}$}

\section{T. Markus, M. Ohnesorge, D. Kobertz and K. Hilpert}

The studies are part of the systematic investigations of metal halide salt systems, which are performed in our lab. In the work presented here the determination of the chemical activities of the components $\mathrm{NaI}$ and $\mathrm{CeI}_{3}$ for the complete composition range of the $\mathrm{NaI}-\mathrm{CeI}_{3}$ system is described as well as the partial pressures of the identified gaseous species.

The obtained thermochemical data are important for fundamental research for the chemistry of molten salts and applied physical chemistry for the development of metal halide lamps.

Twelve NaI-CeI 3 samples with the compositions $x_{\mathrm{NaI}}=$ $0,0.201,0.351,0.400,0.496$ (two independent runs), 0.554, $0.601,0.700,0.800,0.898$, and 1 were prepared by melting together $\mathrm{NaI}(\mathrm{s})$ and $\mathrm{CeI}_{3}(\mathrm{~s})$ under argon atmosphere in sealed quartz ampoules. The pure salts were supplied by Alfa Aesar, USA with a purity of 99.9 mass $\%$ for $\mathrm{CeI}_{3}$ and 99.5 mass \% for $\mathrm{NaI}$.

The vapour of the system $\mathrm{NaI}-\mathrm{CeI}_{3}$ was investigated under equilibrium conditions in the temperature range from $728 \mathrm{~K}$ to $923 \mathrm{~K}$ by using Knudsen Effusion Mass Spectrometry with a one compartment Knudsen cell. The partial pressures of the abundant species were determined. For all of the investigated compositions the temperature dependence of the partial pressures of the gaseous species were determined from the measured ion intensities. Based on the partial pressure measurements the thermodynamic activities were determined as a function of the melt composition. From the activities the enthalpies of mixing were determined.

Calphad type thermodynamic modelling was accomplished using the measured activities as well as other thermodynamic data present in the literature. The phase diagram of the system was calculated.

The latter has also been determined by us experimentally using Differential Thermal Analysis (DTA). A comparison between the experimental results and the calculations will be given.

Low temperature heat capacities and debye temperatures of organic "plastic" crystals

Anjali Talekar, Raja Chellappa, Dhanesh Chandra, Tsokol A. O and Sampaio J.A

Solid state phase change materials can be used as thermal energy storage (TES) for passive heating systems and other thermal applications. Alcohol and amine derivatives of neopentane are attractive for TES as they offer advantages of high enthalpy during solid-solid phase transition. Examples of these organic compounds include: Pentaerythritol [PE:C(CH2OH)4)], Pentaglycerine [PG:(CH3)C(CH2OH)3], Neopentylglycol [NPG:(CH3)2C(CH2OH)2], Neopentylalcohol [NPA:(CH3)3C(CH2OH)] Tris(hydroxymethyl)aminomethane [TRIS:(NH2)C(CH2OH)3], and 2-amino-2-methyl1,3-propanediol [AMPL:(NH2)(CH3)C(CH2OH)2]. These organic compounds undergo solid-solid phase transitions from low temperature ordered polymorphs (tetragonal, monoclinic, etc.) phase to an orientationally disordered high temperature "Plastic Crystal" modulated cubic phase (FCC or BCC) with unusually high enthalpies of transitions. The low temperature heat capacities of these compounds are invaluable for phase diagram computations and will aid in the development of a coherent thermodynamic database from $0 \mathrm{~K}$. There is also one reported study on NPG that indicates a very low temperature solid-solid phase transition at $60.4 \mathrm{~K}$. In this study, we have determined the heat capacities of pure PE, PG, NPG, NPA, AMPL, and TRIS from 3 to $350 \mathrm{~K}$ using a semi-adiabatic heat pulse calorimeter. We have also conducted a careful study in the low temperature regime to identify any solid-solid transition in these compounds. In this study we present the effect of the number of hydroxyl groups (that provide the hydrogen bonding for the crystal structure framework) on the heat capacities, and the dependence of the Debye temperature $\left(\Theta_{D}\right)$ on the number of hydroxyl groups is also presented.

Excess molar heat capacities of organic "plastic crystal" binary system: Tris(hydroxymethyl)aminomethaneNeopentylglycol

\section{Suresh C. Divi, Raja Chellappa and Dhanesh Chandra}

Tris(hydroxymethyl)ami nomethane (TRIS) and Neopentylglycol (NPG) belong to a special class of organic molecular crystals that have been evaluated for thermal energy storage applications. Both TRIS and NPG undergo solid-solid phase transitions from a low temperature layered structure (TRIS: orthorhombic, NPG: monoclinic) to an orientationally disordered 
plastic crystal phase (TRIS: BCC, NPG: FCC). The experimental phase diagram of the TRIS-NPG binary system has been established using both Differential Scanning Calorimetry (DSC) and X-ray Diffractometry by us as well as other researchers. However, there are no reported measurements of excess molar heat capacities of the solution phases. The excess molar heat capacities are important thermochemical properties which can be invaluable if a thermodynamic optimization of the binary system is to be performed. For example, the knowledge of excess molar heat capacity of liquid phase could provide a validation of the often used assumption of ideal liquid phase for such organic binary systems. In this study, we are reporting the excess molar heat capacities of the high temperature BCC (TRIS-rich), FCC (NPG-rich), and liquid phases of the TRISNPG binary system using Modulated Differential Scanning Calorimetry (MDSC ${ }^{\mathrm{TM}}$ ). MDSC ${ }^{\mathrm{TM}}$ is considered to be an effective alternative approach to adiabatic calorimetry for measuring heat capacities. In principle, $\mathrm{MDSC}^{\mathrm{TM}}$ experiments provide more accurate heat capacity values (compared to DSC) by imposing a complex heating profile (typically sinusoidal) as well as slower heating rate on the sample. We have used the MDSC $^{\mathrm{TM}}$ option provided in DSC Q100 to conduct our experiments. The excess molar heat capacities of these binaries and phase diagram will be discussed.

\section{Experimental investigation and CALPHAD description of} the quaternary organic alloy system AMPD-DC-NPG-SCN

\section{V.T. Witusiewicz, L. Sturz, U. Hecht and S. Rex}

Transparent organic substances with low entropy of fusion are known as orientationally disordered phases or plastic crystals. For the past seventy years plastic crystals have been used as analogues to metals, as far as their solidification behaviour is concerned, because they allow for in situ observation of the microstructure evolving at the solid/liquid interface. Unfortunately, the number of such organic alloy systems is quite limited and experimental information concerning the phase diagrams and related thermodynamic data is scarce. Furthermore, no hints in the literature on the existence of ternary or quaternary eutectic alloys formed by plastic crystals have been found.

The search for new suitable organic alloys gained new drive within the frame of solidification studies addressing pattern formation in multicomponent, multiphase alloys. We have found experimentally that a AMPD-DC-NPG-SCN system is suitable for such purposes.

The temperature and enthalpy of phase transformations of organic alloys of the constituent binary and ternary systems of the quaternary AMPD-DC-NPG-SCN system were measured by means of differential scanning calorimetry.

The analytical description of the Gibbs energies of pure substances were derived utilizing data available in the literature about temperature and enthalpy of transformations, and the temperature dependencies of heat capacity.

The quaternary phase diagram was assessed via the CALPHAD approach using Thermo-Calc by simultaneously optimizing the thermodynamic and phase equilibrium data measured in the present work. A good agreement between the experimental and calculated data for the phase diagram as well as for the thermochemical properties was achieved.

Additionally unidirectional solidification of several eutectic alloys was performed in order to verify the nature of the eutectics. We have found the composition region for eutectic alloys that grow with three nonfacetted phases and result in very regular lamellar or rod like patterns. Other univariant eutectic reactions in the quaternary alloy system correspond to growth of three phases with at least one being a facetted phase. Due to optical activity of DC its distribution in the multiphase solid sample and crystallographic orientation is easily detectable in polarised light.

\section{Thermodynamic activity measurements in the $\mathrm{B} 2$ phase $(\mathbf{N i}, \mathbf{F e})_{1-x} \mathbf{A l}_{x}$}

L. Bencze, D. Raj, T. Markus, S. Das, W. Löser, W.A. Oates, D. Kath, L. Singheiser, and K. Hilpert

The equilibrium vaporisation of the ternary $\mathrm{B} 2$ phase $(\mathrm{Ni}$, $\mathrm{Fe}) \mathrm{Al}$ has been investigated in the temperature range between 1200 and $1500 \mathrm{~K}$ by using Knudsen effusion mass spectrometry. Alloys of the three composition series $\mathrm{Al}_{0.45} \mathrm{Ni}_{0.55-x} \mathrm{Fe}_{x}$, $\mathrm{Al}_{0.50} \mathrm{Ni}_{0.50-x} \mathrm{Fe}_{x}$ and $\mathrm{Al}_{x} \mathrm{Ni}_{0.5(1-x)} \mathrm{Fe}_{0.5(1-x)}$ were investigated in addition to the $\mathrm{B} 2 \mathrm{NiAl}$ and $\mathrm{B} 2 \mathrm{FeAl}$ boundary phases. Knudsen cells made of molybdenum and lined completely with yttria showed no chemical interactions with the samples to be investigated and did not give rise to interfering background ion intensities during the measurements. The sample compositions investigated covered the complete homogeneity range of the intermetallic phase considered. Large emphasis was laid on the precise characterisation of the samples due to strong dependence of the partial pressures on the 0.1 at $\%$. It is considered that the accuracy of the compositions is about \pm 0.1 at $\%$.

The partial pressures of all alloy components were directly measured in temperature ranges of about $100-300 \mathrm{~K}$. Thermodynamic activities of $\mathrm{Fe}, \mathrm{Ni}$ and $\mathrm{Al}$ resulted. Different evaluation methods were used such as direct calibration using the pure alloy components and the ion intensity ratio integration method. The results evaluated according to the two methods showed generally excellent agreement. Moreover, enthalpies of mixing were evaluated. Integral thermodynamic properties $(\Delta G, \Delta H)$ resulted from the partial thermodynamic properties.

The results clearly indicate that the energetics of the ternary $(\mathrm{Ni}, \mathrm{Fe}) \mathrm{Al}$ alloys is mainly determined by the strong interactions between Ni and Al. Partial thermodynamic properties were obtained for the ternary alloys for the first time to our knowledge. They complement the recent calorimetric thermodynamic measurements which led to the determination of the integral heat of mixing [1,2]. The results of this study obtained by the vaporisation measurements are compared with those obtained by calorimetry and are used as the basis for thermodynamic modelling. 


\section{References}

[1] H.-N. Su, P. Nash, in: E. Opila, H. Pleraggi, P. Hou, D. Shifler, T. Maruyama, E. Wuchina (Eds.) High Temperature Corrosion and Materials Chemistry IV, in: The Electrochemical Society Proceedings Series, Proc.Vol. 2003-16, Pennington, 2003, pp. 489-502.

[2] J. Breuer, A. Grün, F. Sommer, E.J. Mittemeijer, Metall. Mater. Trans. 32B (2001) 913-918.

\section{Thermodynamic modelling of the A2/B2 phases in the Fe-Ni-Al-Va system}

\section{W.A. Oates, L. Bencze, T. Markus and K. Hilpert}

The experimental results obtained from our recent KEMS measurements [1], together with results from calorimetric [2,3] and vacancy concentration measurements $[4,5]$ have been used in an attempt to develop models for describing both the thermodynamic properties and vacancy concentration levels in the A2/B2 phases. The chemically binary B2 phases in the $\mathrm{Fe}-\mathrm{Al}$ and $\mathrm{Ni}-\mathrm{Al}$ systems differ markedly in both their thermodynamic and vacancy properties. At both the lowest and very highest temperatures, the principal defects in B2$\mathrm{FeAl}$ are antisites, with vacancy defects being only slightly predominant in a fairly small intermediate temperature range. The B2-NiAl phase, on the other hand, is a near-triple defect compound at all temperatures of interest. Similarly, the asymmetry of the partial molar thermodynamic properties about the stoichiometric composition is quite different in the two chemically binary phases.

Rather than concentrating on a multi-parameter description which could be used in phase diagram calculations for the whole system, emphasis has been placed on elucidating the most important factors determining the observations for the A2/B2 phases alone. A constant pairwise nearest neighbour energy Ising model in the zeroth or Bragg-Williams approximation is unable to satisfactorily describe the observed properties. Our paper will discuss the influence of the inclusion of improvements to this basic model in which the influence of second nearest neighbour interactions, atomic size mismatch, the coarse-graining of vibrational contributions into the configurational free energy and the influence of using higher order approximations are considered.

\section{References}

[1] K. Hilpert et al., this conference.

[2] H.-N. Su et al., High Temperature Corrosion and Materials Chemistry $\{I V\}$, in: The Electrochemical Society Proceedings Series, Proc. Vol. 200316, pp. 489.

[3] J. Breuer et al., Met. Trans. B 32 (2001) 913.

[4] L.M. Pike et al., Acta Mat. 50 (2002) 3859.

[5] H.P. Scholz, Doctor's Thesis, University of Goettingen, 2001.

\section{Nuclear materials and other matters}

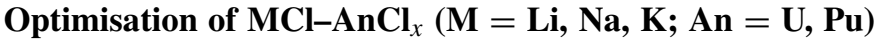 phase diagrams}

\section{Patrick Masset and Rudy J.M. Konings}

Pyrochemical reprocessing using molten salt technology is a promising method to partition actinides from spent nuclear fuel. Chloride melts are most commonly studied for this purpose, generally $\mathrm{LiCl}-\mathrm{KCl}$ eutectic. The assessment of accurate thermochemical data for actinides in molten chlorides is of high importance for the understanding of the process. In the 1950s and 1960s some binary or ternary actinide-based phase diagrams have been determined experimentally by US and Soviet researchers. We have carried out optimisation of these phase diagrams in order to derive the thermochemical properties of the solutions (e.g. excess Gibbs energies as well as activity coefficient of actinide in solution). The results for the key binary phase diagrams relevant to the pyrochemistry process ( $\mathrm{LiCl}-\mathrm{UCl}_{3}, \mathrm{NaCl}-\mathrm{UCl}_{3}, \mathrm{LiCl}-\mathrm{PuCl}_{3}, \mathrm{NaCl}-\mathrm{PuCl}_{3}$ ) will be presented as well as the ternary and quaternary systems derived from the optimised results.

\section{Thermodynamic study of the Zr-Fe system}

Toffolon-Masclet Caroline, Chatain Sylvie, Gueneau Christine and Dupin Nathalie

$\mathrm{Zr}$ alloys $\left(\mathrm{Zy}-4\right.$; $\left.5^{\mathrm{TM}}\right)$ employed for application to the cladding tubes and structural components of reactor fuel assemblies systematically contain several weight ppm of iron. Precipitation of $\mathrm{Zr}-\mathrm{Fe}$ intermetallic phases occurs due to the very low solubility of iron in the $\alpha-\mathrm{Zr}$ matrix (less than $\sim 100 \mathrm{ppm})$. Taking into account the fact that these intermetallic precipitates may influence some of the alloys inreactor properties, such as corrosion resistance and irradiation growth, this system needs to be well described.

A huge amount of experimental studies and thermochemical calculations have been dedicated to the $\mathrm{Zr}-\mathrm{Fe}$ system during the last 30 years [1-10]. Often called into question by the different authors, no definitive version has yet been obtained.

In the framework of this study, different $\mathrm{Zr}-\mathrm{Fe}$ alloys have been fabricated and annealed for long periods at 700, 800 and $900^{\circ} \mathrm{C}$. The oxygen contents were systematically checked before and after annealing treatments.

The microstructures have been studied using different complementary facilities such as electron microprobe analysis, $\mathrm{X}$-ray diffraction and calorimetry. These characterisations allowed us to determine the chemical compositions and the crystallographic structures of the different phases precipitated. They also allowed the determination of the invariant reactions and the liquidus temperatures. Particularly, we checked the metastability of the $\mathrm{Zr} 2 \mathrm{Fe}$ phase below $780^{\circ} \mathrm{C}$, as already demonstrated by Stein et al. [11].

Finally, we propose a new thermodynamic assessment of this system.

\section{References}

[1] O. Kubaschewski, Iron-Binary Phase Diagrams, Springer-Verlag, Berlin, Germany, 1982, pp. 175-178.

[2] D. Arias, J.P. Abriata, The Zr-Fe System, Bull. Alloy Phase Diagrams 9 (1988) 597-604.

[3] Z.M. Alekseeva, N.V. Korotkova, The Zr-Fe Phase Diagram, Russ. Metall. 4 (1989) 197-203.

[4] D. Arias, M. Granovsky, J.P. Abriata, in: H. Okamoto, (Ed.) Fe-Zr in Phase Diagrams of Binary Iron Alloys, ASM Int., Materials Park, OH, 1993, pp. 467-472. 
[5] H. Okamoto, Fe-Zr, J. Phase Equilibria, 14 (1993) 652-653.

[6] A.D. Pelton, L. Leibowitz, R.A. Blomquist, Thermodynamic Analysis of Phase Equilibria in the Iron-Zirconium System, J. Nucl. Mater. 201 (1993) 218-224.

[7] C. Servant, C. Gueneau, I. Ansara, Experimental and thermodynamic assessment in the Fe-Zr System, J. Alloys Compounds 220 (1995) 19-26.

[8] M.S. Granovsky, D. Arias, Intermetallic phases in the iron-rich region of the Zr-Fe phase diagram, J. Nucl. Mater. 229 (1996) 29-35.

[9] H. Okamoto, Fe-Zr, J. Phase Equilibria 18 (1997) 316.

[10] M. Jiang, K. Oikawa, T. Ikeshoji, L. Wulff, K. Ishida, Thermodynamic calculations of Fe-Zr and Fe-Zr-C systems, J. Phase Equilibria 22 (2001) 406-417.

[11] F. Stein, G. Sauthoff, M. Palm, Experimental determination of intermetallic phases, phase equilibria, and invariant reaction temperatures in the Fe-Zr System, J. Phase Equilibria 23 (6) (2002) 480-494.

\section{Thermodynamic assessment of Al-Li-O-Zr system}

\section{Drouelle, C. Gueneau, S. Chatain and Ph. Zeller}

In the nuclear industry, zirconium based alloys are mainly used as structural materials in the reactor assembly, as pressure tubes, channels, guide tubes or fuel cladding as examples. In the present work, the chemical interaction between the $\mathrm{LiAl}_{5} \mathrm{O}_{8}$ spinel and zircaloy cladding tubes at temperatures higher than $1000{ }^{\circ} \mathrm{C}$ is studied. A thermodynamic assessment of the basic $\mathrm{Al}-\mathrm{Li}-\mathrm{O}-\mathrm{Zr}$ system is performed using the CALPHAD method in order to better understand and predict the possible liquid and/or solid phase formation. An accurate knowledge of the phase diagram and thermodynamic data of all the binaries and ternaries sub-systems is necessary to understand the phase relations in the quaternary.

A thermodynamic assessment of the $\mathrm{Al}-\mathrm{Li}-\mathrm{Zr}, \mathrm{Al}-\mathrm{O}-\mathrm{Zr}$ and $\mathrm{Al}-\mathrm{Li}-\mathrm{O}$ ternary sub-systems is presented (Fig. 5). For the $\mathrm{Al}-\mathrm{O}-\mathrm{Zr}$ system, several databases for the $\mathrm{Al}-\mathrm{Zr}$ and $\mathrm{Zr}-\mathrm{O}$ binaries are reported in the literature [4,1] and [3]. The assessments of Wang [4] and Liang [3] are chosen for respectively the $\mathrm{Al}-\mathrm{Zr}$ and $\mathrm{Zr}-\mathrm{O}$ binaries, on the basis of the existing experimental data on phase diagram data and thermodynamic properties from the literature. Ternary interaction parameters are optimized to take into account the experimental data for the $\mathrm{Al}_{2} \mathrm{O}_{3}-\mathrm{ZrO}_{2}$ system [2]. Differential Thermal Analysis experiments are undertaken to bring liquidus data in the metal rich part of the diagram of the ternary system.

For the $\mathrm{Al}-\mathrm{Li}-\mathrm{Zr}$ system, the thermodynamic properties of the Al-Li binary system from [1] are used. The Li-Zr binary system is assessed on the basis of [5]. Because of the lack of thermodynamic data, the enthalpy of formation of the ternary $\mathrm{AlLi}_{2} \mathrm{Zr}$ and $\mathrm{Al}_{3} \mathrm{Li}_{x+y} \mathrm{Zr}_{5-x}$ compounds are calculated using the density functional theory (DFT) approach.

The thermodynamic properties of the phases are described using the compound energy model with ionic constituents for the oxide solid phases and an ionic two-sublattice model for the liquid.

For each system, isothermal sections and thermodynamic properties are presented.

The next step of the present work will concern the pseudoternary $\mathrm{Al}_{2} \mathrm{O}_{3}-\mathrm{LiO}_{2}-\mathrm{ZrO}_{2}$ system in which the $\mathrm{LiAl}_{5} \mathrm{O}_{8}$ spinel phase lies (Fig. 1).

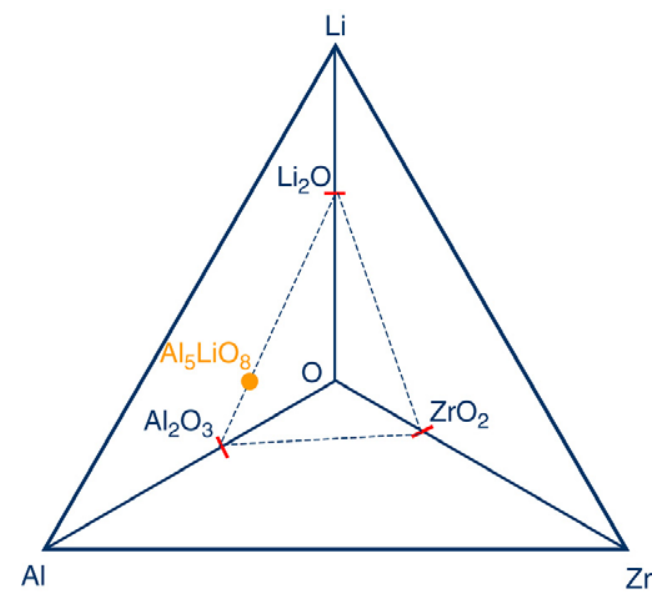

Fig. 5. Position of the $\mathrm{Al}_{5} \mathrm{LiO}_{8}$ spinel in the quaternary $\mathrm{Al}-\mathrm{Li}-\mathrm{O}-\mathrm{Zr}$ system.

\section{References}

[1] N. Saunders, Z. Metallkd. 80 (1989) 894-903.

[2] M. Lakiza et al., J. Am. Ceram. Soc. 80 (1997) 893-902.

[3] P. Liang et al., Z. Metallkd. 92 (2001) 747-756.

[4] T. Wang et al., J. Phase Equilibria 22 (2001) 544-551.

[5] G.M. Zatorska, V.V. Pavlyuk, V.M. Davydov, J. Alloys Compounds 333 (2002) 138-142.

Thermodynamic assessments of stability parameters for metastable $\omega$-phases of $\mathrm{Zr}$ and $\mathrm{U}$ and phase diagram of the $\mathrm{U}-\mathrm{Zr}$ system, including $\delta$-UZZr $\mathbf{U}_{2}$-phase

\section{A.L. Udovsky, D.A. Vasilyev and H.A.J. Oonk}

In [1] we have calculated preliminarily different parts of the phase diagram of the uranium-zirconium system, which have not included phase equilibria with $\mathrm{U}_{0,333} \mathrm{Zr}_{0,667}$-base solid solution ( $\delta$-phase). It is necessary to note that the $\delta$-phase is isomorphic with the metastable $\omega$-phase of pure $\mathrm{Zr}$. In this report we have developed a method for calculation of stability parameters between $\omega$ - and BCC- phases of pure $\mathrm{Zr}$ by using the temperature-pressure phase diagram of the pure Zr. Then using experimental data for enthalpy transformation between $\delta$ phase and BCC-phase for alloys with different compositions of this system [2] we have assessment enthalpy of the $\omega \Leftrightarrow$ BCC transformation of pure $\mathrm{Zr}$ by extrapolation procedure to pure $\mathrm{Zr}$.

We have applied a new minimization algorithm with the goal function (the generalized $\chi^{2}$-method [3]) to calculate phase diagrams and thermodynamic properties of the binary system [1] for solution of the indirect task (calculation of interaction parameters for BCC- phase, $\beta-\mathrm{U}$-base solid solution, $\delta$ phase solid solution, $\alpha-\mathrm{U}-$ base solid solution, $\mathrm{HCP}-\mathrm{Zr}$ - base solid solution) for the uranium-zirconium system. We have compared calculated as thermodynamic properties as a function of composition and temperature for a phase diagram with experimental data obtained by different scientists, which have been assessed in the review [4].

We have performed our computations within the framework of a number of models for the description of the Gibbs energy of phases for the uranium-zirconium system. As a 
test we have compared predicted temperature dependencies of thermodynamic properties of alloys of different compositions for the uranium-zirconium system [5], which we have not used in the optimisation procedure, with experimental data.

\section{Acknowledgement}

The work supported by Dutch-Russian Program NWORFBR (Project 047.011.2001.011) and Russian Federation Target Program "Integration" (Project B0056).

\section{References}

[1] A.L. Udovsky, D.A. Vasilyev, M. Jacobs, H.A.J. Oonk, Program \& Abstracts of CALPHAD XXXII, La Malbaie, Quebec, Canada, May 25-30, 2003, p. 122.

[2] M. Akabori, T. Agawa, A. Itoh, Y. Morii, J. Phys.: Condens. Matter. 7 (1995) 8249-8257.

[3] A.L.Udovsky, Russian Metally (2) (1990) 136-157.

[4] R.I. Sheldon, D.E. Peterson, The U-Zr (Uranium-Zirconium) System, Los Alamos National Laboratory, Bull. Alloys Phase Diagrams 10 (2) (1989) 165-181.

[5] Y. Takahashi, K. Yamamoto, T. Ohsato, H. Shimada, T. Terai, J. Nucl. Mater. 167 (1989) 147-151.

\section{Reassessment of the $\mathrm{Zr}-\mathrm{Sn}$ binary system}

Jerlerud Pérez Rosa, Baykov Vitaly, Sundman Bo and ToffolonMasclet Caroline

A new assessment of the $\mathrm{Zr}-\mathrm{Sn}$ binary system has been performed using old and new experimental information together with first principles calculated enthalpies of formation of all the intermetallic compounds in this system. First principles calculations found the controversial $\mathrm{Zr}_{5} \mathrm{Sn}_{4}$ to be stable at $0 \mathrm{~K}$. The results also conformed the stability of $\mathrm{Zr}_{3} \mathrm{Sn}$ with $\mathrm{Zr}$ anti-site defects on the $\mathrm{Sn}$ sublattice giving the stoichiometry $\mathrm{Zr}_{4} \mathrm{Sn}$ and resolved the incompatibility between the $\mathrm{Zr}_{4} \mathrm{Sn}$ stoichiometry and its structure, cubic A15 $\left(\mathrm{Cr}_{3} \mathrm{Si}\right.$ prototype).

The new experimental information consists of electron microprobe analysis, X-ray and calorimetry [2] and high temperature direct calorimetry [1].

Based on both theoretical and experimental facts, the Compound Energy Formalism has been applied to describe the stability $\mathrm{Zr}_{5} \mathrm{Sn}_{3}$ and $\mathrm{Zr}_{5} \mathrm{Sn}_{4}$ phases as a single phase and also the $\mathrm{Zr}_{4} \mathrm{Sn}$ phase. The liquid, bcc, hcp and bct have been treated as substitutional solutions.

The first Principles calculations have been performed using VASP code and the thermodynamic assessment using Thermo_Calc.

\section{References}

[1] S.V. Meschel, O.J. Kleppa, Thermochimica Acta 314 (1998) 205-212.

[2] C. Toffolon_Masclet, A experimental study of the $\mathrm{Zr}-\mathrm{Sn}$ system, to be presented in this conference.

\section{Thermodynamic modelling and experiments on LiF-NaF-} $\mathbf{L n F}_{3}$ and $\mathrm{LiF}-\mathrm{NaF}-\mathrm{AnF}_{\mathbf{3}}$ for Molten Salt Reactor fuel

\author{
Juliette van der Meer, Rudy Konings and Harry Oonk
}

The Molten Salt Reactor (MSR) is one of the proposed Generation IV systems. These reactor systems of the future should be safer, more efficient and economical and produce less waste than the current generation of reactors. The MSR fuel is a closed cycle of a fissile phase dissolved in a molten fluoride mixture. The reactor can be designed in two ways: as a breeder of thorium, using the Th-232/U-233 cycle, or a burner of actinides. For the latter application, it has been found that a $\mathrm{LiF}-\mathrm{NaF}$ mixture is preferable as the dissolving matrix, because of the good solubility for $\mathrm{Pu}$ and other minor actinide fluorides. Numerous phase diagrams have been measured in the past already, especially in Oak Ridge National Laboratory in the 1960s. But since it is impossible to perform measurements on every single composition, it is desirable to develop general models for the thermal behaviour of multicomponent systems of interest.

The systems that we have focused on are $\mathrm{LiF}-\mathrm{NaF}-\mathrm{LnF}_{3}(\mathrm{Ln}$ $=\mathrm{La}, \mathrm{Ce}, \mathrm{Nd})$ and $\mathrm{LiF}-\mathrm{NaF}-\mathrm{AnF}_{3}(\mathrm{An}=\mathrm{Pu}, \mathrm{Am})$. The latter is of greater interest for the MSR, but the former serves as a proxy for the actinide systems, since many more data are known in the literature and experiments are relatively easily performed on the inactive lanthanide fluorides.

The $\mathrm{LiF}-\mathrm{NaF}-\mathrm{LnF}_{3}$ systems were thermodynamically assessed according to the CALPHAD method. Experimental data from the literature as well as our own data from new calorimetric and thermal analyses were used in the assessments. Two different models have been applied to describe the excess Gibbs energy coefficients: the asymmetric Kohler-Toop model using general polynomials and a quasichemical model. The phase diagrams of $\mathrm{LiF}-\mathrm{NaF}-\mathrm{AnF}_{3}$ have been calculated, using literature data from the binary subsystems and the information obtained from the assessments of $\mathrm{LiF}-\mathrm{NaF}-\mathrm{LnF}_{3}$.

\section{Incorporation of boron in MgO-based composites for transmutation}

\section{G.J.L.M. de Haas, R.P.C. Schram and M.J. den Exter}

Discussions about the reduction of greenhouse-gas emissions have revitalized the discussion about the future role of nuclear power production. Use of nuclear power plants avoids the emission of $\mathrm{CO}_{2}$. On the other hand, enlargement of the contribution of nuclear power in order to meet increasing energy demands is directly related to the issue of nuclear waste, a problem for which a socially acceptable solution has yet to be found. Re-irradiation of the most radiotoxic or most longlived components from the waste with neutrons can reduce the long-term environmental impact of nuclear power. This is also known as 'transmutation'. Development of innovative fuels that enable efficient transmutation of nuclear waste, involves research into both nuclear physics and materials science, followed by irradiation tests, where practical trials of transmutation of nuclear waste are carried out. 
The fuels for transmutation generally consist of an inert matrix, like $\mathrm{MgO}$, spinel and zirconia, in which a fissile nuclidebearing phase has been dispersed. One of the nuclides of interest is americium, an actinide that contributes about $10 \%$ to the radiotoxic inventory of the waste. Transmutation of Am gives rise to the production of large volumes of helium, which leads to swelling of the matrix. In order to facilitate research into the effects of helium production on the mechanical stability of the matrix material, ${ }^{10} \mathrm{~B}$-bearing compounds may be used. Upon irradiation of ${ }^{10} \mathrm{~B}$ with thermal neutrons ${ }^{7} \mathrm{Li}$ and an alpha particle is formed. The alpha particles simulate the He production, which is characteristic for Am transmutation. Because of the high cross section of ${ }^{10} \mathrm{~B}$ for thermal neutrons, irradiation experiments with ${ }^{10} \mathrm{~B}$-bearing compounds are very efficient and timesaving.

One of the issues to be addressed is the compatibility of the B-bearing compound with inert matrix material like $\mathrm{MgO}$ and spinel. A combined approach including fabrication experiments, XRD analysis and thermodynamic calculations has been applied to determine the most suitable conditions, compounds and combinations with various types of matrices. Results for magnesiumorthoborate, $\mathrm{Mg}_{3} \mathrm{~B}_{2} \mathrm{O}_{6}$, look promising; this compound remains stable when sintered in a matrix of $\mathrm{MgO}$ at a temperature of $1650^{\circ} \mathrm{C}$ in an $\mathrm{Ar}$ atmosphere (Ar5.7). On the other hand, no more magnesiumorthoborate is detected in sintered samples with a spinel matrix. A thermodynamic analysis using the FACTSAGE program has been performed to compare the calculated thermodynamic stability of the magnesiumorthoborate in $\mathrm{MgO}$ and spinel under sintering conditions with the experimentally found reaction products.

\section{Thermodynamic investigations and assessment of the Mn-Ni-C system}

Lidong Teng, Ragnhild E. Aune, Wenchao Li and Seshadri Seetharaman

In the present work, phase relationships in selected phase regions of the $\mathrm{Mn}-\mathrm{Ni}-\mathrm{C}$ system have been investigated at 1073 $\mathrm{K}$ and $1223 \mathrm{~K}$ by use of an equilibration technique. Alloys of $\mathrm{Mn}-\mathrm{Ni}-\mathrm{C}$ were prepared from pure $\mathrm{Mn}, \mathrm{Ni}$ and $\mathrm{C}$ powders by powder metallurgy method. The phase identification of the heat treated samples was carried out by scanning electron microscope (SEM) and transmission electron microscope (TEM). The main phase compositions of the alloys have been analyzed by X-ray diffraction (XRD). The experimental results show that the site fraction of $\mathrm{Ni}$ in the metallic sublattice of the carbides $\mathrm{M}_{23} \mathrm{C}_{6}, \mathrm{M}_{7} \mathrm{C}_{3}$ and $\mathrm{M}_{5} \mathrm{C}_{2}$ is quite low and the value is around $2 \%-3 \%$. The thermodynamic activities of manganese in 16 different $\mathrm{Mn}-\mathrm{Ni}-\mathrm{C}$ alloys have been studied by a solid-state galvanic cell technique with $\mathrm{CaF}_{2}$ as the solid electrolyte in the temperature range $940-1165 \mathrm{~K}$. The experimental results obtained, as well as the results from the literature, were employed in the assessment of the $\mathrm{Mn}-\mathrm{Ni}-\mathrm{C}$ system using the CALPHAD approach.
Modeling the volumetric properties of multicomponent liquids: The $\mathrm{NaCl}-\mathrm{KCl}-\mathrm{MgCl}_{2}-\mathrm{CaCl}_{2}$ and $\mathrm{Na}^{+}, \mathrm{Al}^{3+}$, $\mathrm{Ca}^{2+} / / \mathbf{F}^{-}, \mathrm{O}^{2-}$ systems

\section{Christian Robelin and Patrice Chartrand}

It is of great importance to be able to predict the density of liquid phases involved in various industrial processes: for instance, the density of liquid alloys during casting or the density of the $\mathrm{Na}^{+}, \mathrm{Al}^{3+}, \mathrm{Ca}^{2+} / / \mathrm{F}^{-}, \mathrm{O}^{2-}$ electrolyte used to produce aluminum by the Hall-Heroult process.

For a given liquid phase, the density is easily derived from the molar volume, which is an extensive property defined as the pressure derivative of the molar Gibbs energy at fixed temperature and number of moles of components. Therefore, by introducing in the Gibbs energy of the phase temperature-dependent molar volume expressions for the pure components and pressure-dependent excess parameters for the binary subsystems, it is possible to reproduce, and eventually predict, the molar volume of the multicomponent phase using derivatives of the Gibbs energy and the classical CALPHAD techniques.

For each pure component, the molar volume at temperature $T$ is related to the molar volume at a reference temperature and the thermal expansion $\alpha$, where $\alpha$ is given by an expression of the type $a+b T+c / T+d / T^{2}(a, b, c$ and $d$ are optimized parameters which allow us to best reproduce the available density measurements for the pure component). For each binary subsystem, pressure-dependent excess Gibbs energy parameters are introduced (as standard $\mathrm{L}$ terms for example) in order to best reproduce all available density measurements from the literature. The density of the multicomponent phase can then be predicted by the model using standard Kohler/Toop/Muggianu interpolation methods [1].

The present approach has been used successfully to model the density of the $\mathrm{Al}-\mathrm{Mg}-\mathrm{Si}$ and $\mathrm{Al}-\mathrm{Mg}-\mathrm{Zn}$ ternary liquids $[2,3]$. Results for the densities of the $\mathrm{NaCl}-\mathrm{KCl}-\mathrm{MgCl}_{2}-\mathrm{CaCl}_{2}$ and $\mathrm{Na}^{+}, \mathrm{Al}^{3+}, \mathrm{Ca}^{2+} / / \mathrm{F}^{-}, \mathrm{O}^{2-}$ electrolytes will be presented (the former electrolyte is used for magnesium production). The "conventional" thermodynamic properties (enthalpy of mixing of the liquid, activities in the liquid, phase diagram, vapor pressure measurements) of both systems have been previously modeled [4,5]; the models used for the liquids were the Modified Quasichemical Model (taking into account cation-cation short-range order) and the Modified Quasichemical Model in the Quadruplet Approximation (evaluating coupled 1st- and 2nd-nearest-neighbor short-range order) respectively. In both cases, the density of the multicomponent liquid predicted from the pressure-dependent excess Gibbs energy parameters introduced for the binary (and sometimes higher order) subsystems compares satisfactorily to the available density measurements. Since these added parameters are always very low, the equilibrium cation-cation pair fractions (or quadruplet fractions) are virtually identical to the ones calculated from the previous models (with no pressure-dependent excess Gibbs energy 
parameters). Consequently, both the density and the "conventional" thermodynamic properties of the multicomponent liquid can now be predicted from the excess Gibbs energy parameters for the binary (and sometimes higher order) subsystems.

The present approach is only suitable for total pressures up to a few bars. At high pressures, the pressure dependence of the molar volumes of the pure components would have to be considered using the Birch-Murnaghan model and the pressure-dependent binary excess Gibbs energy parameters previously obtained for low pressures may not be applicable.

\section{References}

[1] P. Chartrand, A.D. Pelton, J. Phase Equil. 21 (2) (2000) 141-147.

[2] F. Gemme, Master's Project, Ecole Polytechnique, Montreal, 2004.

[3] F. Gemme, P. Chartrand, Application of Thermodynamic Models to the Calculation of Volumetric Properties and Viscosity of Liquid Aluminum Alloys, Poster at CALPHAD XXXIII, May 30-June 4, Krakow, Poland, 2004.

[4] P. Chartrand, A.D. Pelton, Metall. Mater. Trans. A 32A (2001) 1361-1383.

[5] P. Chartrand, A.D. Pelton, unpublished work.

\section{Cluster variation subjects}

\section{Crystal-Glass transition studied by CVM and PPM}

\subsection{Tetsuo Mohri and Yoshitaka Kobayashi}

Bulk Metallic glasses have been attracting broad attention for their superior mechanical, magnetic and corrosion properties. Thermodynamic stability and its structural correlation, however, leave numerous subjects un-clarified. The purpose of the present investigation is to attempt thermodynamic and kinetics descriptions of the crystal-glass transition. We employed the free energy of the L10 ordered phase within the tetrahedron approximation of the Cluster Variation Method (CVM). By minimizing the free energy with respect to all the independent short range order parameters, the free energy of the system is obtained as a function of temperature and long range order parameter $\eta$. The long range order parameter is regarded as an amount of generalized defects which induce a solid-liquid transition. From the dependences of free energies on $\eta$ at various temperatures, a $T_{0}$ diagram is obtained. It is confirmed that the melting temperature decreases with the increase of defects. Furthermore, a tri-critical point appears in the $T_{0}$ diagram. This corresponds to the ideal glass transition temperature at which the entropy of a defective crystal becomes identical to that of a liquid. When the defect is further introduced into the crystal at a tri-critical state, the defective crystal transforms into an ideal glass, but upon raising the temperature above the tri-critical temperature, the ideal glass becomes a supercooled liquid. It is noticeable that the ideal glass transition temperature is nothing but a spinodal ordering temperature in the order-disorder transition. Hence, thermodynamically, one may conclude that the glass transition is driven by the spontaneous loss of stability with respect to a fluctuation of the order parameter. Yet, the critical difference between glass transition and ordering transition is the fact that kinetics plays a crucial role in the former transition. In order to investigate the kinetics aspects, we employed Path Probability Method (PPM) which is the natural extension of the CVM to the time domain. The relaxation process during the continuous cooling is investigated in terms of a cooling rate and viscosity. It should be noted that the present studies only confirm the feasibility of the CVM and PPM for the descriptions of thermodynamic and kinetic frameworks of glass transition. However, reasonable results obtained in the present investigation is quite encouraging to perform future study based on Continuous Displacement Cluster Variation Method in which actual structural information of glass may be incorporated.

\section{CVM calculations on the bec Fe-Rh-Ti system}

\section{Luiz Eleno, Jozef Balun, Cláudio Schön and Gerhard Inden}

The bcc Fe-Rh-Ti system shows ordering reactions in all three binary sub-systems. The ordered phases extend into the ternary system, giving rise to broad miscibility gaps. These reactions can only be understood and described quantitatively by means of the Cluster Variation Method (CVM), which takes both short range and long range order into account [1]. The present work shows the results obtained for this system, both theoretically by CVM modelling and experimentally.

The irregular tetrahedron (IT) was adopted as the basic cluster for the CVM calculations in the bcc lattice. Within this formalism it is possible to describe the $\mathrm{B} 2, \mathrm{~B} 32$ and $\mathrm{D} 0_{3}$ ordered structures, as well as the A2 disordered solid solution.

The interaction parameters for the calculations were obtained through a fitting to experimental results on phase equilibria at $800^{\circ} \mathrm{C}$ and $1000^{\circ} \mathrm{C}$, starting with the binary systems and later on including ternary parameters to match the ternary experimental data. The ternary phase diagram at these temperatures shows the stability range of the B2 ordered structure over a broad composition range within the ternary. Nevertheless, a large A2 + B2 miscibility gap opens up in the region with more than 30 at.\%-Fe.

When comparing diffusion couple results with CVMcalculated iso-potential lines, the latter show nicely the trend of the observed diffusion paths. The observations will be discussed on the basis of a previous work by Schön [2], considering the substitutional diffusion theory.

Keywords: Cluster Variation Method; CVM; Fe-Rh-Ti; Computational Thermodynamics; Ordering in alloys.

\section{References}

[1] L.T.F. Eleno, C.G. Schön, J. Balun, G. Inden, Intermetallics 11 (2003) 1245-1252.

[2] C.G. Schön, J. Phase Equilib. 22 (2001) 287-290.

\section{A CVM-based study of the effect of alloying on hydrogen solubility in palladium alloys}

\section{D.E. Nanu, S. Shang and A.J. Böttger}

The knowledge of hydrogen solubility in palladium alloys is important for designing membrane materials for hydrogen gas separation. In particular the phase boundaries between the $\alpha$-metal solid solutions and $\beta$-metal hydrides formed during hydrogen absorption are of interest. 
In this work, the cluster variation method (CVM) is applied to describe the $\alpha-\beta$ phase boundaries in $\mathrm{Pd}-\mathrm{H}$ and $\mathrm{Pd}-\mathrm{M}-\mathrm{H}$ systems. In particular, the systems in which the interstitial atoms $(\mathrm{H})$ occupy the octahedral sites formed by the closepacked fcc metal lattice are investigated.

The tetrahedron approximation of the CVM is used in combination with two approaches for describing the interaction energies i.e., semi-empirical effective pair potentials (EPP) and $a b$ initio derived effective cluster interactions (ECI). Both CVM-EPP and CVM-ECI models are used to calculate the phase diagram of the $\mathrm{Pd}-\mathrm{H}$ system. The phase boundaries calculated with both models are in agreement with experimental data. While the CVM-ECI approach is predictive, the CVMEPP model requires experimental data for fitting some of the model parameters. The use of EPP is however much simpler and faster and hence more convenient to use for practical applications. Therefore the CVM-EPP model was used to explore the influence of alloying elements on the phase diagrams of $\mathrm{Pd}-\mathrm{M}-\mathrm{H}$ systems. The results illustrate the effect of alloying on the solubility of interstitial atoms. It is shown by the CVM-EPP approach that the strength of the effective field of the metal sublattice and the relative interaction strength between nearest-neighbour occupied and unoccupied interstitial sites determine the phase boundaries and degree of short range order. Examples of using the CVM-EPP model in designing new membrane materials for hydrogen gas separation are given.

\section{A combination of the cluster variation method and ab initio calculations: Application to hexagonal interstitial $\varepsilon-\mathrm{Fe}_{6} \mathbf{N}_{y}$ alloys}

\section{S. Shang and A. J. Böttger}

A combination of ab initio and statistical thermodynamics, i.e., the cluster variation method (CVM), is applied to describe phase stability and site occupations of interstitial atoms in hexagonal $\varepsilon-\mathrm{Fe}_{6} \mathrm{~N}_{y}$ alloys. Firstly, the total energies of ordered compounds $\varepsilon-\mathrm{Fe}_{6} \mathrm{~N}_{y}(y=0,1,2, \ldots, 6)$ are calculated by using the first principles projector-augmented wave (PAW) method including the magnetic contributions as implemented in the Vienna Ab initio Simulation Package (VASP), where the electronic structure calculations are carried out in the generalized gradient approximation (GGA). Secondly, the cluster expansion method and the Connolly-Williamslike inversion scheme are employed to obtain a set of volume-dependent effective cluster interactions (ECIs) which parametrize the internal energy of a hexagonal $\mathrm{Fe}-\mathrm{N}$ alloy. Thirdly, the cluster variation method (CVM) in the simple prism approximation (SPA) is applied to investigate the phase equilibrium of hexagonal $\varepsilon-\mathrm{Fe}_{6} \mathrm{~N}_{y}$ phase. The vibrational contributions are also considered by means of the Debye-Grüneisen model. Finally, the lattice parameters, the phase boundaries (between $\varepsilon-\mathrm{Fe}_{6} \mathrm{~N}_{y}$ and cubic $\gamma^{\prime}-\mathrm{Fe}_{4} \mathrm{~N}$ ) and the distribution of $\mathrm{N}$ atoms over the octahedral interstitial sites of $\varepsilon-\mathrm{Fe}_{6} \mathrm{~N}_{y}$ alloys are investigated. The calculations indicate that for the favoured $\varepsilon-\mathrm{Fe}_{6} \mathrm{~N}_{y}$ compounds there are no direct contacted $\mathrm{N}$ atoms in the nearest-neighboring direction, which also compare with the experimental diffraction and Mössbauer data available in the literature.

\section{CALPHAD thermodynamics and related subjects}

Check list for publishing CALPHAD-type thermodynamic and kinetic assessments: Proposal for the CALFOR standard format

\section{Suzana G. Fries}

The number of publications reporting the so-called CALPHAD assessments is growing. This is good news. Due to the reason that assessments are carried out for systems that are envisaged as potential for a given applied material these publications are being done in specialized magazines related to the application, for instance: electronic materials, crystal growing, intermetallics, surfaces, high temperature materials, etc. In these cases the assessment is a by product of the report and many times the referees will pay attention to the application, which is their expertise, and not to the assessment itself which is in many cases a foreign issue in the scope of that magazine. Detailed information about the assessment is very often skipped in these cases and considered as irrelevant. This is less good news.

In the other way round, even for researchers specialised in thermodynamic descriptions it is many times an issue to decide what is new, what is relevant for the given assessment, which experimental information is relevant, how much the models used should be detailed, what are the reference states, which quantities are useful to be calculated even if no experimental data exists to allow a comparison, in short, what and how the assessment can be published at its best in thermodynamic description specialised magazines. The problems of the author are in a way also transferred to the referee, who usually has a short time to scan the completeness of the manuscript and for checking if the reported numbers reproduce the reported results. This can end in bad news as many mistakes survive in the publications even for the ones specialised in assessments, as well as, what is even worst, information is missing and results cannot be reproduced and checked.

CALPHAD-type assessments reached a maturity and models, reference states, software used, etc, are well documented. That allows us to think about a standard format where the results (e.g. parameters of the thermodynamic description) can be reported together with the used methodology. A similar procedure like the one used for the standard files provided by the crystallographers when publishing crystal structures can be adopted (cef files in Acta Crystallographica). The definition of the information necessary to characterise an assessment would provide a kind of check list that also could help authors and referees to improve and facilitate their tasks. In the case of publications in applied magazines this standard would also help as the information would concisely appear.

Some trials to propose a check list for authors and referees were already done as an initiative by some researchers, and 
more recently, the idea of a standard format is popping out here and there. One of the reasons this appears so often now is that there are young scientists coming to the area and no advice about how to report assessments is available.

In this communication a $\boldsymbol{C A L F O R}$ standard format file is proposed where the main information from an assessment would be retained. It is suggested that the software used for the assessments would provide an output easily imported by the standard format file or even producing directly the CALFOR file as an output. Of course, other details not available in the output file should be filed separated.

The proposal will be opened for discussions during the meeting and once the file format and its content is finally agreed, the success of this action will depend on the participation of CALPHAD-type assessors and magazine editors and publishers. storage of these files in a public area can be discussed with international organizations (e.g. CODATA, SGTE, etc), universities and magazine publishers as well and eventually the action will hold. This will be the best news.

\section{Thermodynamic modeling of the system Na-K-S}

\section{Daniel Lindberg, Patrice Chartrand and Rainer Backman}

The chemical system $\mathrm{Na}-\mathrm{K}-\mathrm{S}$ is of primary importance for the combustion of black liquor in the Kraft recovery boilers in pulp and paper mills. A thermodynamic evaluation and optimization for the system $\mathrm{Na}-\mathrm{K}-\mathrm{S}$ has been made. All available data for the system has been critically evaluated to obtain optimized parameters of thermodynamic models of all phases. The liquid model is the quasichemical model in the quadruplet approximation which evaluates 1st- and 2ndnearest-neighbor short-range-order. In this model, cations $\left(\mathrm{Na}^{+}\right.$ and $\mathrm{K}^{+}$) are assumed to mix on a cationic sublattice, while anions $\left(\mathrm{S}^{2-}, \mathrm{S}_{2}^{2-}, \mathrm{S}_{3}^{2-}, \mathrm{S}_{4}^{2-}, \mathrm{S}_{5}^{2-}, \mathrm{S}_{6}^{2-}, \mathrm{S}_{7}^{2-}, \mathrm{S}_{8}^{2-}, \mathrm{Va}^{-}\right)$are assumed to mix on an anionic sublattice. The thermodynamic data of the liquid polysulfide components $\mathrm{M}_{2} \mathrm{~S}_{\mathrm{n}}(\mathrm{M}=\mathrm{Na}$, $\mathrm{K}$ and $n=2-8)$ are fitted to $\Delta G_{r}=A(n)+B(n) \cdot T$ for the reaction $M_{2} S(l)+(n-1) S(l)=M_{2} S_{n}(l)$. The solid phases are the alkali alloys, alkali sulfides, several different alkali polysulfides and sulfur. The solid solutions $(\mathrm{Na}, \mathrm{K}),(\mathrm{Na}, \mathrm{K})_{2} \mathrm{~S}$ and $(\mathrm{Na}, \mathrm{K})_{2} \mathrm{~S}_{2}$ are modeled using the compound energy formalism. The models can be used to predict the thermodynamic properties and phase equilibria in the multicomponent heterogeneous system. The experimental data are reproduced within experimental error limits for equilibria between solid, liquid and gas. The ternary phase diagram of the system $\mathrm{Na}-\mathrm{K}-\mathrm{S}$ has been predicted as no experimental determinations of the phase diagram have been made previously.

\section{The effects of alloying elements on thermodynamic properties of $\mathrm{Nb}$-Carbide in microalloyed steels}

Sang hwan Lee and Kyung jong Lee

There is an increasing tendency of adding alloying elements such as $\mathrm{Nb}, \mathrm{V}$ and $\mathrm{Ti}$ in HSLA steels recently. Very fine carbonitrides are obtained by combining transition metals such as $\mathrm{Nb}, \mathrm{V}$ and $\mathrm{Ti}$ with $\mathrm{C}$ and $\mathrm{N}$. The formation of fine carbonitrides improves mechanical properties by grain refinement and precipitation hardening. It is important to predict precipitation behavior (dissolution temperature, maximum fraction, size and type of precipitates) precisely for improving the quality of steels. But the size of precipitates in microalloyed steels depending on temperature is so fine to very fine that quantitative measurement of precipitates is far from satisfactory.

The dilute solution model is quite widely used because the chemical potential is more easily defined than that in the sublattice model. Moreover, the Wagner interaction parameter in the dilute solution model is more useful to explain the effects of alloying elements on thermodynamic properties than the $\mathrm{L}$ parameter in the sub-lattice model. In the present study, the thermodynamic model for the $\mathrm{Fe}-\mathrm{Mn}-\mathrm{Si}-\mathrm{Nb}-\mathrm{Ti}-\mathrm{V}-\mathrm{C}-\mathrm{N}$ system was conducted by evaluating Wagner interaction parameters. The data used in this work was collected and modified by means of TCFE-database in Thermo-Calc and upto-date references. The relationship of $\mathrm{L}$ parameters in the sublattice model and Wagner interaction parameters in the dilute solution model was derived. The composition dependency of the reference state, the restrictive mixture of substitutional atoms and interstitial atoms in each lattice and the higher order interaction parameters of the excess Gibbs energy in the sublattice model were considered to evaluate Wagner interaction parameters.

Thermodynamic calculations of the phase equilibria between austenite and complex carboniterides containing $\mathrm{Nb}$, $\mathrm{Ti}$ and $\mathrm{V},(\mathrm{Nb}, \mathrm{Ti}, \mathrm{V})(\mathrm{C}, \mathrm{N})$ were perfomed by the dilute solution model. Especially, the effects of alloying elements on thermodynamic properties of $\mathrm{Nb}$-carbide in microalloyed steels were considered by the Wagner interaction parameter in the dilute solution model. As a result, the calculations in this study were compared with the experimental data.

\section{Ab initio calculations on garnet solid solutions}

\section{Marcel H.F. Sluiter, Victor L. Vinograd and Y. Kawazoe}

Recent studies [1,2] have shown that the mixing enthalpy of a two-component regular solid solution, e.g. $\mathrm{CaAl}_{2 / 3} \mathrm{Si}_{4}-\mathrm{MgAl}_{2 / 3} \mathrm{Si}_{4}$ garnet, can be well predicted from $a b$ initio calculated static energies of only four structures (configurations). The first two structures represent the endmembers, while the other two structures are derived from the end-members by substituting one exchangeable atom in their supercells with an atom of the other sort. The changes in the relaxed energies of the end-members due to the incorporation of the impurity atoms give the Margules parameters. Similar calculations can be performed with empirical force-field methods [3]. Here we extend the application of the Impurity Method to solid solutions with coupled substitutions such as $\mathrm{CaMgSi}_{2} \mathrm{O}_{6}-\mathrm{NaAlSi}_{2} \mathrm{O}_{6}$ pyroxens. The concept of an impurity atom is then replaced with the concept of an impurity pair. However, due to different possible locations of the impurity 
pairs in the end-member hosts, one arrives at two sets of different configuration energies corresponding to the two doped compositions. The Margules parameters can be easily extracted from these sets by applying Boltzmann weights to the different configurations. The calculated Margules parameters thus depend on the temperature. Boltzmann's analysis allows also evaluation of the free energies and entropies of the impurity configurations. Thus, it becomes possible to estimate the effect of SRO on the thermodynamics of mixing. The evaluation of the effect of LRO requires a more sophisticated analysis, but the mixing in the low-temperature limit can be easily predicted with the impurity calculations applied to the end-members and stable ordered compounds.

\section{References}

[1] M.H.F. Sluiter, Y. Kawazoe, Prediction of mixing enthalpy of alloys, Europhys. Lett. 57 (2002) 526-532.

[2] M.H.F. Sluiter, V.L. Vinograd, Y. Kawazoe, Intermixing tendencies in garnets: Pyrope and grossular, Phys. Rev. B 70 (2004) 184120-1-4.

[3] V.L. Vinograd, M.H.F. Sluiter, B. Winkler, A. Putnis, U. Hålenius, J.D. Gale, U. Becker, Thermodynamics of mixing and ordering in pyrope-grossular solid solution, Min. Mag. 68 (2004) 101-121.

\section{Special Quasirandom Structure calculation of binary HCP alloys}

Dongwon Shin and Zi-Kui Liu

With the recent development of first-principles technique and computing power, formation enthalpy and entropy of stoichiometric compounds with known crystal structures can be readily calculated and used in CALPHAD thermodynamic modeling [1,2]. To directly apply a first-principles technique to disordered or partially disordered solid solution phases, one needs to construct large supercells, which is beyond today's computing resources.

One approach to this issue is to use the so-called Special Quasirandom Structure suggested by Zunger et al. [3], creating a small supercell to mimic the pair, triple and higher order correlation functions of a random solution phase. The generated structures can be used for any element to calculate the enthalpy of mixing. At present, the SQS's of the fcc [4], bcc [5], and B2 phases are available by Wei et al. and Jiang et al., respectively.

In this work, three different special Quasirandom structures for $\mathrm{A}_{1-x} \mathrm{~B}_{x}$ binary random alloys $(x=0.25,0.5$ and 0.75$)$ with the hexagonal closed packed phase have been generated by ATAT package [6]. The calculated enthalpy of mixing of eight binary systems shows good agreement with both thermodynamic and crystallographic experimental data. These supercell structures can be used for any binary hcp solutions.

\section{References}

[1] Y. Zhong, C. Wolverton, Y.A. Chang, Z.K. Liu, Acta Mater. 52 (2004) 2739.

[2] K. Ozturk, Y. Zhong, L.Q. Chen, C. Wolverton, J.O. Sofo, Z.K. Liu, Metall. Mater. Trans. A 36A (2005) 5.

[3] A. Zunger, S.H. Wei, L.G. Ferreira, J.E. Bernard, Phys. Rev. Lett. 65 (1990) 353.

[4] S.H. Wei, L.G. Ferreira, J.E. Bernard, A. Zunger, Phys. Rev. B 42 (1990) 9622.
[5] C. Jiang, C. Wolverton, J. Sofo, L.-Q. Chen, Z.-K. Liu, Phys. Rev. B 69 (2004) 214202/1.

[6] A. van de Walle, M. Asta, G. Ceder, CALPHAD 26 (2002) 539.

\section{Titles of the exposed posters}

\section{Group one}

E.C. Do and B.J. Lee

Semi-Empirical Interatomic Potentials for Nitrogen and Nitrides

J.W. Jang and B.J. Lee

Semi-Empirical Interatomic Potentials for Hydrogen and Hydrides

D.W. Shin and Z.K. Liu

Automatic Thermodynamic Database Development

\section{A.L. Udovsky, A.A. Mirzoev and M.M. Yalalov}

Calculation of the mixing energy of the $\mathrm{Fe}-\mathrm{Cr}$ alloys by the first principles methods of computer simulations

W.J. Golumbfskie, D.W. Shin, R. Arroyave and Z.K. Liu

Combining First-Principles and CALPHAD: Al-Ni-Y Phase Diagram Prediction

G.C. Coelho, J.M. Fiorani, C.A. Nunes, N. David, J.C. Gachon and $M$. Vilasi

New assessment of the Si-B (silicon-boron) system

\section{J.P. Harvey and P. Chartrand}

The Al-Li-Mg System Revisited

M. Ohno and R. Schmid-Fetzer

Thermodynamic assessment of $\mathrm{Mg}-\mathrm{Al}-\mathrm{Mn}$ phase equilibria

S. Al Shakhshir and M. Medraj

Thermodynamic Modeling of the Mg-Al-Y System

J. Wang

Thermodynamic assessment of the $\mathrm{Nb}-\mathrm{Cr}-\mathrm{Al}$ system

M. Hosseinifar and D.V. Malakhov

The development of a database on the Al-Mg-Fe-Si-Mn-R system $(\mathrm{R}=\mathrm{Y}, \mathrm{La}, \mathrm{Ce})$ - the first steps

N. Hanaya, Y. Koui, H. Ohtani and M. Hasebe

Thermodynamic analysis of the Fe-Nb-P ternary system

K. Frisk, J. Bratberg and A. Markström

Thermodynamic modelling of the $\mathrm{M}_{6} \mathrm{C}$ carbide in cemented carbides and high-speed steel

\section{B. Uhrenius}

Comments on the FeCrWC system

\section{E. Povoden, A. Nicholas Grundy and L.J. Gauckler}

Assessment of the $\mathrm{Cr}-\mathrm{O}$ and $\mathrm{Cr}-\mathrm{Mn}-\mathrm{O}$ Systems in the Frame of SOFC research

\section{J.Y. Shen, W.K. Kim, M.Y. Chu and T.J. Anderson}

Thermodynamic Optimization of the $\mathrm{Cu}-\mathrm{In}-\mathrm{Se}$ Ternary System

J. de Keyzer, K.C. Hari Kumar, B. Blanpain and P. Wollants

Thermodynamic optimisation of the $\mathrm{Co}-\mathrm{Cu}$ system

M. Palumbo, S. Curiotto and L. Battezzati

Thermodynamic analysis of the stable and metastable $\mathrm{Co}-\mathrm{Cu}-\mathrm{Fe}$ phase diagrams 
A.L. Udovsky, M.V. Kupavtsev, H.A.J. Oonk and M. Jacobs The Comparison between U-algorithm and J-algorithm calculations the miscibility gaps for ternary systems

\section{A.L. Udovsky, M.V. Kupavtsev and H.A.J. Oonk}

The application of self-consistent on one association model for calculation miscibility gap of melts for uranium-oxygen system

I.V. Pentin, A.A. Grosheva and N.V. Kozhemiakina

The Miscibility Gap in Cadmium, Mercury and Zinc Tellurides. Theoretical description

\section{A. Kostov, B. Friedrich, D. Zivkovic, C. Lochbichler and} J. Stoephasius

Predicting thermodynamic stability of crucible oxides in molten titanium alloys

V.N. Kuznetsov, and A.L. Udovsky

CALPHAD-analysis of influence of the decay of Fe-Cr BCC phase on temperature dependence of its heat capacity

I. Ohnuma, R. Kainuma and K. Ishida

Application of CALPHAD approach for Development of Carbide Dispersion Carburized (CDC) Steels

R. Tenu, A.J. Bougrine, V. Goutelle and J.J. Counioux

Modelling of the solid-liquid-vapor equilibria in the $\mathrm{HNO}_{3}-$ $\mathrm{H}_{2} \mathrm{O}$ system

N. David, Y. Cartigny, T. Belmonte, J.M. Fiorani and M. Vilasi Thermodynamic description of the $\mathrm{Cr}-\mathrm{Nb}-\mathrm{Si}$ isothermal section at $1473 \mathrm{~K}$

C.S. Oh, H.N. Han, J.K. Lee, D.W. Suh and S.J. Kim

Analysis of Austenite to Ferrite Transformation in Hypoeutectoid Steel by the Modified JMAK Equation and Diffusion Simulation

\section{A. Costa e Silva and F.Rizzo}

Modeling the austenite transformation in "TRIP-like" steels

\section{A. Costa e Silva}

Challenges and opportunities in the development of clean steels using computational thermodynamics

\section{S. Petersen, K. Hack, G. Eriksson and P. Monheim}

SimuSage-The Component Library for Rapid Process Modelling

K. Hack, T. Jantzen, A. Ruh, M. Spiegel, K. Pentillä, U. Krupp and V. Braz da Trindade

Development of Databases and Thermochemical Modelling of Processes during Hot Corrosion of Heat Exchanger Components

\section{Group two}

S.G. Fries, B. Böttger, P. Schaffnit and I. Steinbach

Learning about liquid-solid and solid-solid transformations using MICRESS as a teaching tool

\section{A.Yu. Zakharov}

On the exact results in statistical thermodynamics of condensed matter

P. Perrot, É. Walle, M. Parise, G. Reumont and M.N. AvettandFénoël

Evaluation of the $\mathrm{Zr}-\mathrm{U}-\mathrm{I}-\mathrm{O}$ Diagram and Influence of the Iodine Potential on the Zircaloy Cladding Behavior
R. Fourmentin, M.N. Avettand-Fénoël, G. Reumont and P. Perrot

Thermodynamical Investigation of the Al-Cr-Zn System at $460{ }^{\circ} \mathrm{C}$

L. Eleno, A. Schneider and G. Inden

Experimental determination and thermodynamic modelling of Fe-based high-melting alloys

M. Kaskiala, M. Hämäläinen, M. Arponen

Prevention of Red Scale Formation during Hot Rolling

A. Janz, J. Gröbner, D. Mirkovic and R. Schmid-Fetzer

$\mathrm{Mg}-\mathrm{Al}-\mathrm{Ca}-\mathrm{Li}$ - Alloys: Thermodynamics and Key Experiments

H.Y. Kim, S.W. Han and H.M. Lee

Effect of $\mathrm{Mn}$ and $\mathrm{Cr}$ addition on crystallization sequence and phase formation in A356 alloy; comparison between calculations and experiments

M. Kraus, A. Kroupa, P. Miodownik, M. Svoboda and J. Vrestal Microstructure of Superaustenitic Steels After Long-term Annealing

S. Matsumoto, H. Ohtani and M. Hasebe

Thermodynamic analysis of Phase Equilibria in the $\mathrm{Nb}-\mathrm{Ni}-\mathrm{Ti}$ system

S.S. Lian, C.D. Wu, T.T. Shun and A.K. Li

The exploring of phase diagram of high entropy alloys $\mathrm{Fe}-\mathrm{Al}-\mathrm{Cu}-\mathrm{Co}-\mathrm{Ni}-\mathrm{Cr}$

C. Toffolon-Masclet, T. Guilbert, T. Cozzika and R. JerlerudPérez.

An experimental study of the $\mathrm{Zr}-\mathrm{Sn}$ system

O. Dovbenko, M. Palm and F. Stein

Phase equilibria in the Al-Co-Nb ternary system in the vicinity of the Laves phases

P. Amornpitoksuk, J.C. Tedenac and D. Ravot

Phase transformations in the $\mathrm{Co}-\mathrm{Fe}-\mathrm{Sb}$ system

F. Bosselet, S. Pontevichi, F. Barbeau, M. Sacerdote-Peronnet, O. Dezellus and J.C. Viala

Experimental refinement of the $\mathrm{Al}-\mathrm{Fe}-\mathrm{Si}$ phase equilibria

L. Glaner, A. Watson, L.A. Cornish and R. Süss

Calorimetric Measurements for a Pt-based Thermodynamic Database

E.Chakroun-Ouadhour, R. Ternane, D. Ben Hassan Chehimi, M. Trabelsi Ayadi and N. Kbir Ariguib

Modelling of the Equilibrium Diagrams of the Systems: $\mathrm{Na}_{3} \mathrm{PO}_{4}-\mathrm{Pb}_{3}(\mathrm{PO} 4)_{3}$ and $\mathrm{Ag}_{3} \mathrm{PO}_{4}-\mathrm{Pb}_{3}(\mathrm{PO} 4)_{3}$

D. Kobertz, M. Florjan, T. Markus and K. Hilpert

Study of the $\mathrm{NaI}-\mathrm{CeI}_{3}$ System by Differential Thermal Analysis

P. Masset, M. Jorgensen, C. Apostolidis, R.J.M. Konings

Determination of the $\mathrm{LiCl}-\mathrm{NpCl}_{3}$ phase diagram

A. Markström

Prediction of volume fractions, densities and thermal expansion for multi-component alloys using thermodynamic calculations combined with a database for molar volumes 
D. Zivkovic, I. Katayama, R. Novakovic, J. Lee and T. Tanaka Thermodynamic and surface properties of liquid $\mathrm{Bi}-\mathrm{Ga}-\mathrm{Sn}$ alloys

\section{R. Pajarre, P. Koukkari, T. Tanaka and J. Lee}

Computing Surface Tensions of Binary and Ternary Alloy Systems with the Gibbsian Method

L.C.Pardo, M. Barrio, J.Ll. Tamarit, D.O. López, J.Salud, Ph. Negrier and D. Mondieig

Pressure-temperature phase diagrams and two-component systems: Non-experimentally available thermodynamic properties

\section{R. Chellappa, D. Chandra}

High Pressure Raman Spectroscopy and Synchrotron Powder X-ray Diffraction Studies on Organic "Plastic Crystal" Thermal Energy Storage Materials

M. Barrio, L.C. Pardo, H.A.J.Oonk, J.Ll. Tamarit, D.O. López and J. Salud

Mixed Crystals formed by methylchloromethanes: Thermodynamic overview of the orientationally disordered forms

J.H. Los and M. Matovic

Kinetic phase separation domains

M. Matovic, J.C.van Miltenburg and J. Los

Metastability in Solid Solution Growth

M.A. Cuevas-Diarte, T. Calvet, L. Ventolà, V. Metivaud, E. Moreno, D. Mondieig and H.A.J. Oonk

Molecular Alloys as temperature-adjustable Phase Change Materials

E.R.T. Bevers and P.J. van Ekeren

Waste Heat made useful by a Chemical Heat Pump

\section{Summary of the discussions on Monday and Tuesday evenings}

The topic of the discussion on the Monday evening was the relation of the ab initio calculations vs. CALPHAD method. In the introduction, Prof. Sob summarized the basic ideas of $\mathrm{ab}$ initio electronic structure calculations, enumerated the state-of-the-art methods and characterized their advantages and disadvantages. He also listed the quantities, which are directly obtainable from the ab initio electronic structure calculations, such as total energies of competing structures (lattice stabilities), equilibrium lattice parameters, elastic constants, heats of formation, energies associated with the point and extended defects, theoretical (ideal) strength etc. All these quantities are obtained at zero Kelvin; including the effect of non-zero temperature at the level of ab initio calculations is very difficult.

Subsequently, Prof. Sob provided some illustrative examples, showing the calculated total energies of competing structures in W, Ir and Mo as well as their behavior at the high-strain tetragonal and trigonal deformation, which is very helpful in assessing the stability of higher-energy structures. When discussing iron, he has shown how different types of magnetic ordering are reflected in total energies and deformation behavior of various iron structures. It turns out that ferromagnetism is the stabilizing agent of the bcc structure of iron; if magnetic ordering is neglected, the most stable structure of iron is hcp.

He argued that the ab initio values of the total energies may be used in the CALPHAD method. They may be considered as a good basis for lattice stabilities at $0 \mathrm{~K}$; the entropy terms may be then fitted from the experimental data.

At the end of his contribution, Prof. Sob mentioned two crucial problems in comparing the ab initio and CALPHAD results:

To obtain a good agreement with experimental phase diagrams,

1 the CALPHAD lattice stabilities often differ from the ab initio lattice stabilities and

2 in most cases, the ab initio calculations show that, at $0 \mathrm{~K}$, the higher-energy structures, such as, for example, fcc Mo or bcc Ir, are dynamically unstable, i.e. not stable with respect to tetragonal or trigonal deformation or to some other mode of deformation or to some phonon mode.

On the basis of this, an urgent question emerges: Are the CALPHAD values of the lattice stabilities used in the construction of the phase diagrams the same as the structural energy differences obtained from the ab initio calculations? May it be true also in the cases if the investigated higher-energy structures are dynamically unstable?

There was a lot of discussion during the talk of Prof. Sob, as he himself asked the audience to ask immediately when they see any problems or would like to put a question. Among others, Dr. Kaufman argued that, in the case of Mo [1] the CALPHAD lattice stabilities differ from those obtained by ab initio methods by a factor 4-5. For Fe the difference is 60\% [2,3]. Substantial differences (by a factor of 4-8) exist for Ru [1,3-5], Os [4,5], Ir [5], W [5] and Rh [5].

Prof. Vrestal commented that if the higher-energy structure is dynamically unstable, one still can employ the corresponding structural energy difference (or, what is the same, the lattice stability) values as certain effective values and to fit the temperature-dependent part of the Gibbs energy from the experimental data.

Subsequently, Prof. Liu presented his recent considerations of the lattice stability of fcc- $\mathrm{Cr}$ in the $\mathrm{Fe}-\mathrm{Ni}$ and $\mathrm{Cr}-\mathrm{Ni}$ systems with the values from the first-principles calculations and CALPHAD being 36760 [6] and $7284+0.163 \mathrm{~T} \mathrm{~J} / \mathrm{mol}$, respectively. By fitting to the $\gamma+\alpha$ loop and keeping the interaction parameters of the $\alpha$ phase intact, the interaction parameters of the $\gamma$ phase were evaluated as ${ }^{0} L=-37583-$ $5.613 T$ and ${ }^{1} L=-18179+2.064 T$ in comparison with ${ }^{0} L=10833-7.477 T$ and ${ }^{1} L=1410$ in the SSOL database. This is in line with an early discussion by Kaufman [7] when comparing the CALPHAD lattice stability with the Engel-Brewer electron configuration. While both models could reproduce well the thermochemical and phase equilibrium data in the stable region of the fcc phase, the metastable equilibrium between the liquid and fcc phases are different as shown in the figures with the left figure based on the first-principles lattice parameter and the right one from the SSOL database. The primary difference is on the melting temperature of fcc-Cr. In 
the former, the fcc-Cr is never stable, while in the latter, a finite melting temperature is observed, which was also mentioned in the discussion of the publication by Kaufman [8].

In summary, it may be concluded that there are still differences between the ab initio and CALPHAD lattice stabilities. Also the meaning of the lattice stabilities corresponding to dynamically unstable higher-energy structures is not fully clear yet. However, the ab initio results are being applied more and more in the CALPHAD community, particularly for stable structures, and there is a strong trend to convergence. Hopefully, further progress in this area will be seen at future CALPHAD meetings.
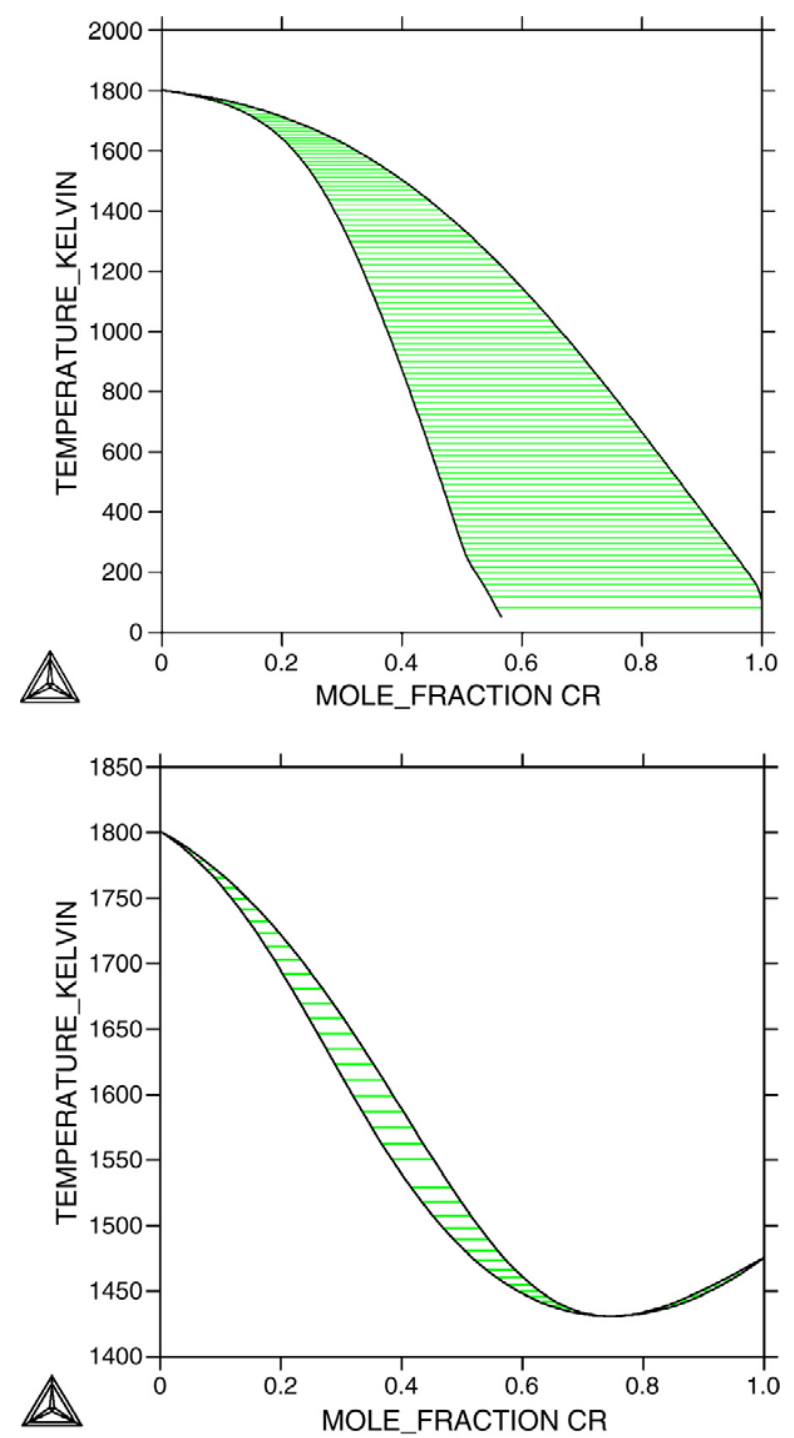

\section{References}

[1] A.E. Kissavos, S. Shallcross, V. Medved, L. Kaufman, I.A. Abrikosov, CALPHAD 29 (2005) 17.

[2] Q. Chen, B. Sundman, CALPHAD J. Phase Equilibrium 22 (2003) 631

[3] L. Kaufman, "Complex Inorganic Solids" in: P.E.A. Turchi, A. Gonis, K. Rajan, A. Meike (Eds.), Springer, NY, 2005, p. 73.

[4] L. Kaufman, Scandinavian J. Metals 20 (1991) 317.

[5] L. Kaufman, CALPHAD 25 (2001) 141.

[6] Y. Wang, S. Curtarolo, C. Jiang, R. Arroyave, T. Wang, G. Ceder, L.Q. Chen, Z.K. Liu, CALPHAD 28 (2004) 79-90.

[7] L. Kaufman, Metallurgical Chemistry Symposium 1971—Proceedings of a Symposium at Brunel University and the National Physical Laboratory, July 1971, paper 3.1 .

[8] L. Kaufman, in: P.S. Rudman, J. Stringer, R.I. Jaffe, (Eds.) Phase Stabilities in Metals and Alloys, 1967. 